\title{
combustión y combustibles
}

A. YIRELLA

de la Companhia Portuguesa de Cimentos Brancos "CIBRA"

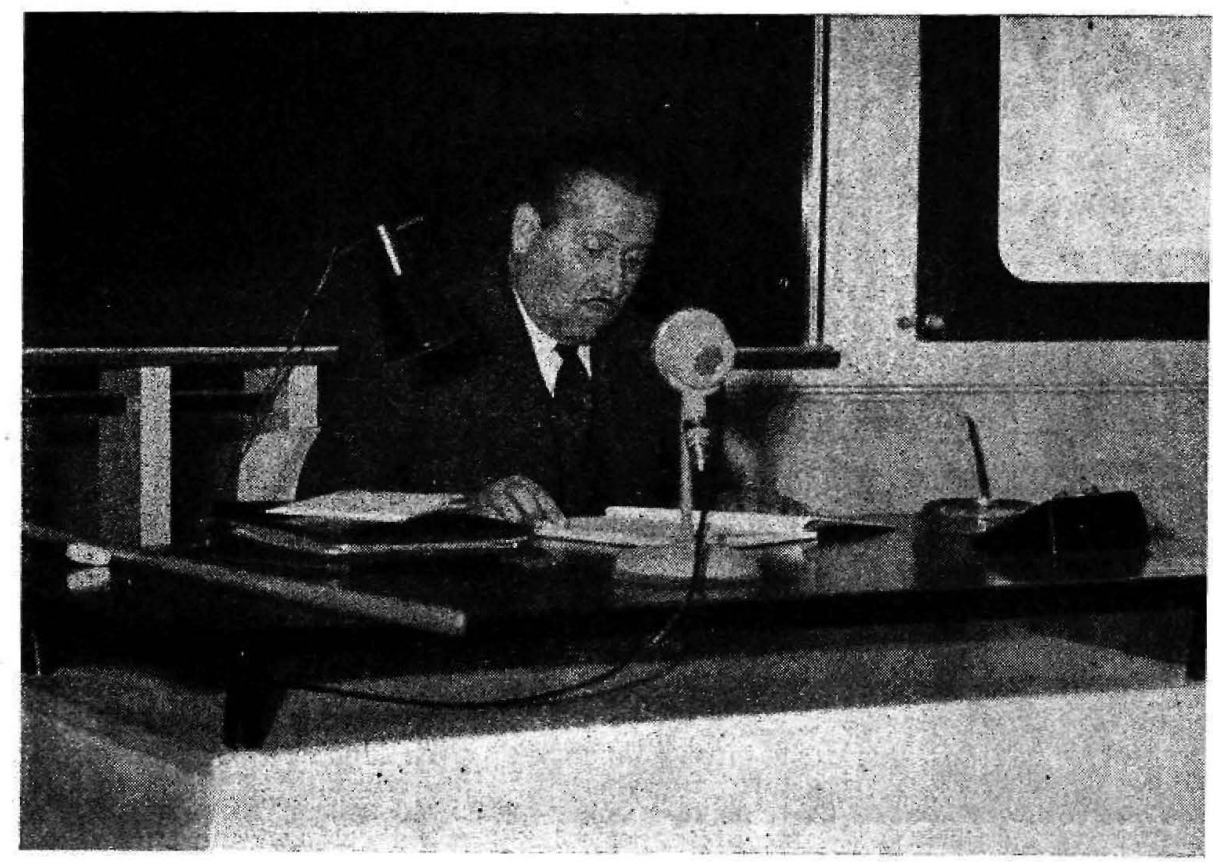

\section{Resumen}

La ponencia trata de los combustibles generalmente empleados en los hornos rotativos de cemento Portland $y$, especialmente, de los problemas relacionados con los carbones pobres.

En cualquier caso, hay que tener un conocimiento previo del poder calorifico del combustible que se pretende emplear, siendo de considerar antes el coste por unidad de calor que el coste por unidad de peso.

Se describen el secado y la molienda de los carbones, señalando la tendencia actual de efectuar ambas operaciones simultáneamente, definiendo la aptitud para la pulverización y la determinación de la finura del polvo de carbón, por los métodos clásicos y por medio del permeabilímetro.

Se expone en qué medida influyen la finura del combustible, el sistema de inyección, el estado del aire primario, su poder comburente, el exceso de aire y la proporción de cenizas en la determinación de la temperatura de la llama, su poder radiante, el flujo térmico y la posibilidad de obtener un clínker bien cocido.

Se propugna por el empleo conjunto de aceites combustibles y carbones pobres como solución muy apropiada en la mayoria de los casos.

Por último, se menciona la posibilidad de que se formen anillos en los hornos rotativos como consecuencia del empleo de carbones de alto contenido de cenizas, indicando algunas soluciones para evitar dicha perturbación. 


\section{Combustibles empleados en la fabricación de cementos}

Cuando José Aspdín descubrió el produeto por él llamado cemento Portzand, patentado en 1824, lo obtenia, según se sabe, en hornos de cuba-idénticos a los que entonces se aplicaban a la fabricación de cal hidrálica-y empleaba en eflos coque como combustible.

El coque fue luego sustituído por otros carbones minerales, y durante algunas décadas se emplearon exclusivamente los combustibles sólidos en la industria cementera.

En 1885 Ransome patentó un homo rotativo destinado a la producción de cemento Portland, provisto de un quemador para combustibles gaseosos. El sistema prosperó poco en Inglaterra, su pais de origen. Fue necesarta la audacta del español José de Navarro para que fuera trasplantado, en 1888, el horno rotatorio al Continente americano. En los Estados Unidos comenzaban las primeras aplicactones industriales del petróleo, y fue precisamente petróleo bruto el combustible que hizo funcionar, en 1892, los dos primeros hornos rotativos de Navarro.

La relativa facilidad con que eran fnyectados los combustibles gaseosos o líquidos hizo que éstos se aplicaran antes que los carbones al calentamiento de los hornos de cemento Pero desde 1866, en que el inglés Crampton y los americanos Whelpley y Btorer estaban trabajando sobre las posibilidades de quemar carbón en polvo en los hogares ordinarios, las tentativas fueron tantas como los fracasos, hasta que en 1896 se consiguió el primer éxito al inyectar carbón pulverłzado en un horno rotativo de cemento.

Durante un cuarto de slglo fue paralela la evolución de los hornos rotativos y de los quemadores de carbón puIverizado. Los hornos se multiplicaron y la fndustria cementera tomó un insospechado Impulso al contar con el poderoso auxilio de un combustible en aquel tiempo barato, como era el carbón en polvo. Este combustible, por su parte, era un subproducto sin cualquier aplícación industrial importante con excepclón de los hónos de cemento. Hasta el año 1920 no se consigujó quemar carbón pulverizado en las calderas de vapor.

La entrada del carbón en polvo en otros campos de aplicación, con la escasez de combustibles que acompanió $\mathrm{y}$ siguí a las varias perturbaciones que ha sufrido el mundo y la orientacion necesariamente autárquica de clertas economías naclonales obilgó a Ios cementeros a emplear combustibles tan pobres que, sin la menor duda, habrian sido rechazados unos pocos años antes.

En muchos casos, los combustibles de emergenela eran de tan baja calidad que no se podía obtener con ellos solos "Ia temperatura necesaria para el funcionamiento de los hornos. Fue necesario acudir a las mezclas, blen sea de combustlbles sólldos, blen de sólidos con líquidos y aún de solidos con gases. Todo ello vino a complicar el ya confuso cuadro de los combustibles empleados en la fabricación de cemento.

Hoy en día, 136 afios después de la Invención del cemento Portland, y a los 75 años de la aplicación de los hornos rotativos a la cocclón del cemento, puede muy bien decirse que se ha intentado, por lo menos, aplicar todos los combustibles imaginables a la fabricación de cemento. No siempre el éxito acompañó a la buena voluntad, porque las posibilidades humanas tienen su limite.

No vamos a ser tan ingenuos como para suponer que en la elección del combustible entren muchos factores dependientes de la poluntad del consumidor. En muchos casos no existe otra alternativa que el consabido "lo toma o lo deja"; pero, aún así, no podemos eludir la obligación de estudiar con atención e interés las propledades y las posibilidades para una mejor aplicación de los poco gratos combustibles que nos veamos en la necesidad de emplear.

Tampoco vamos a tener la pretensión de que se pueda decir algo nuevo u original sobre la combustión y los combustibles. Tiene el tema un tan rancio abolengo, y ha sido exprimido por tantas y tan expertas manos que poco o ningún jugo podré hoy sacar el exprimidor de turno. Apenas con la buena intención de dar un repaso a cosas que de tan sabldas ya las habiamos olvidado nos atrevemos a penetrar en una selva que, no por ser muy frondosa, ha dejado de ser hollada en todos los sentidos.

\section{Poder calorifico de un combustible}

El primer criterio que preside la aceptación de un combustible es su poder caloriflco, o sea, la cantidad de calor que se puede obtener con la unidad de peso.

Importa saber, en todo caso, no el precio que pagamos por una tonelada de combustlble (carbón, petróleo o gas), sino el precio de la kilocaloría o de la termia. $Y$ éste es el primer escollo que se atraviesa en nuestra derrota.

Porque la mayoria de las fábricas de cemento no tienen una bomba calorimétrica apta pară la determinación del poder caloríflco de los combustlbles con un decoroso grado de aproxlmación. Ante tan frecuente falta del materlal indispensable, tenemos que aceptar por buenos los datos que nos presentan los abastecedores de combustibles, enviar una muestra para ser analizada en un laboratorio oflclal en caso de duda, o calcular por aproximaclón el poder calorifico a partir del análisls elemental o del análisis inmediato.

Otro punto que no está muy claro, es la pronunciada dlferencia que existe entre el poder caloriflco superior y el inferlor. Se nos puede ofrecer, por efemplo, un carbón de 6.000 calorias, sin más datos, nos quedamos sin saber nada concreto de la bondad del susodicho combustible. Por la bomba calorimétrica determinamos el poder caloriflco superior, o sea, la cantidad de caior liberada por la combustión 
en vaso cerrado, a volumen constante, y con condensación de la totalidad de agua extstente, sea higroscóplea, sea combinada, o sea formada por la combustión del hidrógeno. En los hornos rotativos, sin embargo, trabajamos en un recinto abierto, con pocas variaciones de presion $y$, en cambio, con una variación de volumen proporcional a la temperatura absoluta. El agua existente o formada permanece en estado de vapor. El combustible, en suma, desarrolla apenas su poder caloriftco inierior, 0 sea, bastantes calorias a menos en relación con las obtenidas por el calorímetro.

Esta diferencia viene expresada por la fórmula:

$$
\mathrm{H}_{1}=\mathrm{H}_{\mathrm{a}}-\mathrm{QW}
$$

donde:

$\mathrm{H}_{1}=$ Poder calorifico tnferlor de un combustible en $\mathrm{kcal} / \mathrm{kg}$.

$\mathrm{H}_{\mathrm{s}}=$ Poder caloriftco superior en $\mathrm{kcal} / \mathrm{kg}$.

$Q=$ Calor de evaporación del agua a la temperatura to $\mathrm{C}$.

$\mathrm{W}=$ Agua total presente en los productos de la combustión.

Corrientemente, se suelen descontar 600 calorías por cada gramo de agua formada. Esta correcclón es tan sólo aproximada. La Institución de Ingenieros Civites de la Gran Bretaña consideran 586 cal/g. Por la norma DIN 51708 debe emplearse la corrección de 585 cal/g. Finalmente, la norma ASTM: D 407-44 establece la correcclón en $572 \mathrm{cal} / \mathrm{g}\left(20^{\circ} \mathrm{C}\right)$, anotando que esta corrección no es igual al calor Iatente de evaporación del agua porque se reduce el poder caloríflco superior a volumen constante a poder caloriflco inferior a presión constante. Si damos algún valor a este argumento, debemos adoptar la corrección establecida por la A.S.T.M.

El agua total $W$, a su vez, vale:

$$
\mathrm{W}=\mathrm{H}_{2} \mathrm{O}+8,9365 \mathrm{H}_{3} \simeq \mathrm{H}_{2} \mathrm{O}+9 \mathrm{H}_{2}
$$

Supongamos un carbón totalmente desprovisto de agua hlgroscópica o de constitución ( $\mathrm{H}_{2} \mathrm{O}$ ) y con un contenido de hidrógeno $\mathrm{H}_{3}$. En este combustibie la ecuación [1] se transformaria en:

$$
\mathrm{H}_{\mathrm{I}}=\mathrm{H}_{3}-5,72 \times 8,9365 \mathrm{H}_{1}=\mathrm{H}_{\mathrm{a}}-51,12 \mathrm{H}_{2}
$$

o sea, tendremos una disminuclón de 51 calorías por cada $1 \%$ de hidrógeno que aparezca en el análisis elemental, mientras que para $1 \%$ de humedad la disminuclón no llega a 6 calorías.

De acuerdo con este resultado, y para carbones secos, tendremos las siguientes diferencias entre los poderes caloriftcos superior e inferior:

COMBUSTIBLES

Antracitas .......................

Hulla magra ................

Hulla grasa $\ldots \ldots \ldots \ldots \ldots \ldots$

Lignitos $\ldots \begin{array}{lllllll} & \ldots & \ldots & \ldots & \ldots & \ldots & \ldots\end{array}$

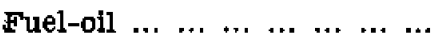

Gas natural

\begin{tabular}{rrr}
$\mathbf{H}_{2} \boldsymbol{*}_{\mathrm{o}}$ & \multicolumn{1}{c}{$\mathbf{H} \cdot \mathbf{H i}$} \\
3,0 & $153 \mathrm{cal} / \mathrm{g}$ \\
4,0 & $204 \quad "$ \\
5,0 & $256 \quad "$ \\
5,5 & $281 \quad "$ \\
12,0 & $613 \quad "$ \\
24,0 & $1.227 "$
\end{tabular}

Estas correcclones se pueden aplicar, en primera aproximaclón, si no se sabe exactamente el contenido de hidrogeno del combustible.

\section{El poder calorifico y el andisis elemental}

Cuando no se dispone de bomba calorimétrica, pero sí de los medios indispensables para el análists elemental de un combustible, es sabido que podemos calcular el primero en función del segundo.

Tres elementos combustibles encontramos en todos los análisis de carbones, aceites o gases. Los elementos combustibles, por orden de importancia, son: el carbono, el hidrógeno y el azufre. Algunas características de estos elementos aparecen en el cuadro 1. De conformidad con dlche cuadro, podemos corregir la antigua fórmula de Dulong:

$$
\mathrm{H}_{1}=80,8 \mathrm{C}+287,92\left(\mathrm{H}_{\mathbf{1}}-0,126 \mathrm{O}\right)+22,1 \mathrm{~s}-5,72 \mathrm{H}, \mathrm{O}
$$

\section{El poder calorlfico y el andlisis inmediato}

Lo más corriente en nuestra inđustria es ensayar la calidad de los carbones por medio del análists inmedlato, determinando la humedad, la materia volátil (MV), las centras (A) y el carbón fifo (CF). Suelen completar estas determinaciones el analisis guimlco de las cenizas y el azufre total del combustible. Cuando se trata de combustibles liquidos se efectuan algunas mediciones de la viscosidad, para obtener el correspondlente indice, peso especifico y API. 
Importa mucho puntualizar, en todos los casos, la forma de expresión del análisis inmediato. Recordamos, como de mayor importaneia, las siguientes:

a) Carbón recibido.

b) Secado al aire.

c) Carbón seco (sin agua hłgroscópica).

d) Carbón puro (sin humedad ni materias minerales).

El contenido de materias minerales, según Seyler, se calcula por la fórmula:

$$
\mathrm{M}=1,08 \mathrm{~A}+0,55 \mathrm{~S}+0,8 \mathrm{CO}_{2}
$$

en la cual:

1,08 A = Cenizas más el agua de hidratación, que vale, aproximadamente, $0,08 \mathrm{~A}$.

$\mathbf{S}=$ Azufre total del combustible.

$\mathrm{CO}_{2}=$ Dióxido de carbono procedente de los carbonatos.

En la práctica corriente, sin embargo, se suele tomar por carbón puro la suma de las materias volảtiles y el carbono fijo reducida a clen.

El poder caloriflco de los combustibles se suele referir al carbón puro, o sea, al que corresponde al conjunto de materias volátiles y carbono fjo, con exclusión de la humedad y de las cenizas.

Existen algunas fórmulas empíricas que nos dan el poder calorífico aproximado de un combustible en función de su análisis inmediato. Entre los cementeros quizá la fórmula más conocida sea la de Goutal, pero no quiere esto decir que por ser la más conocida sea la más exacta.

Según Goutal, se tiene:

$$
\text { H. }=a \mathrm{CF}+\mathrm{bMV}
$$

en la cual $a$ y $b$ son, respectivamente, los poderes caloríflcos del carbón fijo y de las materlas volátiles. Goutal suponía $a=8.200$ cal/g para el carbón flja, cantidad que hoy tenemos que considerar muy elevada, ya que el poder caloriftco del carbono amorfo no es más que $8.080 \mathrm{cal} / \mathrm{g}$. También Goutal suponia $b$ varlable, o sea: $b=f(\mathrm{MV})$, presentando una curva de variación que iba desde las $14.500 \mathrm{cal} / \mathrm{g}$ para una antracita con $5 \%$ de volátiles, hasta 8.000 cal/g para una hulla con $40 \%$ de gases. Como que, salvo en muy raros casos, las materlas volátlles de los carbones no llegan a tan altos poderes caloríficos, resulta que por la formula de Goutal se obtienen unos calores de combustión bastante más elevados de lo que son en la realidad.

Existen otras formulas empíricas, entre las cuales podemos citar la norma DIN 51708 para los carbones del Ruhr:

$$
\begin{gathered}
\mathrm{H}_{\mathrm{s}}=3.790+116 \mathrm{CF}-0,68 \mathrm{CF}^{2} \mathrm{cal} / \mathrm{g} \\
\mathrm{H}_{\mathrm{l}}=0,966675 \mathrm{H}_{\mathrm{s}}=3.664+112,1 \mathrm{CF}-0,6574 \mathrm{CF}^{2} \mathrm{cal} / \mathrm{g}
\end{gathered}
$$

Seyler, además del análisis inmediato, utiliza el contenido de hidrógeno y da la ecuaclón siguiente:

$$
\mathrm{H}:=123,9 \mathrm{CF}+388,12 \mathrm{H}_{2}-4.269 \mathrm{cal} / \mathrm{B}
$$

Para Gumz, se tiene:

$$
\mathrm{H}_{1}=8.150+38,33 \mathrm{MV}-1,1806 \mathrm{MV}^{2} \mathrm{cal} / \mathrm{g}
$$

Si construímos un gráfco situando los poderes calorificos reales en función del tanto por ciento de materias volátlles de los combustibles puros y sobre él trazamos las curvas representativas de las anteríores ecuaciones, podremos ver cúb es aquella que se adapta mejor a los carbones utilizados.

En el caso particular de los carbones portugueses se aprecia (fig. 1) una grande dispersión de resultados. Asi y todo, la expresión [10] parece dar un mayor grado de aproximación que cualqulera de las anteriores. Una importante excepción la constituye el poder caiorifico de las antracitas portuguesas, menor que el dado por la fórmula de Gumz y, en cambio, más ajustable al que proporciona la ecuactón:

$$
\mathrm{H}_{\star}=91,8(\mathrm{MV}+\mathrm{CF})-850 \mathrm{cal} / \mathrm{g}
$$

Con estos datos, no pretendemos más que hacer notar la complejidad del problema y lo aleatorio que resulta admitir para un determinado combustible un poder caloriflco calculado por apreclación. S1 sobre este cálculo basamos después determinaciones de rendimientos térmicos de hornos rotativos, por ejemplo, nos expondremos a errores de capital importancia.

\section{Materias voldtiles}

La discusión sobre el poder calorifico de los combustibles nos ha conducldo, irremediablemente, al interesante problema de las materias volátiles. 


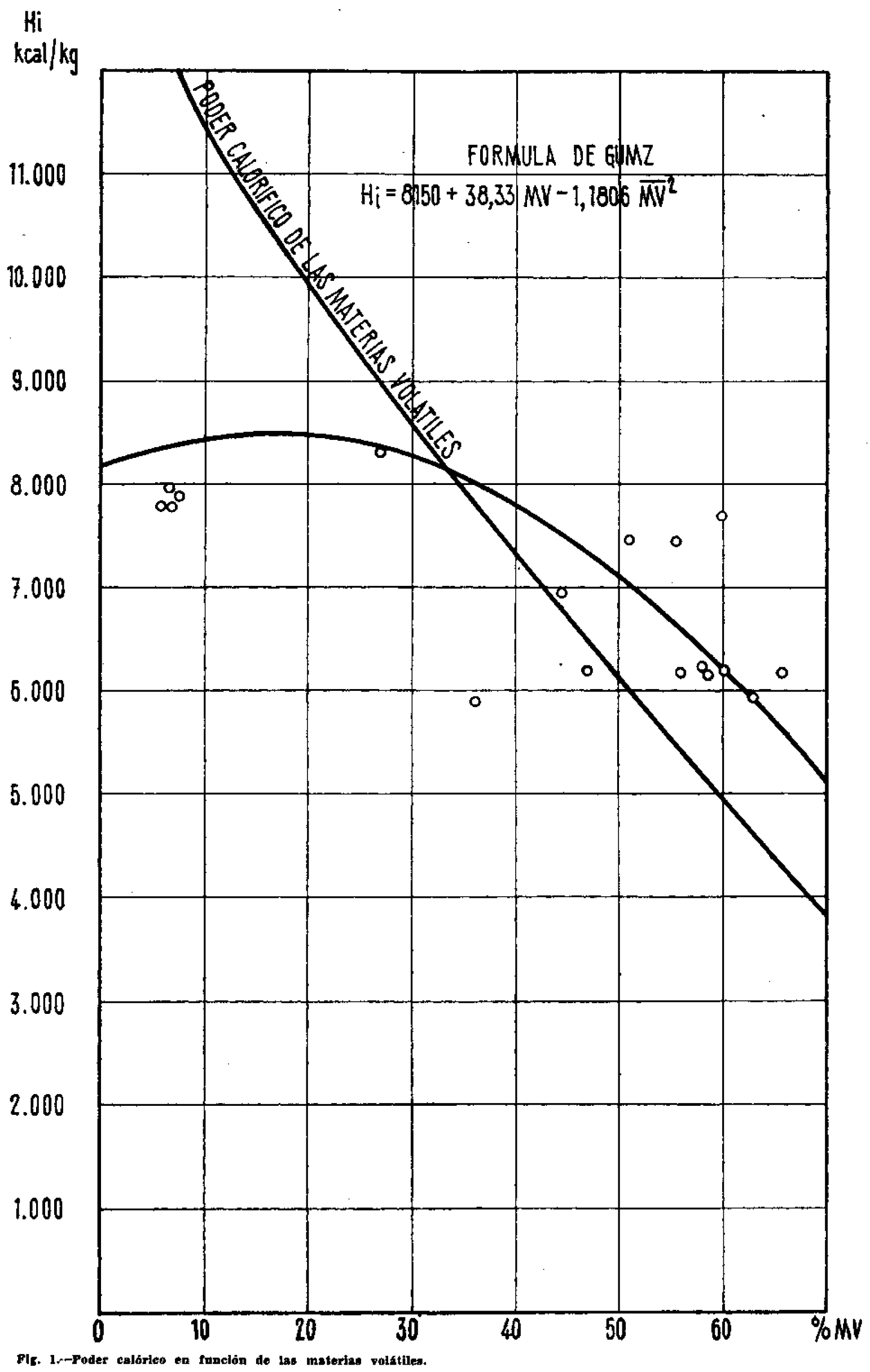


Decimos interesante purque, muchas veces, se ha tomado el contenido de materias volátles de un carbón como uno de los datos fundamentales en que se basa el juzgarlo apto o no apto para ser empleado en la industria del cemento.

Hemos pasado una ligera revista en la bibliografía que se ocupa del tema y hemos constatado que la mayor parte de los autores fljan en un $15 \%$ el límite inferior del contenido de materias volátlies. El limite superior oscila entre 20 y $30 \%$, de modo que, en general, hay una cierta concordancia eit recomendar el empleo de carbones con un contenido de volítiles comprendido entre 15 y $25 \%$. Sin embargo, ya sabemos que estos limites no son barreras infranqueables, y que, hoy en dia, no se siente un exagerado respeto para ellos. Son numerosas las fábricas que, adaptándose a las características de los carbones disponibles y a imperativos de orden económico, funcionan quemando combustibles bastante alejados de Ios antedichos límites,

En la bibliografía consultada, salvo raras excepciones, apenas se hace mención de la composición de las materias volátiles. Parece sobreentenderse que en ellas todo es combustible, cuando, desgraciadamente, sucede lo contrario. Una de las pocas voces de alarma fue, sin duda, la del distinguido ingeniero portugués, señor Rocha y Melo, el cual, hace unos afios, proclamaba: "Hay que tener en cuenta, tamblén, el poder caloriflco de las materias volátlles st se quiere tener una llama capaz. Existen lignitos, en Portugal, en los cuales el poder caloriffeo de las materias volátlles está próximo a las $2.500 \mathrm{kcal} / \mathrm{kg} . . . "$ Creemos que este problema es el caso bastante generaitzado en los carbones peninsulares. $Y$ es precisamente por este motivo que, como dijimos antes, no nos podemos confiar de los cálculos basados en la formula de Goutal, por dar resultados absolutamente disparatados.

Como primera aproximación, podemos orientarnos bastante admitiendo que la calidad de los combustibles es una función de su edad geológlca. Be supone que la .carbonjzactón ha sldo más completa cuantos más años, o mejor dirfamos, millones de afros, han transcurrido desde que se formó el yaclmiento. Los carbones del periodo antracolítico serian los que contendrian menos volátiles inertes: Es el caso de las antracitas y de las hullas, Menos antiguos son los carbones de la era secundaria, principalmente de los períodos juréslco $\mathrm{y}$ trí́sico, entre los cuales se encuentran los mejores lignitos. Finalmente, nos encontramos con las formaciones de lignitos terclarios, que van del eoceno al plioceno, poco mineralizados, con $10 \%$ o más de oxígeno y alto contenido de azufre. Son éstos, los combustibles de peor calldad con que podemos tropezar en nuestra industria.

Una mayor aproximación se consigue con la destilación seca del combustible. Por de pronto, se obtienen productos if́quidos $\mathrm{y}$ gases incondensables. Intre Ios líquidos aparece el agua, y entre los gases se obtienen los del alre: nitrógeno y oxfgeno, monóxldo y bióxido de carbono, sulfuro de hídrógeno, metano, etano, propano, etileno y otras olefinas y también hidrógeno no combinado. Por el cuadro I vemos que Jos principales hidrocarburos gaseosos poseen un poder caloriftco inferior entre los 11.000 y $12.000 \mathrm{kcal} / \mathrm{kg}$. S1 no hubiese otros gases no combustibles en las materias volátiles, éstas aumentarían el poder del combustible con relación a las $8.080 \mathrm{kcal} / \mathrm{kg}$ que posee el carbono.

En los hornos rotativos la destilación seca se efectúa en condiciones muy diferentes, porque el carbón pulverizado, al entrar en la cámara de combustión, se encuentra ante temperaturas superiores a $\operatorname{los} 1.500^{\circ} \mathrm{C}$, las cuales no pueden soportar las paraftnas u olefinas sin disoctarse en sus elementos constituyentes. Para el metano, a los $1.100^{\circ} \mathrm{C}$, tan solamente un $0,8 \%$ permanece no disociado. Ast, pues, y en definitiva, será la cantídad de hldrógeno combustible el importante factor que determinaré la calidad de las materias volátiles.

El análisis elemental será un buen camino para expresar cuantitativamente la calidad đe las materias volatiles.

El contenido de hidrógeno aumenta gradualmente con la proporción de materias volatiles, pero hay que distinguir entre el hidrógeno total y el hidrógeno combustible. Para los carbones puros con menos de $85 \%$ de carbón fijo, el hidrógeno se estabiliza entre $5,35 \pm 0,3 \%$, bajando para menos en los lignitos de formación reciente.

El contenido de oxígeno tamblèn aumenta de las antracitas a los lignitos. En estos últimos, en general, es superior a $10 \%$; y no se crea que se trata de oxigeno libre, ya en disposiclón de servir de comburente, sino casi siempre se trata de oxigeno combinado, y no pocas veces en forma de $\mathrm{CO}_{2,}$ procedente de la descarbonatación de las cenizas calcareas.

El nftrógeno, ya menos importante, se encuentra en proporclones que no suelen pasar del $1 \%$ referido al combustible puro.

El azufre, muy variable, es, sin duda, tno de los huéspedes menos deseables en nuestras fábricas. Sus interferencias en las combustiones espontóneas de 103 combustibles almacenados y en las corrosiones de partes metálicas de los hornos rotativos son bastante conocidas y, por ello, poco recomendables. Por otra parte, en los laboratorios, por poco equipados que estén, se dispone de medíos sencllios y bastante aproxtmados para la determinación ráplda del contenido de azufre.

A pesar de todo, los combustibles con una cierta proporción de materias volätiles son bastante inflamables. A veces demasiado, porque su destilación comienza ya a temperaturas relativamente bajas, a poco más de $300^{\circ} \mathrm{C}$, o sea, que pueden darse casos de desvolatilización durante las operaclones de molienda y secado con el consiguiente peligro de explosión.

Cuando se inyecta en un horno rotativo, se puede creer que el carbón se desprende de sus volátlles muy cerca del quemador. Casi inmediatamente el metano y los demás hidrocarburos se disocian en sus elementos. El carbono asi formado aparece muy finamente dividido $\mathrm{y}$ posee un alto poder radiante. $\mathrm{El}$ hidrógeno arde en seguida, con mayor rapidez que el carbono. Si la llama es oxldante, los hidrocarburos 
CUADRO I - Datos correspondlentes a algunos combustibles puros

\begin{tabular}{|c|c|c|c|c|c|c|c|c|c|}
\hline COMBUSTIBLES & $\begin{array}{l}\text { Azutre } \\
\text { (s) }\end{array}$ & $\begin{array}{l}\text { Hidirógeno } \\
\left(\mathbf{H}_{2}\right)\end{array}$ & $\underset{\text { Carbeno }}{\text { (C) }}$ & $\begin{array}{l}\text { Oxldo } \\
\text { de carbong } \\
\text { (CO) }\end{array}$ & $\begin{array}{l}\text { Sulfuro } \\
\text { de hifdrogeno } \\
\left(\text { (SH: }_{y}\right)\end{array}$ & $\begin{array}{l}\text { Etileno } \\
\left(\mathbf{C}_{2} \mathbf{H}_{4}\right)\end{array}$ & $\underset{\left(C_{0} \mathrm{H}_{3}\right)}{\text { Propano }}$ & $\begin{array}{l}\text { Etano } \\
\left\{\mathbf{C}_{2} \mathbf{H}_{0}\right\}\end{array}$ & $\underset{(\mathrm{CH})}{\operatorname{Metano}}$ \\
\hline 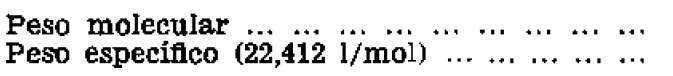 & $\begin{array}{l}32,060 \\
{[1,4305]}\end{array}$ & $\begin{array}{l}2,016 \\
0,08995\end{array}$ & $\begin{array}{l}12,0114 \\
{[0,5359]}\end{array}$ & $\begin{array}{r}28,0114 \\
1,2498\end{array}$ & $\begin{array}{c}34,076 \\
1,5204\end{array}$ & $\begin{array}{r}28,0548 \\
1,2518\end{array}$ & $\begin{array}{r}44,0982 \\
1,9676\end{array}$ & $\begin{array}{r}30,0708 \\
1,3417\end{array}$ & $\begin{array}{r}16,0434 \\
0,7158\end{array}$ \\
\hline 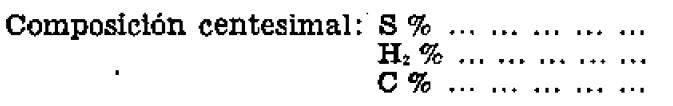 & $\frac{100,00}{-}$ & $100, \overline{00}$ & $\overline{\bar{Z}}$ & $4 \overline{\bar{Z}}, \overline{88}$ & $\begin{array}{r}94,08 \\
5,92 \\
-\end{array}$ & $\begin{array}{l}14 \overline{37} \\
85,63\end{array}$ & $\begin{array}{l}18, \overline{29} \\
81,71\end{array}$ & $\begin{array}{l}20, \overline{11} \\
79,89\end{array}$ & $\begin{array}{l}25,13 \\
74,87\end{array}$ \\
\hline \multicolumn{10}{|l|}{ Poder calorifico superior. } \\
\hline 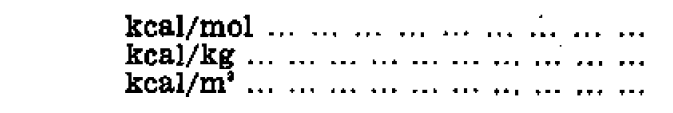 & $\begin{array}{r}70,852 \\
2.210 \\
3.161\end{array}$ & $\begin{array}{r}68,351 \\
33.904 \\
3.050\end{array}$ & $\begin{array}{r}97,052 \\
8.080 \\
4.330\end{array}$ & $\begin{array}{r}67,636 \\
2.415 \\
3.018\end{array}$ & $\begin{array}{r}134,780 \\
3.955 \\
6.014\end{array}$ & $\begin{array}{r}337,234 \\
12.019 \\
15.047\end{array}$ & $\begin{array}{r}530,605 \\
12.032 \\
23.675\end{array}$ & $\begin{array}{r}372,820 \\
12.398 \\
16.635\end{array}$ & $\begin{array}{r}212,798 \\
13.264 \\
9.495\end{array}$ \\
\hline \multicolumn{10}{|l|}{ Poder calortfico inferior. } \\
\hline 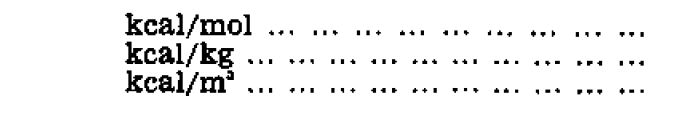 & $\begin{array}{r}70,852 \\
2.210 \\
3.161\end{array}$ & $\begin{array}{r}58,046 \\
28.792 \\
2.590\end{array}$ & $\begin{array}{r}97,052 \\
8.080 \\
4.330\end{array}$ & $\begin{array}{r}67,686 \\
2.415 \\
3.018\end{array}$ & $\begin{array}{r}124,475 \\
3.653 \\
5.554\end{array}$ & $\begin{array}{r}316,624 \\
11.286 \\
14.127\end{array}$ & $\begin{array}{r}489,385 \\
11.098 \\
21.836\end{array}$ & $\begin{array}{r}341,905 \\
11.370 \\
15.255\end{array}$ & $\begin{array}{r}192,188 \\
11.979 \\
8.575\end{array}$ \\
\hline \multicolumn{10}{|l|}{ Combustión neutra. } \\
\hline 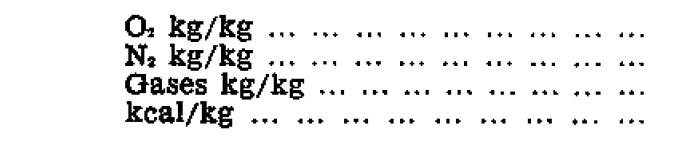 & $\begin{array}{l}0,9981 \\
3,3061 \\
5,3062 \\
417\end{array}$ & $\begin{array}{l}7,9365 \\
26,2889 \\
35,2254 \\
817\end{array}$ & $\begin{array}{r}2,6641 \\
8,8246 \\
12,4887 \\
647\end{array}$ & $\begin{array}{l}0,5712 \\
1,8920 \\
3,4632 \\
698\end{array}$ & $\begin{array}{c}1,4086 \\
4,6658 \\
7,0744 \\
517\end{array}$ & $\begin{array}{c}3,4219 \\
11,3347 \\
15,7566 \\
716\end{array}$ & $\begin{array}{r}3,6283 \\
12,0183 \\
15,6466 \\
709\end{array}$ & $\begin{array}{r}3,7246 \\
12,3374 \\
17,0620 \\
666\end{array}$ & $\begin{array}{r}3,9892 \\
13,2138 \\
18,2030 \\
658\end{array}$ \\
\hline \multicolumn{10}{|l|}{ Gases de la combustion. } \\
\hline 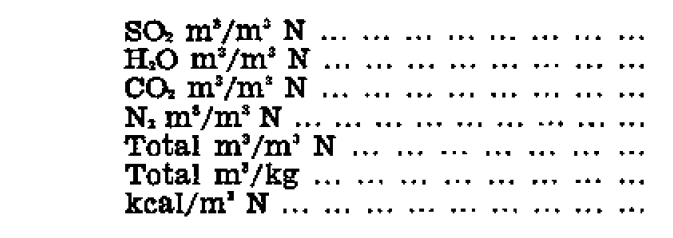 & $\begin{array}{l}1,0000 \\
\overline{7} \\
3,7617 \\
4,7619 \\
3,3288 \\
664\end{array}$ & $\begin{array}{r}\overline{1,0000} \\
\overline{1,8810} \\
2,8810 \\
32,0289 \\
899\end{array}$ & $\begin{array}{l}\overline{-} \\
1,0000 \\
3,7619 \\
4,7619 \\
8,8858 \\
909\end{array}$ & $\begin{array}{l}\overline{7} \\
1, \overline{00000} \\
1,8810 \\
2,8810 \\
2,3052 \\
1,048\end{array}$ & $\begin{array}{l}1,0000 \\
1,0000 \\
\overline{5,6428} \\
7,6428 \\
5,0288 \\
727\end{array}$ & $\begin{array}{r}2, \overline{0000} \\
2,0000 \\
11,2857 \\
15,2857 \\
12,2110 \\
\mathbf{9 2 4}\end{array}$ & $\begin{array}{l}4, \overline{0} \\
3,0000 \\
18,8005 \\
25,8095 \\
13,1173 \\
846\end{array}$ & $\begin{array}{r}3, \overline{0000} \\
2,0000 \\
13,1666 \\
18,1666 \\
13,5400 \\
840\end{array}$ & $\begin{array}{r}2, \overline{2} \\
2,0000 \\
1,0000 \\
7,5238 \\
10,5238 \\
14,7022 \\
815\end{array}$ \\
\hline \multicolumn{10}{|l|}{ Temperatura máxima teórica. } \\
\hline 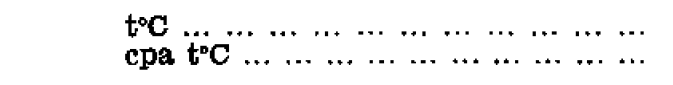 & $\begin{array}{r}1.673^{\circ} \\
0,249\end{array}$ & $\begin{array}{r}2.246^{\circ} \\
0,364\end{array}$ & $\begin{array}{r}2.231^{\circ} \\
0,290\end{array}$ & $\begin{array}{r}2.372^{\circ} \\
0,294\end{array}$ & $\begin{array}{r}1.837^{\circ} \\
0,281\end{array}$ & $\begin{array}{r}2.274^{\circ} \\
0,315\end{array}$ & $\begin{array}{r}2.117^{\circ} \\
0,335\end{array}$ & $\begin{array}{r}2.089^{\circ} \\
0,319\end{array}$ & $\begin{array}{r}2,037^{\circ} \\
0,323\end{array}$ \\
\hline \multicolumn{10}{|l|}{ Volumen de gases a $t^{\circ} \mathrm{C}$} \\
\hline 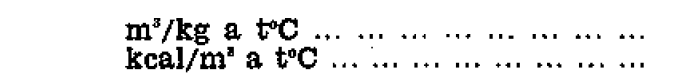 & 23,728 & $\underset{97}{295,534}$ & $\begin{array}{c}81,502 \\
99\end{array}$ & $\begin{array}{c}22,334 \\
108\end{array}$ & $\begin{array}{c}38,852 \\
94\end{array}$ & $\begin{array}{c}113,925 \\
99\end{array}$ & $\begin{array}{c}114,836 \\
97\end{array}$ & $\begin{array}{c}117,148 \\
97\end{array}$ & $\begin{array}{c}124,403 \\
96\end{array}$ \\
\hline
\end{tabular}


se disocian dando $C O$ y $H_{3}$, luego, $C O, y$ vapor de agua, no apareciendo casi nada de carbón libre. Como veremos, estos fenómenos tienen mucha importancia en las propiedades de las llamas.

En el polo opuesto a los lignitos nos encontramos con las antracitás, con 5 a $8 \%$ de volátlles. Estos carbones sólo comienzan a destilar a $750^{\circ} \mathrm{C}$, lo cual ya es una dificultad para el encendido del horno. No se puede contar con la fácil inflamabilidad de sus escasos wolátiles, por lo que se tiene que acentuar su finura al efecto de que sea el proplo carbón en polvo capaz de arder con cierta facilidad. Puede también ocurrir el caso que se da en Portugal, donde las materias volátiles de las antracitas contienen una gran proporción de no combustibles, lo que aumenta todavía las diflcultades de inflamación $y$, según algunos autores, exige un volumen específico de cámara de combustión mayor que otros carbones de mejor calidad.

Ante estas dificultades, se ha ensayado, y no sin éxito, el sistema de las mezclas; y no nos referimos solamente a las ya muy antiguas mezclas de antracitas con carbones bituminosos, sino a las más recientes de antracita y aceites pesados, o bien a la de coque de petróleo y gas natural, hasta ahora solamente aplicada en los Estados Unldos, pero quizá el día de mañana la veamos funcionar en países donde las perforaciones de petróleo o de gas natural pueden proporcionar, todavia, muy agradables sorpresas.

\section{Secado y molienda de los carbones}

No hay por qué ocultar la gran importancia que tienen las operaclones preparatorias de los carbones y lo mucho que de ellas depende si nos referimos a los resultados conseguldos.

El secado puede efectuarse antes de la molienda o simultáneamente con ella. La molienda, en todos los casos, se efectúa en mollnos ventilados, pocas veces funclonando en clrcuito abierto. Los sistemas más usados son dos: de inyección directa y de inyecolón indirecta. En el primer caso el molino descarga su producción, directamente, al quemador. En el segundo caso la descarga se efectúa a unos silos $\mathrm{u}$ tolvas, de donde es extraido, después, por medios adecuados y conducido al quemador.

Recordados estos principios generales nos permitimos, seguidamente, entrar en algunos detalles.

\section{1. Secado preliminar}

El secado previo de los carbones se recomienda siempre que la humedad del combustible sea superior a $15 \%$. También es necesarlo secar los carbones antes de la mollenda cuando no se dispone de un aproplado sistema de secado y molienda en una sola operación $y$, por último, se recomienda el secado preliminar cuando se emplean los citados ststęmas de inyección directa que, aun en el caso de mollenda y secado simultáneos, introducen en el horno la totalldad del agua evaporada.

En el secado de carbones para la industria del cemento se emplean varios tipos de secadores. Recordamos los siguientes:

a) Secadores rotativos.

b) Secadores horizontales con agitadores rotativos.

c) Secadores verticales.

d) Secadores asociados a la molienda.

En cualquiera de estos secadores, se pueden emplear los siguientes sistemas de calentamiento:

I) Gases callentes de un hogar.

II) Vapor recalentado.

III) Gases recuperados del horno rotativo.

IV) Gases recuperados del enfriador de clínquer.

En general, todos los secadores que hemos visto poseen un hogar auxiliar (sistema I), el cual, a veces tan sólo se utiliza para la puesta en marcha. El secado por vapor recalentado sólo lo conocemos por referencias de la literatura consultada. El sistema III, lo hemos visto aplicado en algunos casos de calentamiento por inyección directa, en los cuales, estando situado cada molino indivldual frente a su horno respectivo, se efectúa una extracción de alre caliente de la cabeza del horno y se introduce en el sistema de secado y molienda. También es posible utllizar los gases sallentes de los hornos rotativos, slempre que su temperatura no sea excesiva. Por último, el sistema IV, asociado al I es el que hemos visto más frecuentemente empleado en las instalaciones modernas. En efecto, los enfriadores de clínquer sistemas Fuller, Allis-Chalmers, Folax, Recupol, etc., emplean una cantidad de a1re algo mayor que la necesaria para la combustión deI carbón inyectado en el horno. El exceso de alre, que no va al horno, tiene un buen empleo si se utiliza para el secado del combustible,

Cuando el aire caliente se extrae de la cabeza del horno, o de los enfriadores de clinker, es conveniente someterlo a una operación de despolvoreamiento, hacléndole atravesar un ciclón, al efecto de separar los fnos de clínker arrastrado.

El secado de los carbones es una operación más dificil que el secado de materlas prtmas. Los carbones suelen ser hlgroscópicos y presentar elevados contenidos de agua. Asimismo, muchos de ellos comlenzan a destilar sus materlas volatiles a temperaturas relativamente bajas. El rlesgo de inflamación y de explosiones es tan conocido de todos que no precisa comentarios. Se aconseja la instalación de plrómetros y de una serle de dispositivos termo-reguladores que no permitan subir la temperatura de los gases a más de 300 ó $350^{\circ} \mathrm{C}$. 


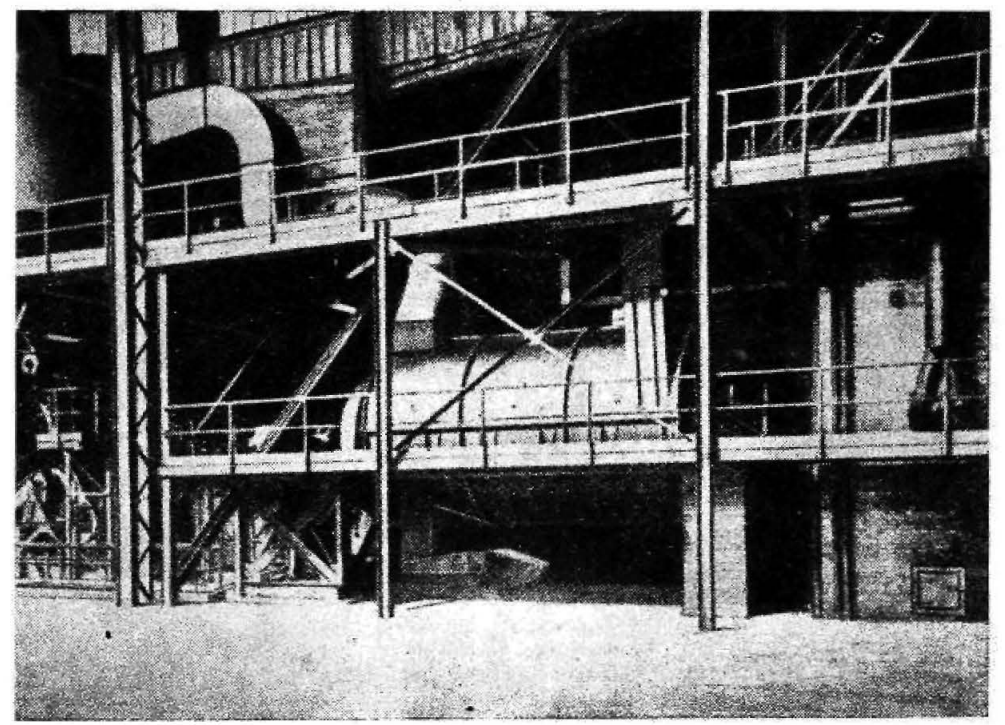
Fig. 2.-Seeador de contacto Haas, instalado en uns
fabrica de cemento belga para secado de *schlammss pegajosos.

Fig. 3.-Esquema de un secador de contacto Haas. A. Hogar de calentaniento.-B. Secador de contacto. dor. - E. Separador de polvo.

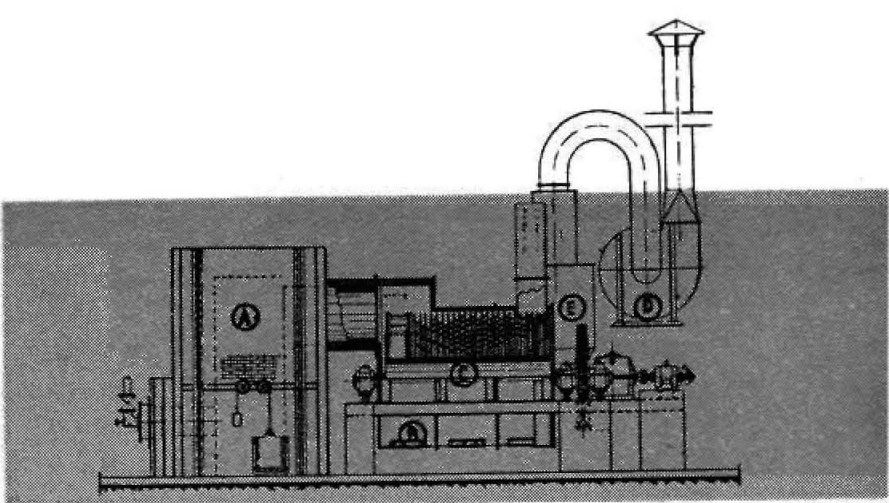

En tales condiciones, o sea, utilizando forzosamente gases a temperaturas relativamente bajas, no se puede esperar un gran rendimiento térmico. Con un $10 \%$ de humedad inicial y $1 \%$ de humedad final se consumen, en los secadores rotativos corrientes, unas $1.300 \mathrm{kcal}$ por cada kilogramo de agua evaporada. El rendimiento es inferior al $50 \%$. Para los secadores verticales se dan rendimientos todavía menores. Se admite un consumo medio de $1.750 \mathrm{kcal}$ por cada kilogramo de agua, lo que representa un aprovechamiento de $34 \%$. Los secadores modernos son presentados con rendimientos algo mejores. Así, para el secador de contacto Haas (figs. 2 y 3 ) se indica un $68 \%$ de rendimiento. Un rendimiento parecido proporciona el secador rápido sistema Andreas (figs. 4 y 5).

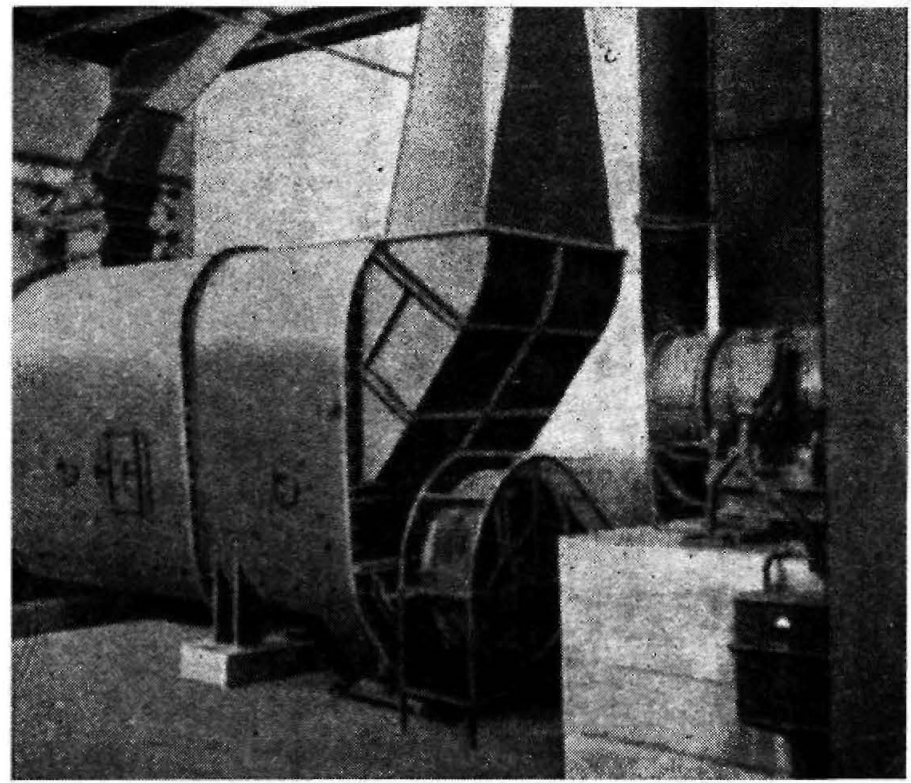

Fig. 4.-Secador rápido Hazemag (sistema Andreas).

Fig. 5.-Esquema de un secador sistema Andreas.

1. Orificio de alimentación.-2. Entrada de los gases calientes.-3. Ag1tador doble de paletas. -4 . Salida de los gases. -5 . Salida del crrbón seco.

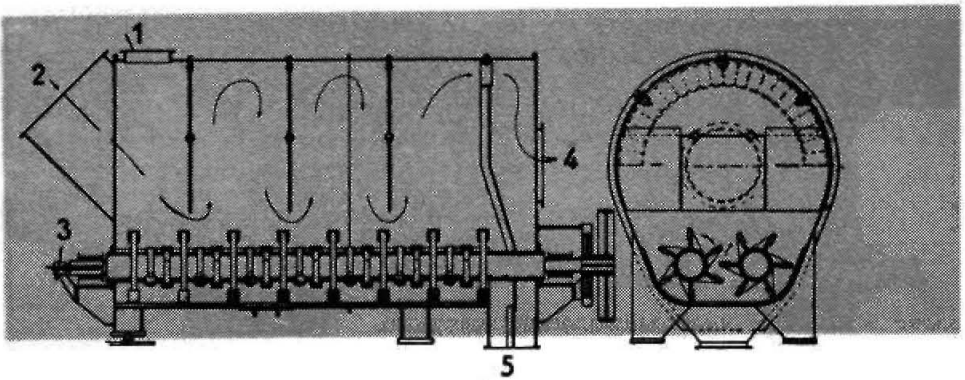




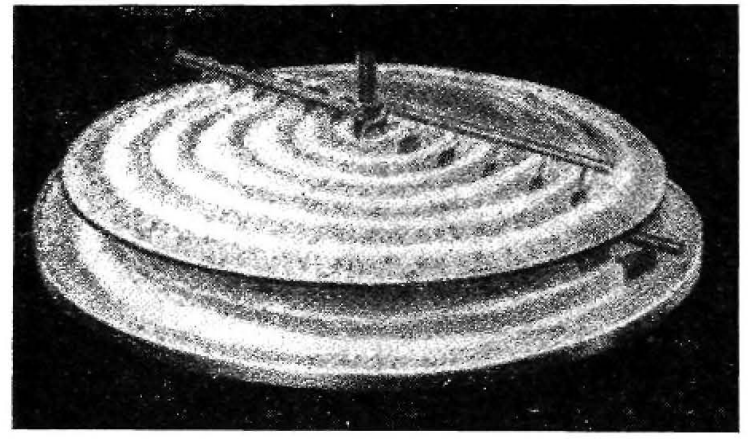

Fig. 6.-Esquema de funcionamiento de un secador vertical de platos rotativos Haas.

Estos dos secadores corresponden al tipo b), ambos son estacionarios, horizontales y provistos de elementos agitadores y transmisores de calor rotativos. La figura 6 esquematiza el funcionamiento de un secador vertical de platos rotativos. En la figura 7 se representa un interesante modelo de secador vertical, el "Turbo" Buell, con tres elementos de turbina de aire en un canal axial que imprimen a los gases calientes una trayectoria serpentina y en contra-corriente con el combustible a secar. Un secador de este tipo puede alcanzar un $75 \%$ de rendimiento térmico.

En las operaciones de secado y molienda simultáneas, el rendimiento térmico del sistema es de $50 \%$ para un $10 \%$ de agua y de $60 \%$ para un $15 \%$ de humedad inicial.

Hay que contar, además, con la energía necesaria para el secado preliminar. Esta energía varía poco, pero hay que contar con los aparatos anexos, muy variables en cada instalación, como son: elevadores, cintas transportadoras, mesas alimentadoras y ventiladores. En todo caso, el consumo referido a una tonelada de combustible varía de 1 a $1,5 \mathrm{kWh} / \mathrm{t}$.

Por último, hay que mencionar el discutído problema de la humedad residual. De una parte, este problema se relaciona con la facilidad para la molienda. En general, el carbón se seca hasta $1 \%$ de agua, y con este secado se consigue una molienda excelente. Puede llegarse según Ferrer y Vidal a $15 \%$, y todavía se trabaja satisfactoriamente. Otro problema va relacionado con la introducción del vapor de agua en el horno. Algunos autores, entre ellos VEH señalan que una pequeña proporción de humedad favorece la inflamación de los carbones. Otros hacen notar la pérdida de calor que acompaña al vapor de agua inyectado. Esta pérdida de calor puede cegar a $1,7 \%$ del calor de combustión si toda la humedad inicial del carbón, supuesta en un $10 \%$, entra en el horno a través de un sistema de inyección directa.

Fig. 7.-Secador vertical «Turbo» Buell, construido por Edgar Allen.

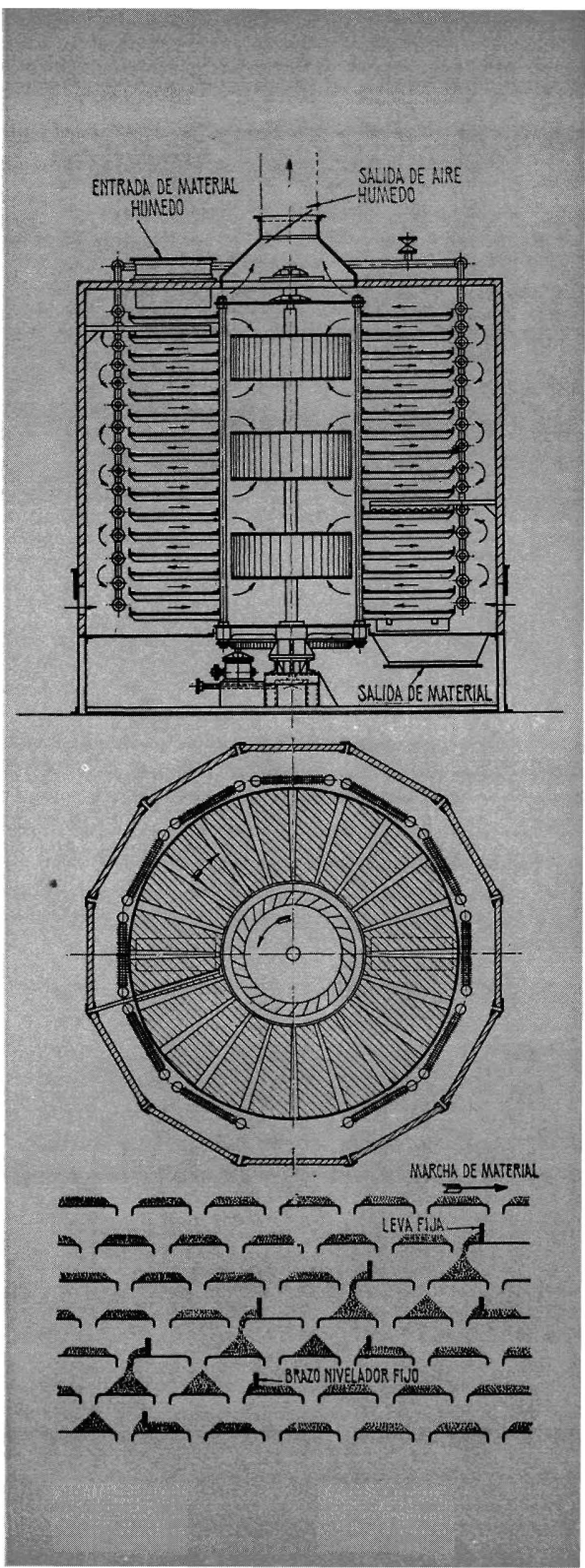


En el sistema de inyección indirecta, el aire húmedo acompaña, en parte, al carbón pulverizado, y éste, en las tolvas, puede reabsorber parte de la humedad que le fue antes sustraida. Cuando esto ocurre el carbón embola y después de inyectado en el horno quema mal, dando lugar al fenómeno que observamos con el nombre de bolas azules.

\subsection{Molienda}

Para la molienda del carbón se emplean molinos trabajando por principios bastante diferentes:

a) Por percusión (martillos, paletas, turbinas, etc.).

b) Por aplastamiento (mup'as, rodillos, péndulos, bolas, etc.).

Lo que importa es conseguir un producto pulverulento a la finura deseada y que esta finura se mantenga constante. La elección de uno u otro sistema debe tener en cuenta las caracteristicas del carbón o carbones a tratar, la finura pretendida, la energía consumida y los gastos de conservación.

En las instalaciones antiguas el problema de elección puede obviarse. El material fue escogido hace tlempo y apenas nos incumbe defendernos lo mejor posible con los elementos que se poseen. De todas formas, se impone un estudio económico serio, para ver si el gasto de instalación de una moderna sección de molienda no seria compensado en poco tiempo por la economía obtenida.

Por lo tanto, parece justiflcado, antes de entrar en la descripción de tipos y sistemas de molienda, tratar cie las diflcultades que presentan los materiales ante la trituración.

\subsubsection{Aptitud para la molienda}

Todos los autores están de acuerdo en que el material que mejor se muele es una buena hulla previamente seca. Pero como este combustible, si existe, no lo encontramos precisamente en las fábricas de cementos peninsulares, tenemos que equiparnos para moler otros carbones más difíciles, como son la antracita y el lignito.

La antracita es menos frlable que la hulla; y como conviene molerla más flnamente, resulta mucho menos apta que la hulla. El rendimlento de los molinos disminuye y aumentan proporcionalmente los gastos de conservación del material.

Los lignitos son de calidad bastante desigual. Algunos de ellos contienen una importante cantidad de madera fosilizada, todavía flbrosa, y son prácticamente ineptos para la molienda. En todo caso son siempre dificiles de moler porque se apelmazan sin pulverlzar perfectamente, y además, porque siendo higroscópicos, contienen stempre una cierta humedad, la cual tamblén es causa de dismínuclón del rendimiento.

La facilidad para la molienda puede ser evaluada por medio de la máquina de Hardgrove, de acuerdo con la norma ASTM D 409-51, aprobada en 1951 y reaprobada, sin cambios, en 1958.

Este método sirve para determinar la aptitud relativa que presenta un carbón a la pulverización, usando como término de comparaclón un carbón tipo con índice igual a 100.

El método se basa en la ley de Rittinger, según la cual el trabajo dispendido en la pulverización es proporcional a la superficle producida.

La máquina de Hardgrove consiste en un pequeño molino con ocho bolas de $25 \mathrm{~mm}$ de diámetro, que ruedan sobre un aro flo, accionadas por otro anillo superior rotativo. Sobre las bolas gravita una carga de $29 \mathrm{~kg} \pm 225 \mathrm{~g}$, constituída por el peso del anlllo superior, eje motor, transmisión y unos pesos suplementarios. El ensayo consiste en someter una muestra de finura conocida a 60 revoluciones del molino de Hordgrove, determinando después la finura del praducto resultante. La muestra de carbón a ensayar se tritura en una especie de molinillo de café, y se prepara de modo que en su totalldad pase por el tamiz núm. 16 $(1,19 \mathrm{~mm})$ y sea retenida por el tamiz núm. $30(0,59 \mathrm{~mm})$. Se toman 50 gramos de carbón así preparado y se someten al trabajo de 60 vueltas en la máquina de Hardgrove. El indice de aptitud se calcula por la fórmula:

$$
\mathrm{IH}=13+6,93 \mathrm{p}
$$

donde:

$\mathbf{P}=$ Peso del carbón fino que atraviesa el tamiz de $0,074 \mathrm{~mm}$ de abertura de malla (núm. 200 - ASTM)

Para un indice igual a $100, p=12,5$ gramos.

Si en el ensayo se obtiene una cantidad de polvo fino superior a 12,5 gramos (sobre 50 gramos de muestra), el indiee de aptttud será mayor que 100; en caso contrario, un carbón menos apto, proporcionando una cantidad de polvo inferlor a $12,5 \mathrm{~g}$, tendrá un bajo indice (menor que 100). Supongamos que el ensayo de Hardgrove ha dado para una antracita 9,5 gramos de polvo fino, pasando por el tamlz número 200 . $\mathrm{Su}$ indice correspondiente será:

$$
\mathrm{IH}=13+6,93 \times 9,5=78,8 .
$$




\subsubsection{Finura de los combustibles}

Sucede frecuentemente en nuestra Industria que, preocupados por el vital problema de la finura de molienda del cemento acabado, relegamos a un segundo plano la finura de los carbones y nos quedamos muy satisfechos después de unas determinaciones más o menos sistemáticas de residuos sobre los tamices normales.

Sin embargo, es tanta la importancia teórica y práctica de este problema que fue, precisamente, del estudio de la granulometria de los carbones, que se pudo formular, por Rosin y Rammler, su tan famosa ley de la distrfbución de los gránulos por sus pesos y tamaños de partícula. Esta ley, según se sabe, se puede representar por la siguiente ecuaclón:

$$
\mathbf{R}_{\mathbf{x}}=100 e^{-\left(\frac{x}{d^{\prime}}\right)^{n}}
$$

representando:

$\mathbf{R}_{\mathbf{x}}=$ Residuo sobre un tamiz de paso igual a $\boldsymbol{x}$ micras.

$e=$ Base de los logaritmos naturales $(e=2,71828$ ).

$d^{\prime}=$ Grado de fnura (valor de $x$ correspondiente a $\mathrm{R}=36,788 \%$ ).

$n=$ Constante de dispersión.

Si en [13] hacemos $x=d^{\prime}$, se tiene:

$$
R_{a} \cdot=100 / e=36,788 \%
$$

Como se sabe, representando esta ecuación en papel cuadriculado a las escalas logaritmica y doble logarítmica, según la ecuación

$$
\log \left(\log \frac{100}{\mathbf{R}_{\mathbf{x}}}\right)=\log (\log e)-n \log d^{\prime}+n \log x
$$

obtenemos una linea recta en la cual $n$ es la tangente del ángulo que forma con el eje de las abscisas.

He aqui algunas características granulométricas de varios carbones, segín Anselm.

\section{CA B B O N E B}

Hulla calibrada 0-80 $\mathrm{mm}$

Antracita

Finos de hulla

tignito pardo

Carbón pulverizado, blando $\ldots \ldots \ldots \ldots \ldots$

Carbón pulverizado, semi-duro $\ldots \ldots \ldots$

Carbón pulverizado, duro $\ldots \ldots \ldots \ldots$

Polvo de los flltros, antracita ... ........

Polvo de los filtros, lignito

$\begin{array}{ccc}\begin{array}{c}\text { d' } \\ \text { (micras) }\end{array} & \text { n } & \text { are } \mathbf{t g} \text { } \\ 12.000 & 0,572 & 30^{\circ} \\ 4.000 & \mathbf{0 , 6 2 5} & 32^{\circ} \\ 3.250 & 0,933 & 43^{\circ} \\ 2.000 & 0,727 & 36^{\circ} \\ 44 & 1,150 & 49^{\circ} \\ 45 & 1,192 & 50^{\circ} \\ 46 & 1,235 & 51^{\circ} \\ 16,8 & 0,840 & 40^{\circ} \\ 3.8 & 0,840 & 40^{\circ}\end{array}$

En general, la flnura de los carbones se determina por medito de los tamices normales y se expresa por los residuos sobre uno o varios de ellos. Sería más correcto emplear la superficle específica como medio de expresión de la finura de los carbones. La superflcie especiflca, según sabemos, se defne por la ecuaclón:

$$
\mathrm{S},=\frac{600}{\rho} \int_{\mathrm{r}_{2}}^{x_{1}} \frac{\Delta \mathrm{P}}{\Delta \mathrm{I}} d \log x
$$

Como sea que la determinación analitíca de la superflcle especiflca es poco práctica, se ha empleado, con éxito, el permeabllímetro de Blaine. Recordemos la ecuación fundamental del permeabilímetro:

$$
\mathbf{S}_{\mathrm{u}}=\mathrm{k} \frac{V_{\bar{z}^{3}} V_{\bar{t}}^{\bar{t}}}{p(1-z ! \sqrt{\eta}}
$$

por la cual vemos que la superflcie especiflca es función inversa de la densidad del material. Asi, pues, a igualdad de granulometría, tendremos para el carbón una superfleie específlca 2,4 veces mayor para el cemento. 


\begin{tabular}{|c|c|c|c|c|}
\hline & MATERIALES & $\begin{array}{c}\text { Peso } \\
\text { espeoifica } \\
\left(\mathrm{z}+\mathrm{mm}^{-5}\right)\end{array}$ & \multicolumn{2}{|c|}{$\begin{array}{l}\text { Superficie } \\
\text { espectifex }\end{array}$} \\
\hline \multirow[t]{6}{*}{ 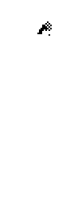 } & Cemento Portland $\ldots \ldots \ldots \ldots \ldots \ldots$ & 3,15 & 3.600 & $\mathrm{~cm}^{2} \cdot \mathrm{s}^{-1}$ \\
\hline & Crudo para cemento $\ldots \ldots \ldots \ldots$ & 2,7 & 4.200 & " \\
\hline & Coke $\ldots \ldots \ldots \ldots$ & 1,8 & 6.300 & $"$ \\
\hline & Antracita $\ldots \ldots \ldots \ldots$ & 1,7 & 6.670 & " \\
\hline & Lignito $\ldots \ldots \ldots \ldots \ldots$ & 1,4 & 8.100 & 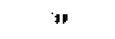 \\
\hline & 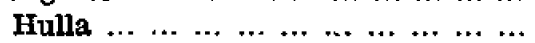 & 1,3 & 8.723 & $"$ \\
\hline
\end{tabular}

En todos los ejemplos anteriores se ha supuesto un diámetro medio constante, deflnido por la ecuación:

$$
d_{\mathrm{med}}=\frac{6 \times 10^{4}}{\varphi \mathrm{S}}=5,29 \text { micras }
$$

La finura de molienda que se recomlenda es, en definitiva, muy variable. En general, se suele especiflcar un $10 \%$ de residuo sobre el tamiz de 4.900 mallas $/ \mathrm{cm}^{3}$, o sea, $90 \%$ de partículas de tamaño inferior a 90 micras. Sin embargo, sabemos que son muchos los hornos que funcionan correctamente inyectando carbón a menor fnura. Algunos autores creen suficlente moler con un residuo de $15 \% \mathrm{y}$ para algunos lignitos se admiten residuos de hasta $20 \%$.

Para Simon, un carbón grueso proporciona mayor constancia en el factor de emisión, pero se corre el peligro de que aparezcan fracciones no quemadas. Para evitar este peligro se debe aumentar la flnura de molienda en función inversa de la inflamabilidad del combustible. El desprendimiento de las materias volátiles y la velocidad de combustión del coke aumentan con la finura del carbón. Si las materias voláthles son escasas, como sucede con las antracitas, se debe apurar la flnura más que con carbones bituminosos. Los carbones densos, además de ser de mayor dureza, por razón de su elevado peso especifico, exlgen mayor finura si se quiere obtener la misma superficle especiflea. El mismo caso se da con los carbones pobres, de alto contenfdo de cenizas, pues, como certeramente apuntó López Peciña, en los coloquios de 1957, una parte de la superfleie creada no está formada por elementos combustibles, sino por cenizas que no intervienen en la combustión, lo que equivale a una mollenda más grosera del carbón.

Se ha observado que aumentando la finura de molienda del carbón pulverizado, se acorta el tiempo de combustión, aumentando la temperatura de Ia Ilama. Asi, pues, slempre que haya diflcultades para la inflamación del combustible, o que se desee una llama más corta y caliente se deberá actuar, si es posible, en el sentido de inyectar un carbón de mayor finura.

\subsubsection{Rendimiento en la molienda de los carbones}

Las operaciones de molienda de carbón-como consecuencia de lo antedicho-deben presentar rendimientos muy variables, que dependerán tanto del material a moler como de las máquinas empleadas. La aptitud de mollenda $y$ el rendimiento de un molino no dependen exactamente de la dureza del material a moler. El clinker de cemento Portland es unas 2,5 veces más duro que los carbones; sin embargo, el consumo de energia por tonélada de material es casi del mismo orden de magnitudes.

Se admite que las buenas hullas se muelen mejor que las antracitas y los tignitos. La facilidad de molienda en los lignitos está sujeta a fluctuaciones mucho mayores que en los demás combusttbles. Infiuye mucho la cantidad de agua higroscópica del combustible a la entrada del mollno. Se admite que la producción de un molfno-secador disminuye, operando con carbones excesivamente húmedos, de acuerdo con la ecuación:

en la cual:

$$
P=P_{n}-140\left(H-H_{n}\right) \mathrm{kg} / \mathrm{h}
$$

$\mathbf{P}_{\mathrm{u}}=$ Producción en $\mathrm{kg} / \mathrm{h}$ del molino en condiciones normales.

$H_{n}=$ Tanto por ciento de humedad considerada "normal".

$\mathbf{P}=$ Producción en $\mathbf{k g} / \mathbf{h}$ del molino alimentado con $\mathbf{H} \%$ de humedad.

Según esta fórmula, un molino con una producción de $5 \mathrm{t} / \mathrm{h}$ con $10 \%$ de humedad, vería mermada su producción en $700 \mathrm{~kg} / \mathrm{h}$ si la humedad aumentase hasta $15 \%$.

La influencia que tienen los slstemas de molienda para un mismo material molido a igual finura, la demuestran los sigulentes consumos, tomados de Anselm, para carbones finos, con $10 \%$ de residuo sobre el tamiz de 4.900 mallas:

$$
\begin{aligned}
& \begin{array}{c}
\text { Molino } \\
\text { de rodillos }
\end{array} \text { Molino } \begin{array}{c}
\text { Moltuo } \\
\text { ventilado }
\end{array} \\
& \text { Antracita } \ldots \ldots \ldots \ldots \ldots \ldots \ldots, 14,0 \mathrm{kWh} / \mathrm{t} \quad 22,0 \mathrm{kWh} / \mathrm{t} \quad 28,0 \mathrm{kWh} / \mathrm{t} \\
& \text { Hulla ... ... ................ 12,5 kWh } / \mathrm{t} \quad 18,0 \mathrm{kWh} / \mathrm{t} \quad 24,5 \mathrm{kWh} / \mathrm{t}
\end{aligned}
$$

Hay que tener en cuenta que la energía consumida por el molino es una parte del total consumido por todo el sistema de molienda. Una Instalación de molienda y secado, por circuito cerrado e inyección Indirecta, tiene un $80 \%$ de potencia suplementaria instalada en relación a la potencla del molino propiamente dicha. Así, pues, admitiendo un consumo de $18 \mathrm{kWh} / \mathrm{t}$ en el molino, hay que contar, por lo 
menos, con $15 \mathrm{kWh} / \mathrm{t}$ más para las restantes máquinas que componen el sistema, incluída la inyección.

Dos ejemplos, tomados de Bodmer-Nisolle, nos proporcionan los siguientes datos comparativos:

\begin{tabular}{|c|c|c|}
\hline SISTEMA DE INYECCION & Directa & Indirecta \\
\hline 1... & $16,60 \mathrm{k}$ & 1 \\
\hline
\end{tabular}

De acuerdo con la ley de Rittinger, ya citada, el consumo de energía es proporcional a la superficle específca creada, e inversamente proporcional al peso especifico. Esta ley es válida entre ciertos límites.

Para un material con una superfele específica $\mathrm{S}_{\mathrm{t}}\left(\mathrm{cm}^{2} \mathrm{~g}^{-1}\right)$ y un consumo de $\mathrm{J}_{\mathrm{t}}(\mathrm{kWh} / \mathrm{t})$, se tendrá una superficie creada de:

$$
\mathbf{S}_{\xi}=10^{\circ} \mathbf{S}_{*} / \mathrm{J}_{1}\left(\mathrm{~cm}^{2} \cdot \mathbf{k W h}^{-1}\right)
$$

slendo necesario un trabajo de afinación de:

$$
\mathrm{J}_{\mathrm{s}}=10^{-15} \mathrm{~J}_{\mathrm{t}} / \mathrm{S}_{\mathrm{t}}\left(\mathrm{kWh} / \mathrm{cm}^{2}\right)
$$

Como sea que el $\mathrm{kWh}$ y el $\mathrm{cm}^{2}$ son unidades de muy distinto orden, Anselm propuso usar, en lugar del kWh como unldad de trabajo, el gramo centímetro, o sea, la clenmilésima parte del kilográmetro. Las equivalencias mutuas se deducen según sigue:

$$
\begin{aligned}
& 1 \mathrm{kWh}=\mathbf{3 , 6} \times 16^{\mathrm{a}} \text { julios. } \\
& 1 \mathrm{Julio}=1 / 9,8 \mathrm{kgm} . \\
& 1 \mathrm{kgm}=10^{3} \mathrm{gcm} . \\
& 1 \mathrm{kWh}=\mathbf{3 6 , 7 3 5 \times 1 0 ^ { \prime }} \mathrm{gcm} . \\
& 1 \mathrm{gcm}=27,22 \times 10^{-15} \mathrm{kWh} .
\end{aligned}
$$

\section{CUADRO It. - Moliendạ de Carbón. Rendimientos}

GaARTEKISTICAS DEL CARBON

Duread

Peso especifteo: $\mathrm{g} / \mathrm{cm}^{3}$

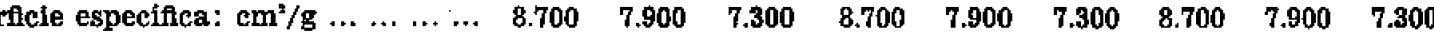

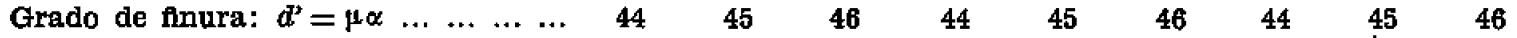

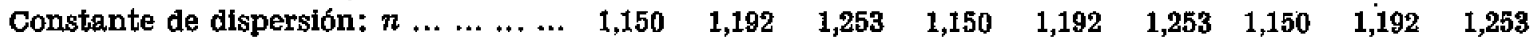

Angulo de inclinación: $\alpha \ldots \ldots \ldots \ldots .49^{\circ} \quad 5^{\circ} \quad \begin{array}{cccccccc} & 51^{\circ} & 49^{\circ} & 50^{\circ} & 51^{\circ} & 49^{\circ} & 50^{\circ} & 51^{\circ}\end{array}$

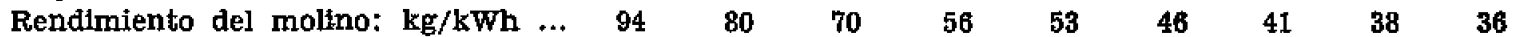

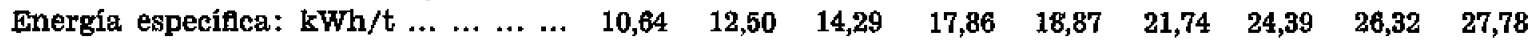

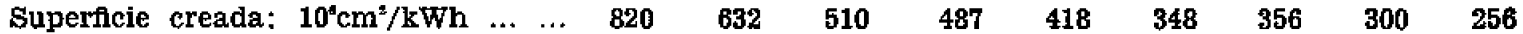

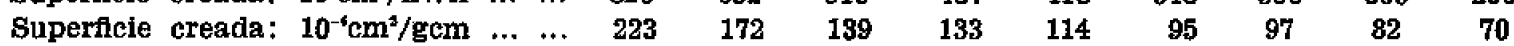

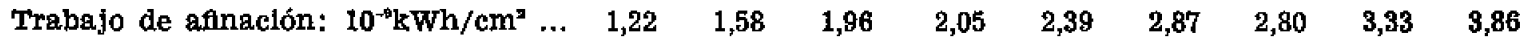

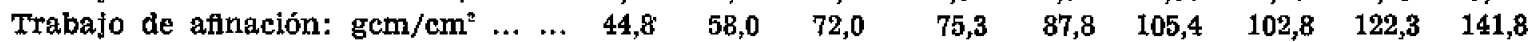

El cuadro II, basado en datos tomados-en parte-de Anselm, da las superficies creadas y los trabajos de afnación en unas $y$ otras unidades. El trabajo de fragmentación de los carbones es muy inferior al consumido en la molienda. Para un carbón seml-duro es de $1,5 \mathrm{gcm} \mathrm{\textrm {cm } ^ { - 2 }}$. Un consumo de $87,8 \mathrm{gcm}^{-3}$ equivale a $1,7 \%$ de rendimiento.

La influencla de la finura en la molienda de un carbón semiduro, con peso especiffico de 1,25 $\mathrm{g} \mathrm{cm}^{-s}$, supuesta una constante de dispersión $n=1,192$ (arc tg $n=50^{\circ}$ ), es, también según Anselm:

Caracteristicas de finura

$\begin{array}{lcl}\text { F } 4900 & \begin{array}{c}\text { Se } \\ \left(\mathrm{cm}^{2} \cdot \mathrm{s}^{-1)}\right.\end{array} & d^{\prime} \\ 5 & 6.880 & 36 \\ 7,5 & 6.190 & 40 \\ 10 & 5.500 & 45 \\ 12,5 & 5.100 & 48,5 \\ 15 & 4.770 & 52 \\ 20 & 4.160 & 59,5 \\ 25 & 3.640 & 68 \\ 36,8 & 2.750 & 90\end{array}$

TIPO DE MOLINo

$\begin{array}{cc}\begin{array}{c}\text { De rodillos } \\ \left(\mathrm{sem} \cdot \mathrm{cm}^{-2}\right) .\end{array} & \begin{array}{c}\text { Ventilado } \\ \left(\mathrm{gem} \cdot \mathrm{cm}^{-3}\right)\end{array} \\ 68 & 91 \\ 64 & 88 \\ 64 & 88 \\ 64 & 88 \\ 64 & 88 \\ 64 & 91 \\ 67 & 97 \\ 80 & 111\end{array}$

Por este cuadro yemos que, dentro de los límites de validez de la ley de Rittinger, el trabajo de afinación es constante, para finuras mayores, o para carbones muy groseros, el trabajo de aflnación es mayor en ambos sistemas de molienda. 

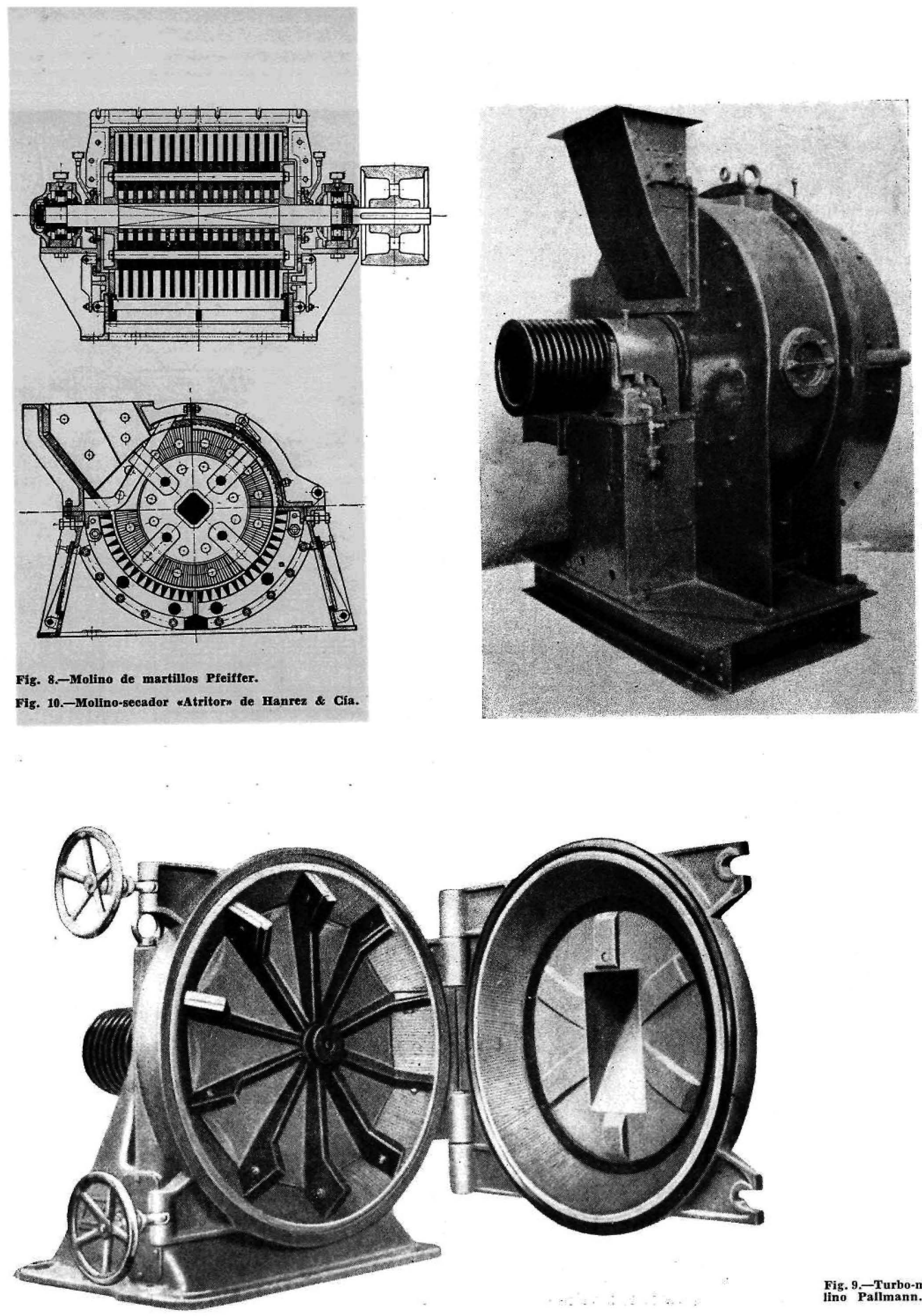

Fig. 9.-Turbo-mo- 


\subsubsection{Molinos de carbón de gran velocidad}

Hay una gran variedad de equipos para la molienda de carbón. Señalar las ventajas e inconvenientes de cada máquina sería muy provechoso; pero no nos atrevemos a hacerlo, por temor a pecar de partidistas al no poder disimular nuestras preferencias para un sistema determinado. Sin embargo, creemos que nuestro trabajo sería incompleto si no hiciera, por lo menos, una breve referencia a los aparatos más usados y a algunas de sus características.

Comenzaremos por los molinos que comprenden un rotor o varios cuerpos móviles, animados de gran velocidad. En estos molinos se puede obtener la afinación: por percusión, por aplastamiento o por combinación de ambos sistemas.

No todos los molinos conceptuados como de gran velocidad giran con el mismo número de vueltas. Algunos, como el "Atritor", tienen su rotor directamente acoplado a un electromotor de $1.350 \mathrm{v} / \mathrm{mn}$ (fig. 10). El molino "Raymond", en cambio, trabaja a unas $150 \mathrm{v} / \mathrm{mn}$.

Se pueden citar, como bastante empleados, los molinos de martillos, siendo el "Pfeiffer" (fig. 8) un conocido ejemplo de los que actúan por percusión o por impacto. E1 turbo-molino de la figura 9 trabaja por abrasión con un consumo de energía sumamente bajo $(6 \mathrm{kWh} / \mathrm{t})$, pero tan sólo apto para pequeñas producciones.

El "Atritor"-del cual ya hemos hablado-se emplea en Inglaterra y Francia (figura 10), teniendo noticia de haberse empleado en una modernísima instalación cementera en la primera de dichas naciones. Al mismo tipo de molinos se pueden referir los aparatos denominados "Aero-Pulverizador", "Pulvero-Quemador" y "Resolutor". Este último se utiliza en fábricas francesas, belgas y españolas. En general, los molinos de impacto consumen poca energía, de 16 a $23 \mathrm{kWh} / \mathrm{t}$, sin proporcionar grandes finuras. Por término medio, se considera aceptable un residuo de $15 \%$ sobre el tamiz de 4.900 mallas, pero este residuo sube hasta $20 \%$ cuando la humedad del carbón a la entrada es superior al $10 \%$.

Tiene gran aceptación en Alemania y otros países de la Europa Occidental el molino Loesche, de muelas cónicas. Según Rezola, este molino se extiende cada vez más para el tratamiento de carbones "normales" (flg. 11). En el cuadro II se dan algunos resultados-tomados de Anselmque se pueden referir a un molino "Loesche". El consumo, bastante variable, oscila entre 15 y $20 \mathrm{kWh} / \mathrm{t}$.

En el molino de rodillos "Wedag", el plano orbital de los rodillos está en la vertical (figura 12). Por el contrario, en los molinos del tipo "ruleta", como el Babcock \& Wilcox (figura 13), se tiene una circunferencia de bolas, dispuesta en un plano horizontal, entre los aros de un cojinete, siendo impulsadas por el aro inferior, giratorio, a velo-

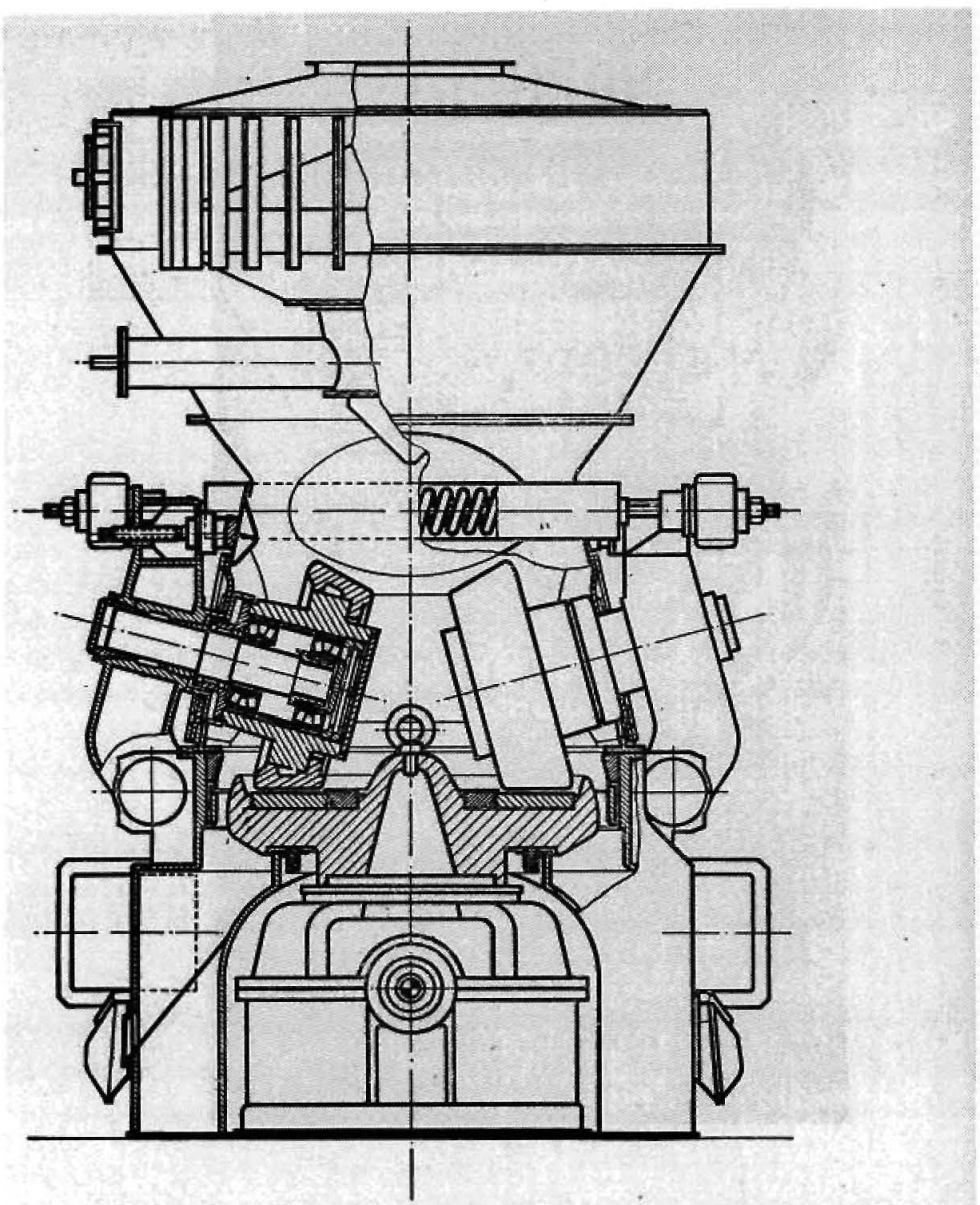

Fig. 11.-Molino Loesche, de muelas cónicas.

Fig. 12,-Molino de rodillos Wedag.

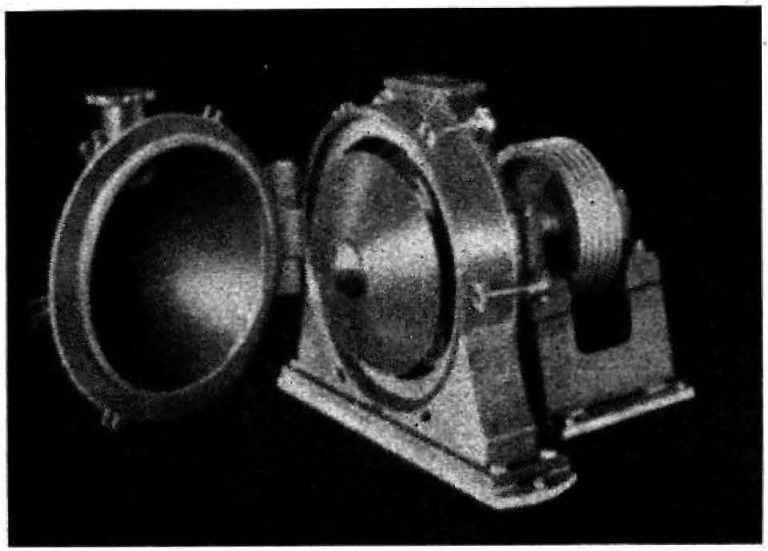




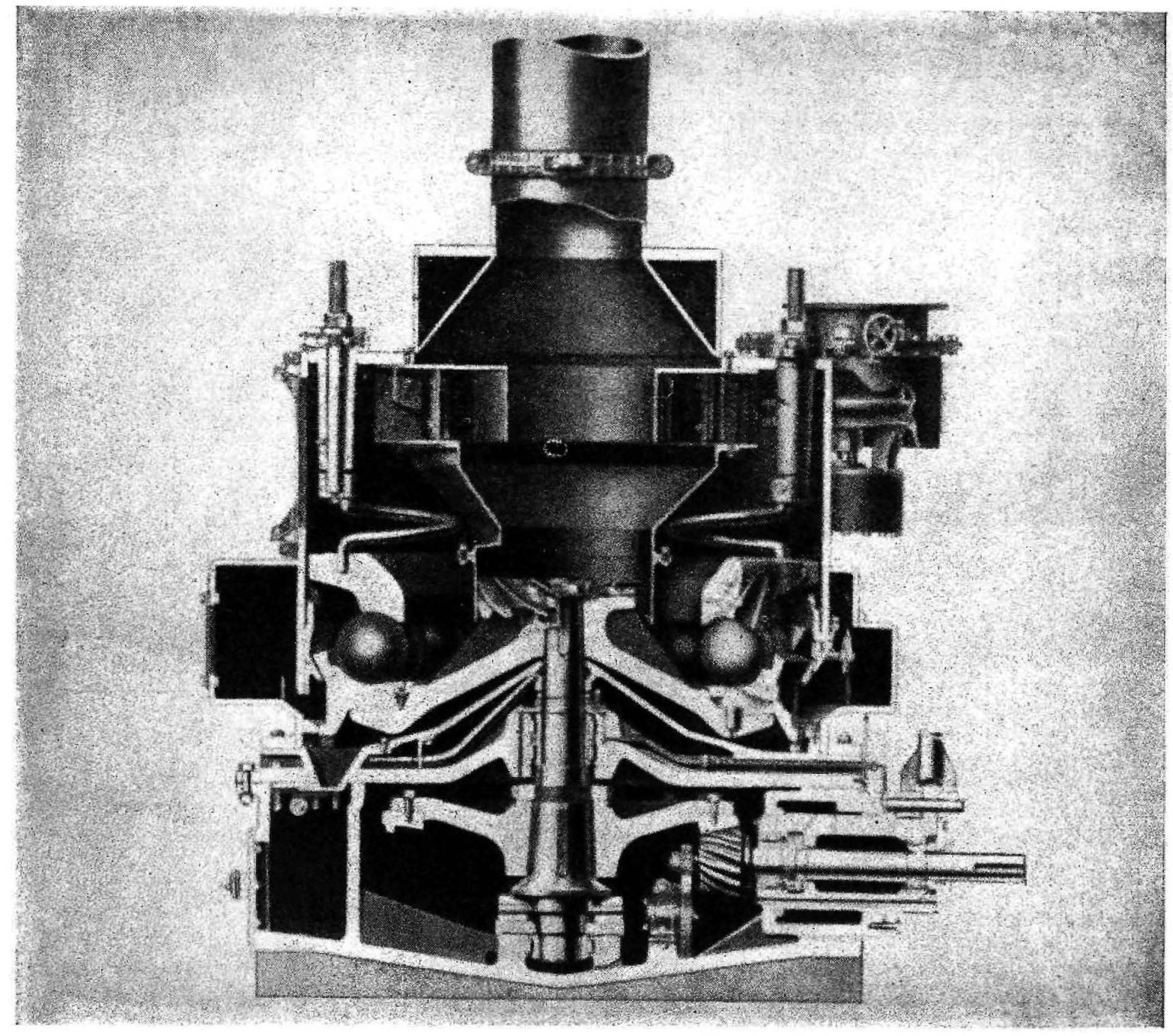

Fig. 13.-Molino Babcock \& Wilcox, tipo ruleta.

Fig. 14.-Molino B. \& $w$. de inyección di-

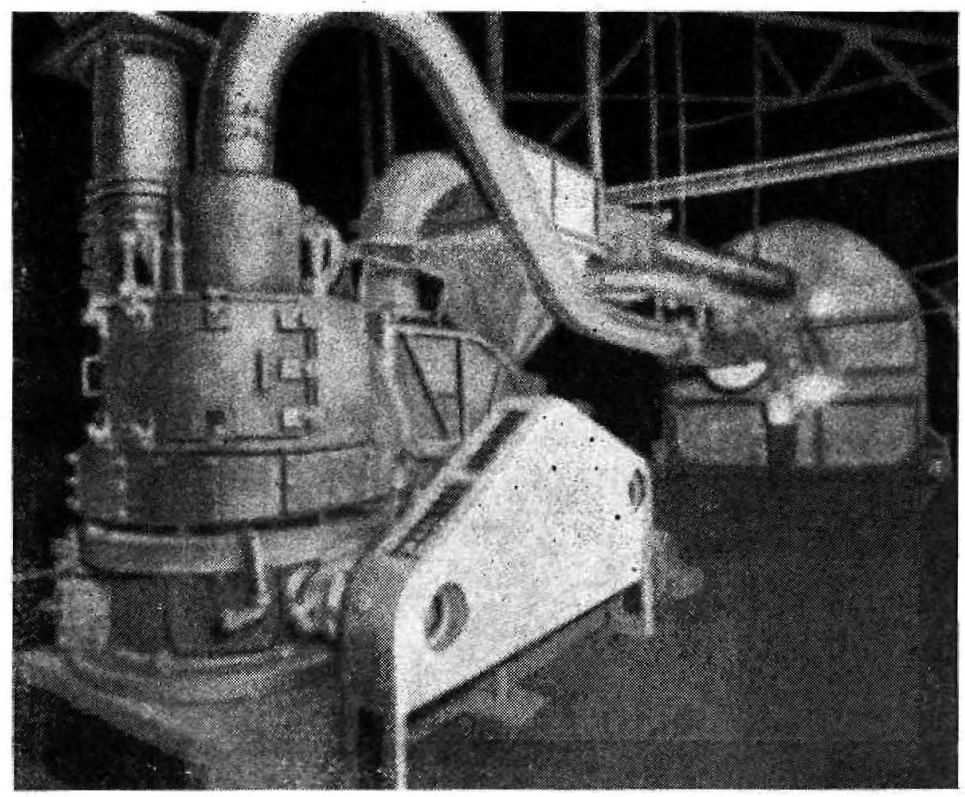


cidad relativamente baja. El molino de laboratorio de Hardgrove es del tipo "ruleta", como el "B. \& W." EI molino tipo "Fuller", todavia muy usado en los Estados Unidos, comprende tan sólo cuatro grandes bolas de hasta $32 \mathrm{~cm}$ de díametro. Estos molinos son de bajo consumo, unos $12 \mathrm{kWh} / \mathrm{t}$, y tampoco suelen proporcionar grandes finuras. Se emplean, generalmente, para la inyeceión directa de carbones de buena calidad (flgura 14).

Lo mismo se puede decir del molino de péndulos "Raymond" (fig. 15), que, sin duda, es el más usado en las fábricas americanas. Consume de 11,5 a $14,5 \mathrm{kWh} / \mathrm{t}$ con residuos del 20 al $25 \%$. En Inglaterra se tiene el molino de rodillos verticales "Rema", construfdo por Edgar Allen (flg. 16), con pn consumo de unos $15 \mathrm{kWh} / \mathrm{t}$.

En resumen, los molinos de gran velocidad son de menor coste de instalactón, la mitad o menos, aproximadamente, que los mollnos convencionales. También son de menor consumo especiflco en $\mathrm{kWh} / \mathrm{t}$. Hoy en día se construyen, algunos modelos, para producciones bastante elevadas. Sin embargo, su empleo no se ha extendido, al parecer, por ser poco indicados para el tratamiento de los carbones de inferior calidad, como son los peninsulares, en los cuales se tiene que conseguir una gran finura y un cuidadoso secado. Otro inconveniente es el desgaste de las plezas sujetas a abrasión, que suelen ser earas, por ser de aceros duros que no siempre se pueden conseguir en las fundiciones que habitualmente suministran los accesorios de las fábricas.

\subsubsection{Mollnos de carbón de pequefia velocidad}

La molienda del carbón en molinos tubulares de bolas, con secado simuitáneo o independiente, es todavia el sistema insustituible cuando se deben tratar carbones difíciles de moler en los cuales se exige una elevada fnura. En estos molinos, como es sabido, la velocidad se determina por una ecuaclón del tipo:

$$
n=\frac{k}{\sqrt{\mathrm{D}}} \text { vueltas/minuto' }
$$

donde la constante $k$ vale 32 ó poco menos. Asi, con $2 \mathrm{~m}$ de diámetro interior de un mollno se tendrian 22,5 vueltas por minuto.

Como cuerpos moledores se emplean bolas de acero fundido de poco diametro, de 30 a $50 \mathrm{~mm}$ de diámetro, y el consumo normal es de 30 a 40 gramos por tonelada de carbón molido. Las corazas que constituyen el blindaje interno del molino tienen también su desgaste, algo menor que el de los cuerpos moledores y un revestimiento de buena calidad puede durar algunos años de trabajo.

Las instalaciones modernas son de molienda y secado simultáneo y, en general, trabajan por circuito cerrado, constando: de un moltno-secador, un hogar auxiliar, un seleccionador de finos y gruesos, un ciclón y un flltro.

Los molinos-secadores de F. L. Smidth comprenden una cámara de secado y otra de molienda. En e "Pyrator", ya en desuso, el secado se conseguía por medio de bolas calentadas separadamente. En el "Tirax", los gases calientes de un hogar auxiliar, del horno o del enfriador de clinker entran al molino a una temperatura cuidadosamente regulada para evitar los riesgos de incendio. El molino ventilado de "Polysius" también es de dos cámaras (flgs. 20 y 21), mientras que en los molinos de bolas "Rema" (flg. 17) y "Humboldt" la molienda y secado se efectúa en una sola cámara. El molino secador "Self", construido por Fives Lille (flg. 22), diflere de Ios anteriores en tener el separador inmediatamente después del molino y devolver el rechazo a través de una envolvente periférica.

En estos molinos el consumo de energía es algo superior al consumo de los molinos de gran velocidad. Varía entre 22 y $30 \mathrm{kWh} / \mathrm{t}$, pero, en compensación, están habilitados para obtener elevadas finuras unidas a un casi perfecto secado. Gozan de general preferencia en ias grandes instalaclones cementeras de Europa y proporcionan una segurldad en la marcha que no consiente graves objeciones.

\subsubsection{Sistemas de inyección}

Como ya hemos dicho, se emplean actualmente dos sistemas de inyección: directa e indirecta.

La inyección directa ejecuta en una misma unidad las operaciones de secado, molienda y envio al horno del carbón recién salido del molino. El carbón se prepara a medida de las necesldades del horno. Fs arrastrado por una fuerte corriente de alre sin necesidad de separador. Esta corriente de aire arrastra, además, el vapor de agua desprendido por secado del carbón. Se asegura que la presencia de esta humedad, aun representando tun inconventente desde el punto de vista del consumo de calor, mejora la combustión y proporciona una mayor facilidad en la regulación de la llama.

Trabajando estas instalaciones bajo una cierta depresión son mis limpias y menos ruidosas que las de inyección Indirecta. El problema del polvo tiene poca importancia y los gastos de instalación muy ventajosos. No es de desdefiar el hecho de ser estas instalaciones menos voluminosas. Este sistema-que emplean algunas fábricas peninsulares-tiene una gran aceptación en los EE. UU. Según Clausen, lo utilizan el $63 \%$ de las fábricas de cemento.

El sistema de inyección directa suele basarse en un molino rápido (Raymond, ruleta o Loesche), con separador, trabajando en circuito cerrado. El alre aspirado del horno pasa por un ciclón que lo limpla de las partículas de clínker (flgs, $14 \mathrm{y}$ 15). Pueden también aplicarse los molinos Ientos al sistema de in- 


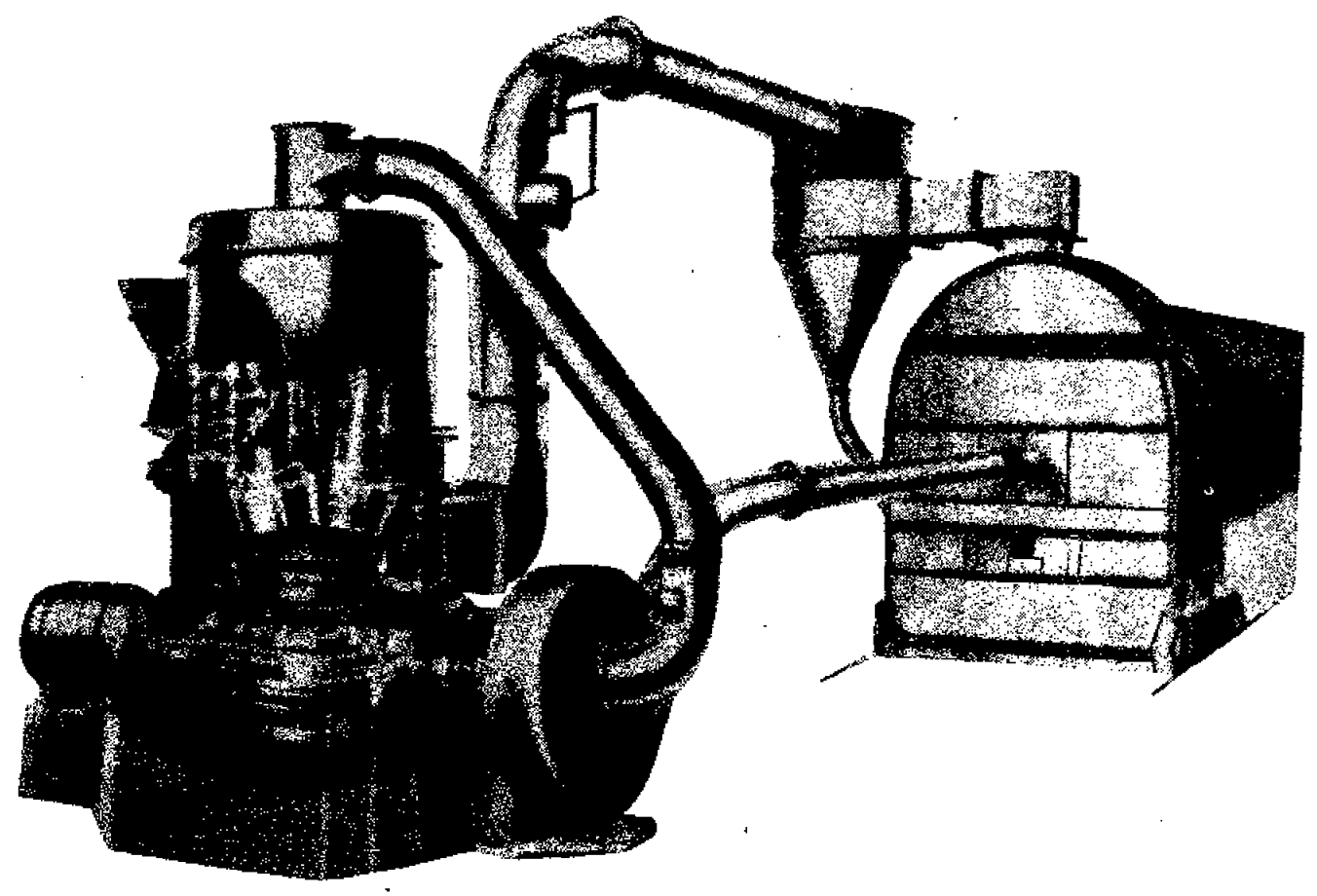

Fig. 15.-Molino Raymond, de péndules.

Fig. 17.-Molino e fnyector de carbón, sistema Rema.

1. Ventilador de aire primario-2. Valvula by-pass. - 3. Fegulador a mano para controlar la finura. 4. Tuberia de alre caliente procedonte del horno,-5. El material a maler se sece por el aire caliente mientras se arrastra por la tu'berla, - 8. Carcasa del molino de bolas. - T. Horno del molino de bolas. A. Caja de engranajes. $\rightarrow$. Transmisión.--10. Alimentador rotatorio.-11. Reductor -12 . Motor. -13 . Horno rotatorio con enfriadores satelites.-14. Trampilla para eliminar partículas de hierro:-15. Clasi-
fleador.-16. Tolva de carbón.
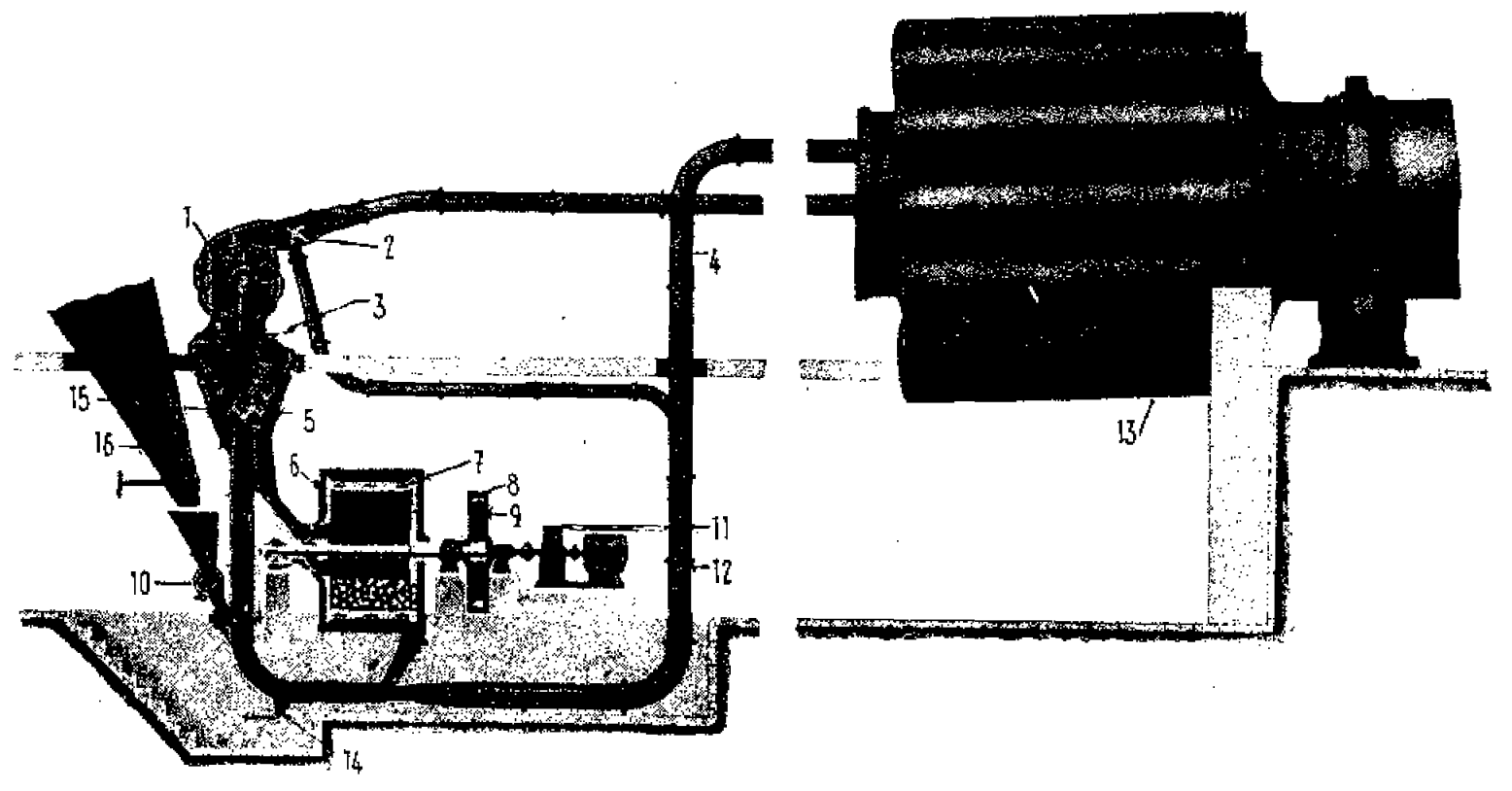


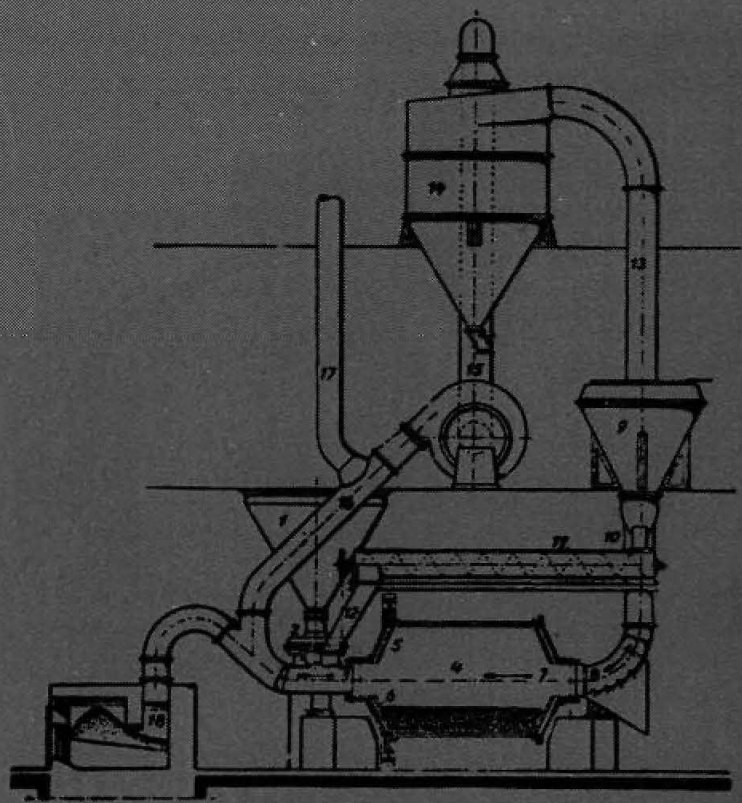

Fi. 18,-Molino-secendor Humboldt.

1. Tolve de carga, -2 . Plato de alimentación,-4. Molimo tubular- -9 . Beparador, -11 . Rosca de retorno.-14. Cielon,-15. ventilador de clrculación.

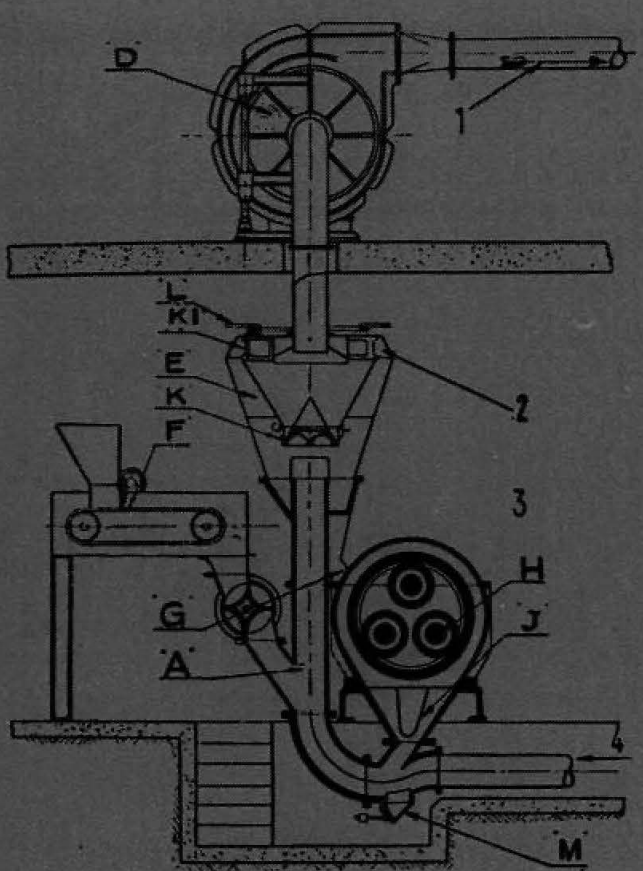

Fig. 16.-Disposición tiples de un molino de rodillo Rema (H), unide al sistema de vacío formado por us separador (B) y un ventilador de inyscelón directa (D).

1. Polvo de carbón y aire hacia el quemador-2. Se gundo rechazo de particulas gruesas por turbuitencia hacia el cono interior de vuelta al molino--3. Primer rechazo de trozos gruesos hacts el molino,-4. Air

Fig. 19.-Molino-secador Humboldt.

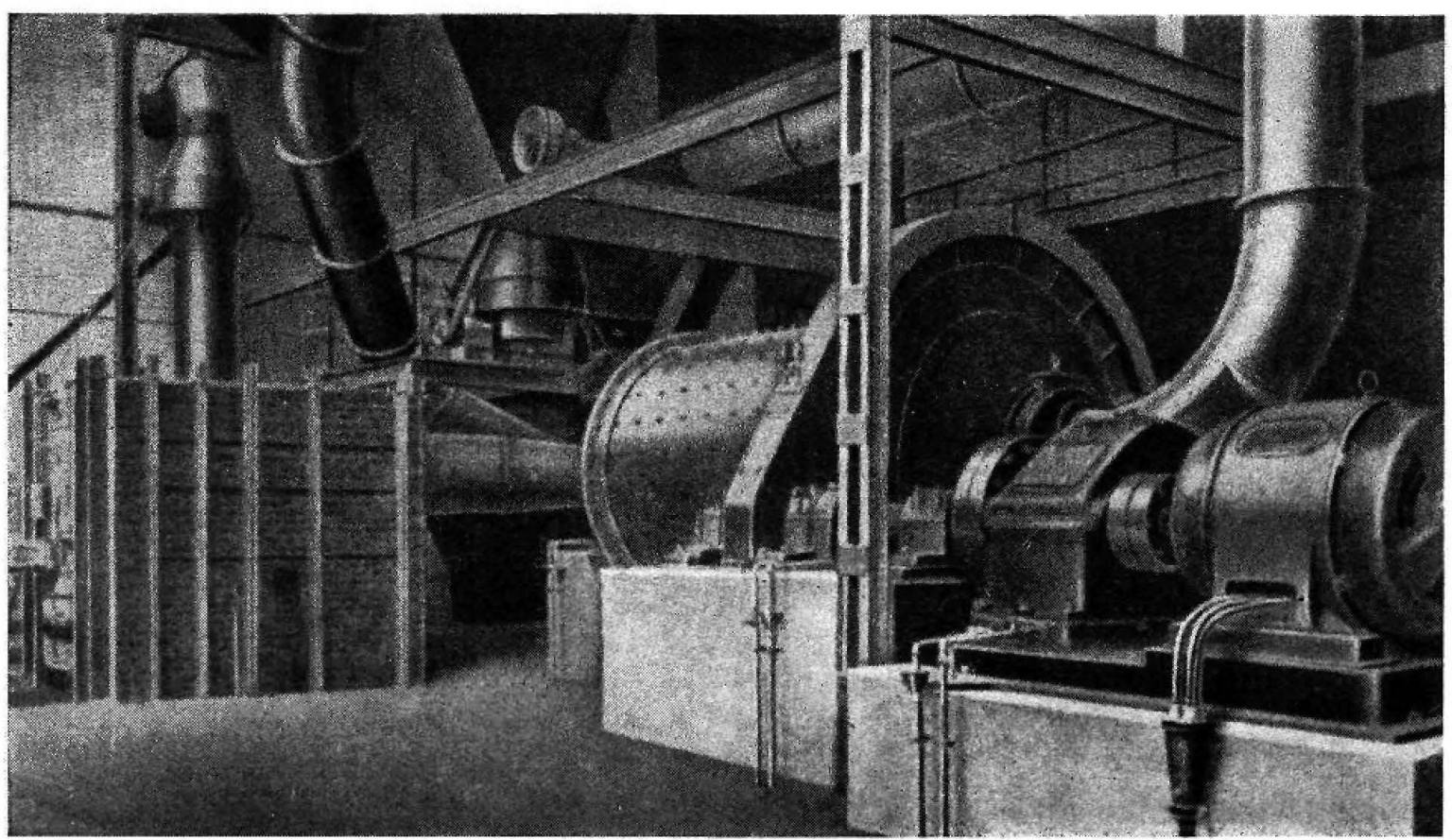


yección directa (fig. 17). Este sistema se recomienda para buenos carbones bituminosos, siendo su principal inconveniente la sujeción de la marcha del horno a la marcha del molino. Si se quiere evitar el paro del horno cuando ocurre cualquter averia en el molino, hay que tener otro molino de reserva.

Esta desventaja se evita introduclendo en el circuito un silo de almacenamiento de carbón pulverizado. Se tiene, entonces, el sistema de inyección indirecta. En los molinos ventilados, el carbón se separa del aire que lo transporta mediante un ciclón que descarga en el silo. EI vapor de agua no pasa al silo y el aire despolvoreado por el ciclón pasa todavía a un flltro, que lo descarga a la atmósfera. De la eficacia del sistema de despolvoreamlento depende que se emitan al exterlor cantidades importantes de carbón en polvo.

El sistema de inyección indirecta es, por varios motivos, muy empleado en Ios casos en que se emplean carbones de baja calidad.

\section{Despolvoreamiento}

Siquiera sea de paso, nos tenemos que referir al despolvoreamiento de las instalaciones de secado y mollenda de carbón. Es bien sabido que estas instalaclones suelen ser unas fuentes de polvos emitidos al exterior cuando no son recuperados eficazmente.

Según Anselm, las características granulométricas de los polvos emitidos por los secadores y molinos de carbón son las siguientes:

$$
\begin{aligned}
& n=\text { de } 0,93 \text { a } 1,2 . \\
& d^{\prime}=\text { de } 5 \text { a } 12 \text { micras. }
\end{aligned}
$$

Recordemos que, según se dijo en el parrafo 6.2.2, la finura del carbón pulverizado presenta para $d^{*}$ valores próximos a 45 micras, jo cual nos indica que los polvos emitidos son de una flnura de 4 a 9 veces mayor.

Los sistemas de filtros más empleados son los eléctricos y los de mangas. Unos y otros deben tener una conveniente regulación de temperatura, evitando que ésta sea inferior al punto de rocío para no correr el rlesgo de que el polvo de carbón se empaste con el agua condensada. He aqú algunos datos complementarios, que también tomamos de Anselm, referentes a la molienda y secado de carbón pulverizado:

Producctón.

Cantldad de alre $\begin{array}{llllllllllllll} & \ldots & \ldots & \ldots & \ldots & \ldots & \ldots & \ldots & \ldots & \ldots & \ldots & \ldots & \ldots\end{array}$

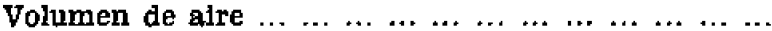

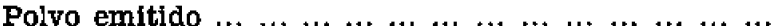

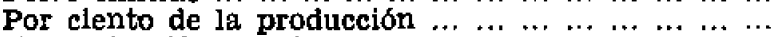

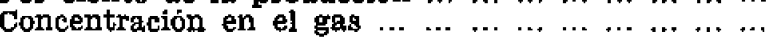

Después del filtrado.

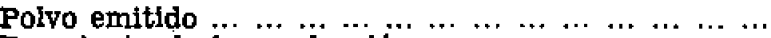

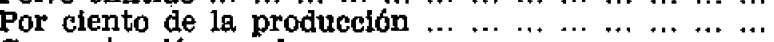
Concentración en el gas

$\mathbf{k g} / \mathbf{h}$
$\mathrm{m}^{2} \cdot \mathbf{k g}^{-1}$
$\mathrm{~m}^{3} \cdot \mathbf{h}^{-3}$
$\mathrm{~kg} \cdot \mathrm{h}^{-1}$
$\mathrm{~g} \cdot \mathrm{m}^{-4}$

$\mathrm{kg} \cdot \mathbf{h}^{-1}$

g. $\mathbf{m}^{-}$

3.000

1,5

90

20
Fig. 20,-Ingtalaolín de un molino ventilado Polysius.

1. Molino de bolas-6ecador- 2 . Plato de ellmentacion.-3, Hogar.-4. Separador.-5. Ciclón.-6. Ventilador de circulacion.-7. Filtro de mangas,-8. Aspirador.-9. y Lo. Roscas transportadoras de carbor en polvo-11. Motor princlpal del molino.

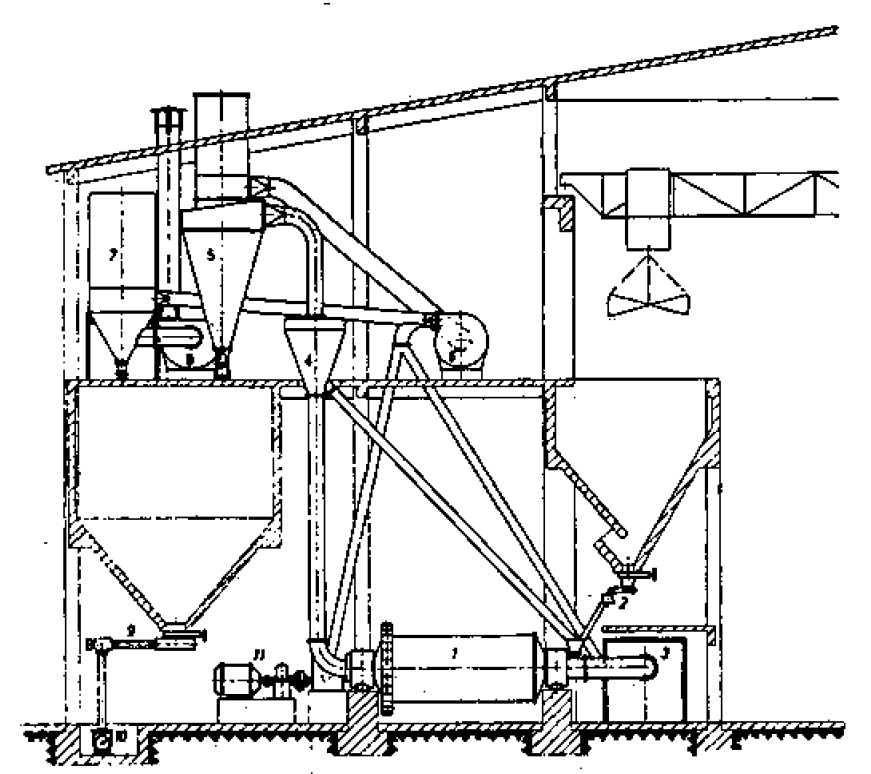




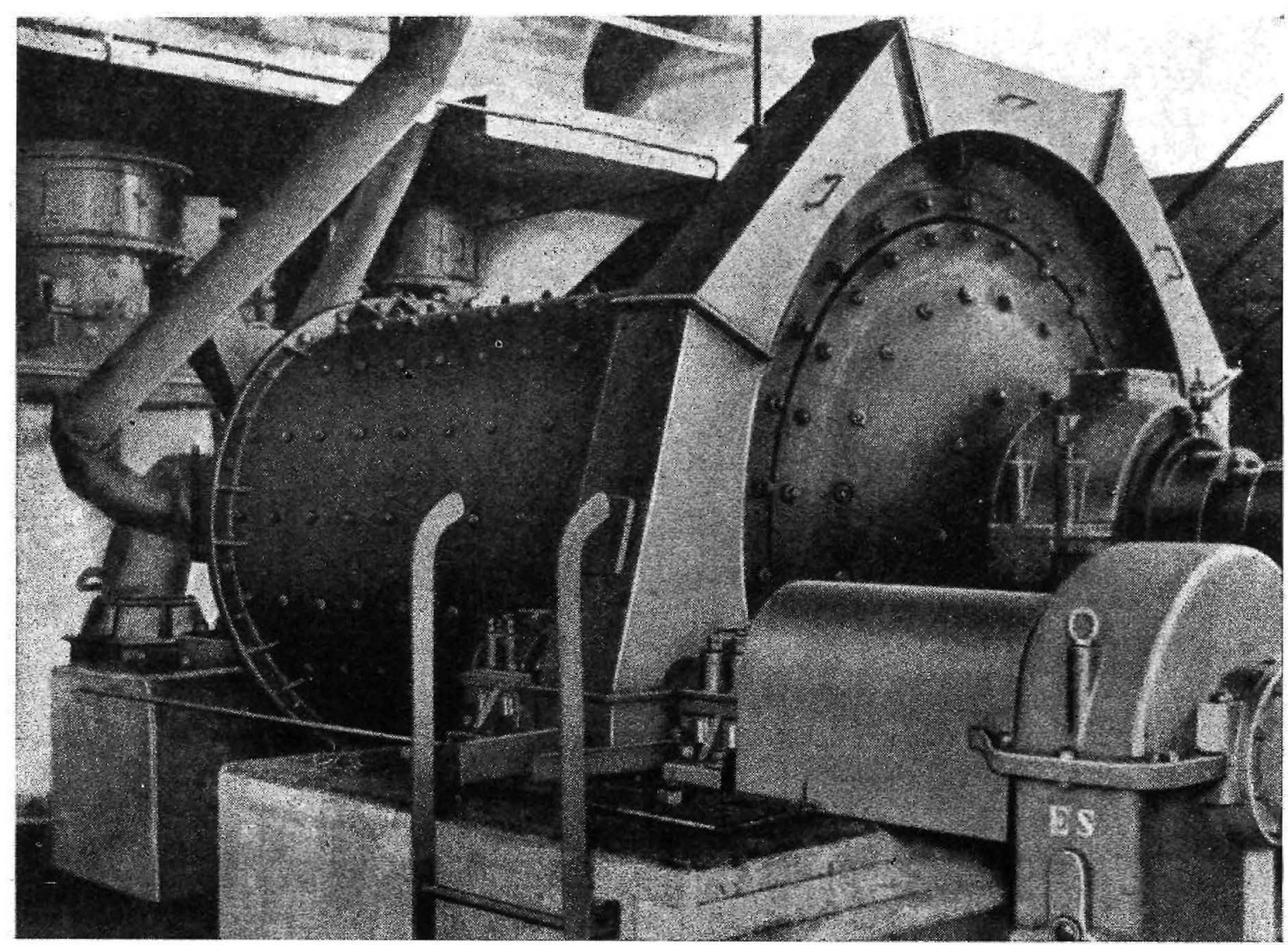

FIg. 21. - Mollino ventilado Polysius.

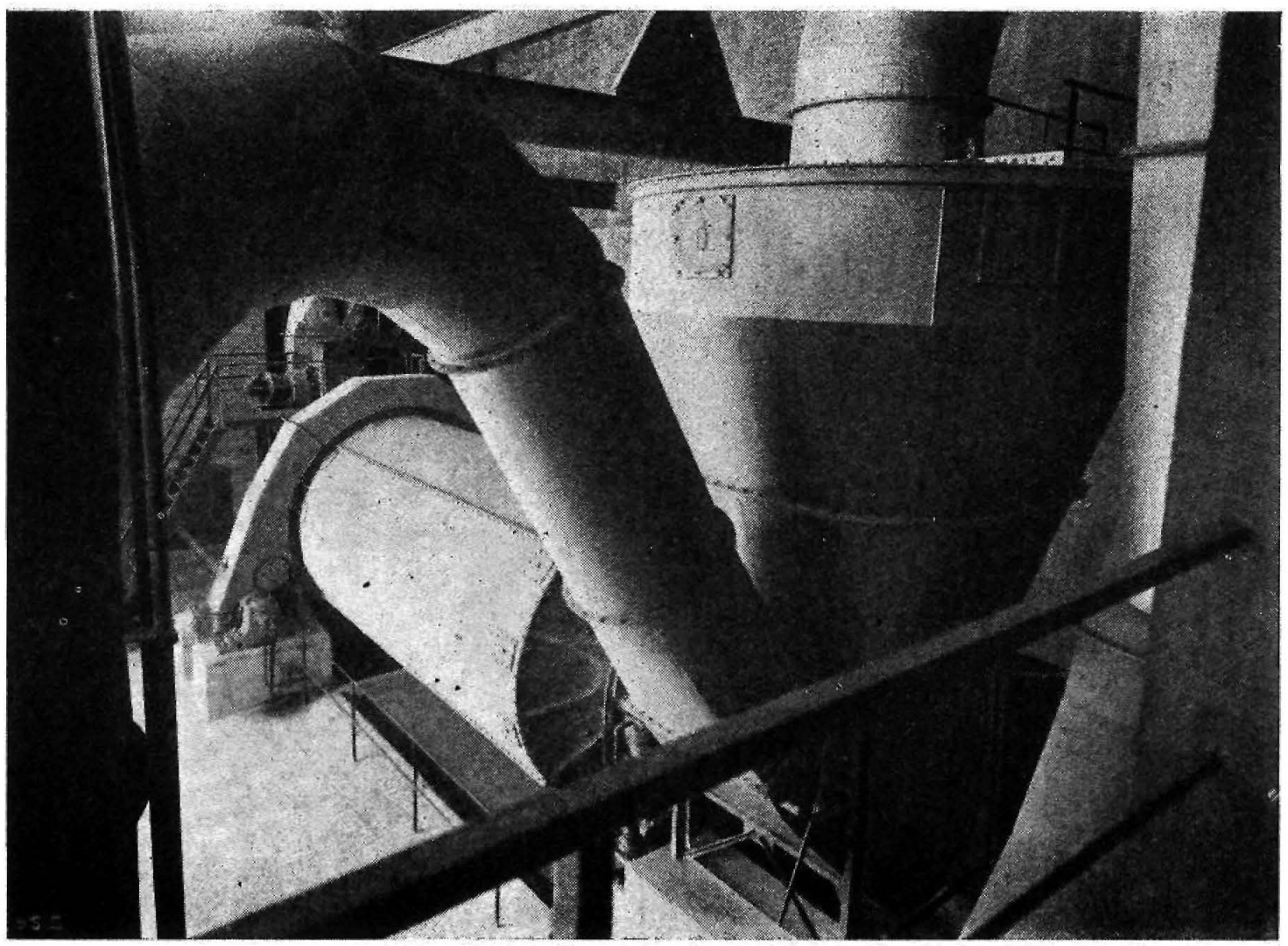

Fig. 22. - Molinosecador ventilado

por Fives-Lille. 

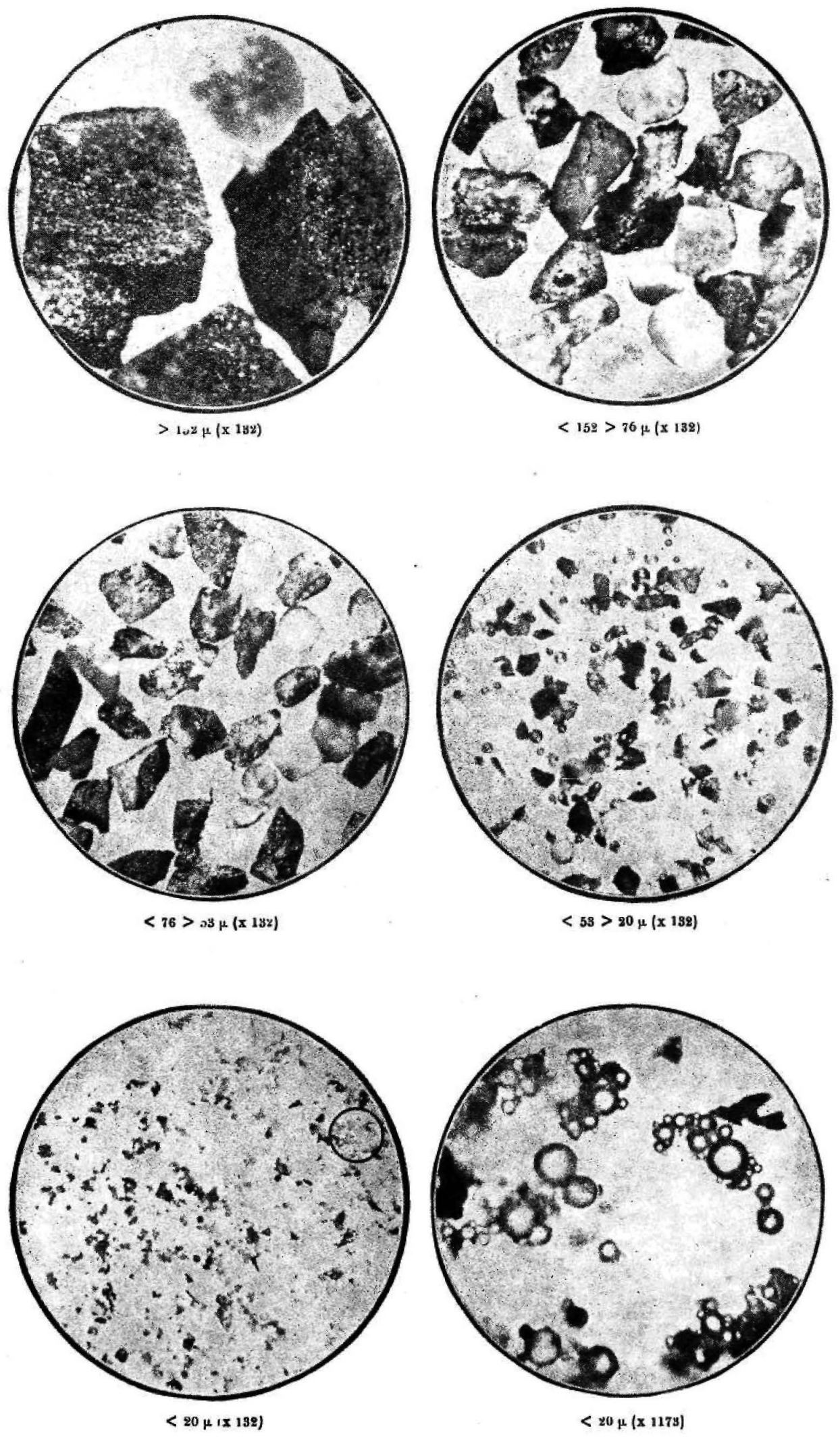

Fig. 23.-Microfotografías de polvo de carbón. (De Sturtevant-Londres). 

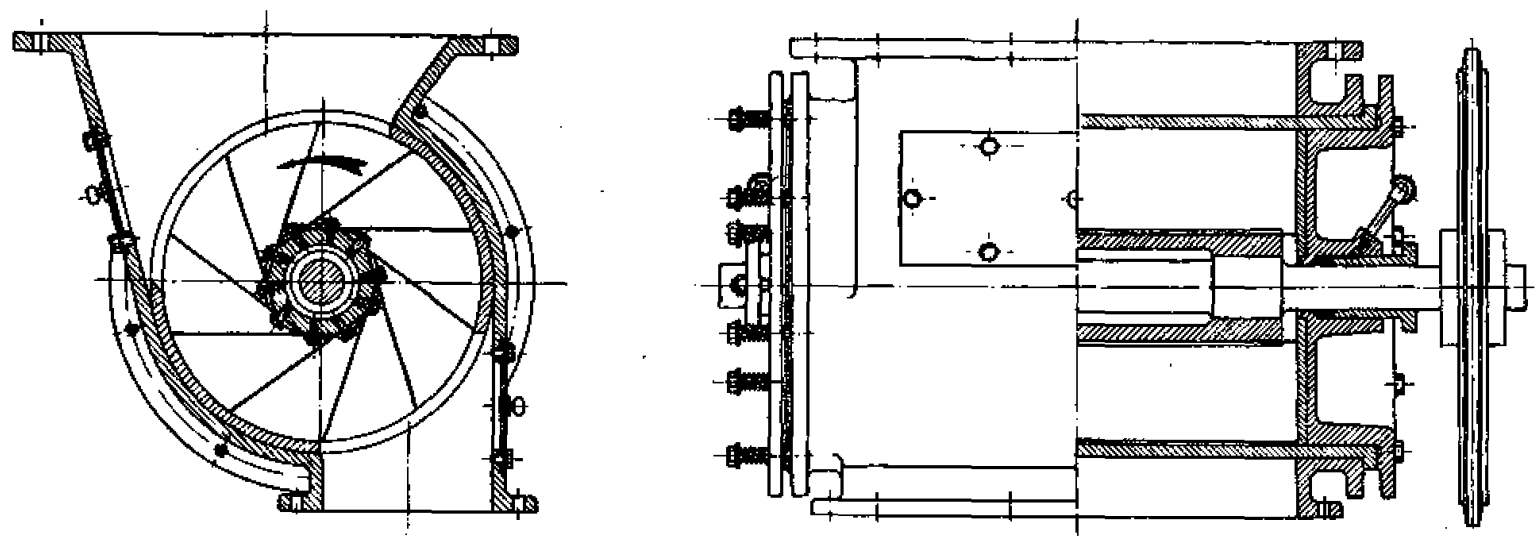

Ftg. 24.-Alimentador celular *Polysíü,-Log allmentadores celulares son eatanques

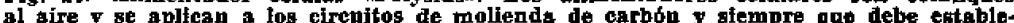
cerse comunicación entre partes del sistema a diferentes prisiones estaticas.

La separación y captación de polvo de carbón es, en definitiva, una operación indiscutiblemente lucrativa. Citaba Rocha y Melo el caso del montaje de electrofiltros en dos instalactones de secado de carbones. La recuperación de polvo de carbón equivalió al 5,95 y al $5,56 \%$ del combustible tratado, $\mathrm{y}$ is amortización de las Instalaciones se consiguió al cabo de 16 y 18 meses, respectivamente.

En la figura 23 se dan varlas microfotografías del polvo de carbón separado por medio de un electroflltro Sturtevant.

\section{Dosificación e inyección del combustible}

La dosiffcación del combustlble es una operación relatlvamente fácll cuando se trata de combustibles gaseosos o líquidos. No lo es tanto cuando se quema carbón. Así como los flúidos pueden trasladarse por la presión propla, el carbón debe emulsionarse con aire a presión. In la inyección indirecta el aire debe atslarse del eircuito de molienda. Esto suele conseguirse por medio de una rueda celular (flg. 24), indispensable siempre que se establece comunicación entre partes del sistema a diferentes presiones estáticas.

Un alimentador de rosca, girando a velocidad variable, deja entrar la cantidad convenjente de carbón a la corriente de aire de inyección.

El aire que arrastra al combustible constituye una parte del necesario para la combustión. Por este motivo le llamamos aire primario, reservándose el apelativo de alre secundario al que entra posterlormente $\mathrm{y}$, en general, a una mayor temperatura.

La misión del aire primario es arrastrar al combustible y proyectarlo al interior del horno en forma tal que pueda inflamarse $\mathrm{y}$ arder sin diflcultades.

Con referencia al alre primario hay que tener en cuenta cuatro importantes variables:

1) Cantidad.

2) Presión.

3) Temperatura,

4) Composición.

\subsection{Cantidad de aire primario}

La cantidad de aire primario depende del tipo dequemador y de la calidad del combustible. Tamblén influyen las dimensiones del horno rotativo.

La relaclón ponderal aire/combustible varfa de 2,5 a 3,5 . Supongamos que se mantiene la relaclón ponderal constante de tres kilogramos de aire por cada khogramo de combustible. Según el Cuadro III, vemos que la cantidad de alre necesaria para la combustión neutra aumenta con el poder caloríflco del combustible. Una relaclón ponderal constante, representaría el 42,2 \% del aire necesario para la combustión de un lignito de $6.140 \mathrm{kcal} / \mathrm{kg}$ y el $22,2 \%$ en un acelte combustible de $9.800 \mathrm{kcal} / \mathrm{kg}$.

En Ias experienclas sobre las llamas realizadas en Ijmulden se inyectaron diversos combustibles con cantldades de atre variables de 35 a $75 \%$ del alre total. Estas experienclas pusieron de manifiesto que los factores de mayor influencia fueron la finura del carbón y la proporción de alre primario. 
Otros estudios expertmentales, realizados en el Japón, por Saji, emplearon de 1,9 a 2,56 veces el peso de aire en relación al de combustible, y por Yoshil, con 26 a $30 \%$ del aire total.

Hardgrove recomienda 2,5 a $3,0 \mathrm{~kg}$ de aire por cada kllogramo de carbón. Para Simon se debe usar del 18 al $20 \%$ del aire total. Los autores espaffoles suelen recomendar proporciones de aire primarto bordeando los límites inferiores. Ferrer-Vidal y Gascuñana recomendaron "la menor cantidad posible"; Fonrodona nos dice de 18 a $20 \%$, cifra esta tultima aceptada por Serratosa.

\section{CUADRO III - Cantidad de aire necesario para la combustión neutra de varios combustibles}

\begin{tabular}{|c|c|c|c|c|}
\hline \multirow{2}{*}{ COMBUSTIBLES } & \multirow{2}{*}{$\begin{array}{c}\text { Poder } \\
\text { calorifico } \\
\text { inferior } \\
\text { (kcal } / \mathbf{k g} \text { ) }\end{array}$} & \multicolumn{2}{|c|}{$\begin{array}{l}\text { Aire necesario para la } \\
\text { combustlon neatra }\end{array}$} & \multirow{2}{*}{$\begin{array}{l}\text { Aire } \\
\text { primario } \% \\
\text { Alire ogmbinist. } \\
=3: 1\end{array}$} \\
\hline & & $(m=N / \mathbf{k g})$ & (kg/kg) & \\
\hline Turba $\ldots \ldots \ldots \ldots$ & 4,710 & 4,12 & $5, \mathbf{3 3}$ & 56,3 \\
\hline $\begin{array}{llllll}\text { Lignito } & \ldots & \ldots & \ldots & \ldots & \ldots\end{array}$ & 6.140 & $\mathbf{5 , 5 0}$ & 7,11 & 42,2 \\
\hline $\begin{array}{llllll}\text { Hulla } I & \ldots & \ldots & \ldots & \ldots & \ldots\end{array}$ & 6.910 & 7,71 & 8,68 & 34,6 \\
\hline Hulla II $\ldots \ldots \ldots$ & 7,890 & 7,76 & 10,04 & 29,9 \\
\hline Semi-coke $\ldots \ldots \ldots c \ldots$ & 8.000 & 7,90 & 10,22 & 29,4 \\
\hline $\begin{array}{lllllll}\text { Coke } & \ldots & \ldots & \ldots & \ldots & \ldots & \ldots\end{array}$ & 8.040 & 8,19 & 10,59 & 28,3 \\
\hline Hulla III ... ... ... ... ... & $8.310^{\circ}$ & 8,31 & 10,75 & 27,9 \\
\hline Hulla IV $\ldots \ldots \ldots \ldots \ldots$ & 8.340 & 8,41 & 10,87 & 27,6 \\
\hline Semi-antracita $\ldots \ldots \ldots$ & 8.420 & 8,71 & 11,25 & 26,7 \\
\hline $\begin{array}{llllll}\text { Hulla-seca } & \ldots & \ldots & \ldots & \ldots\end{array}$ & 8.510 & $\mathbf{8 , 7 2}$ & 11,28 & 26,6 \\
\hline Antracita $\ldots \ldots \ldots \ldots$ & 8.440 & 8,77 & 11,34 & 26,5 \\
\hline Carbono puro $\ldots \ldots \ldots$ & 8.080 & 8,89 & 11,49 & 26,1 \\
\hline Aceite combustib'e... ... & 9.800 & 10,46 & 13,52 & 22,2 \\
\hline Gas natural ... ... ... ... & 11.814 & 12,62 & 16,32 & 18,4 \\
\hline Metano puro $\ldots \ldots \ldots \ldots$ & 11.979 & 13,30 & 17,20 & 17,4 \\
\hline
\end{tabular}

\subsection{Presión del aire primario}

La evidente importancia de la presión del aire primario es señalada, entre otros autores, por Anselm y Fritsch, los cuales nos dilcen que la proporción de aire/carbón depende, principalmente, de la preslón de transporte.

Como es sabido, hay que distinguir la presión estática y la presión dinámica. La primera indica el grado de comprestón proporcionado por el ventilador. La segunda, la velocidad de circulación por el interior de los conductos.

Para ia presión estátlca se recomlendan, por Ferrer-vidal, columnas de agua entre 300 y $800 \mathrm{~mm}$, Estas presiones, hoy dia, han sido bastante excedidas, sobrepasándose, en ciertos casos, los $1.000 \mathrm{~mm}$ de columna de agua.

Por la presión dinámica podemos calcular la veloeldad y el gasto o caudal. Conocido éste y la sección de salida del inyector, podemos saber la velocidad de entrada del aire primarlo al horno.

En Ijmulden se experimentaron velocidades de 20 a $43 \mathrm{~m} / \mathrm{s}$. Xoshit, en el Japón, probó 40 y $41 \mathrm{~m} / \mathrm{s}$; Hardgrove recomienda de 30 a $40 \mathrm{~m} / \mathrm{s}$; Fonrodona, de 60 a $70 \mathrm{~m} / \mathrm{s}$; Hottel, para llamas de combustible liquido, nos dice que éstas se mantienen estacionarias entre $25 \mathrm{y} 65 \mathrm{~m} / \mathrm{s}$.

\subsection{Temperatura del aire primario}

La temperatura del aire primario suele ser relativamente baja, si bien hay diferencias de criterio, al igual que entre las restantes caracteristicas de las que ya hemos tratado. Los autores americanos suelen preferir, con Hardgrove, temperaturas de 70 a $105^{\circ} \mathrm{C}$. Nordberg nos describe una moderna industria canadiense en la cual se inyecta aire de 65 a $80^{\circ} \mathrm{C}$. Simon hace variar la temperatura entre 20 y $120^{\circ} \mathrm{C}$. Harrington, para la combustión de la antracita pulverizada, recomienda una temperatura de la mezcla aire-carbón comprendida entre 120 y $140^{\circ} \mathrm{C}$. En Ijmuiden se operó con alre primarlo a la temperatura de $80^{\circ} \mathrm{C}$. En los grandes hornos de Ouburg, según slegten, la temperatura del aire inyectado es de $100^{\circ} \mathrm{C}$. Los datos de los japoneses Sajl y Yoshii se refleren a temperaturas comprendidas entre 40 y $70^{\circ} \mathrm{C}$. Por último, acudimos a la probada autoridad de los ingenieros españoles Ferrer-Vidal y Gascuñana, ploneros en la utllización de carbones pobres, los cuales siempre recomendaron pura y simplemente el empleo del alre primario frio, es decir, sin precalentamlento alguno.

\subsection{Densidad y viscosidad del aire primario}

Vamos a intentar esclarecer en qué medida influyen la presión y la temperatura del aire primario en sus cualidades de medio soportante de carbón pu'verizado o de combustibles liquidos nebulizado. 


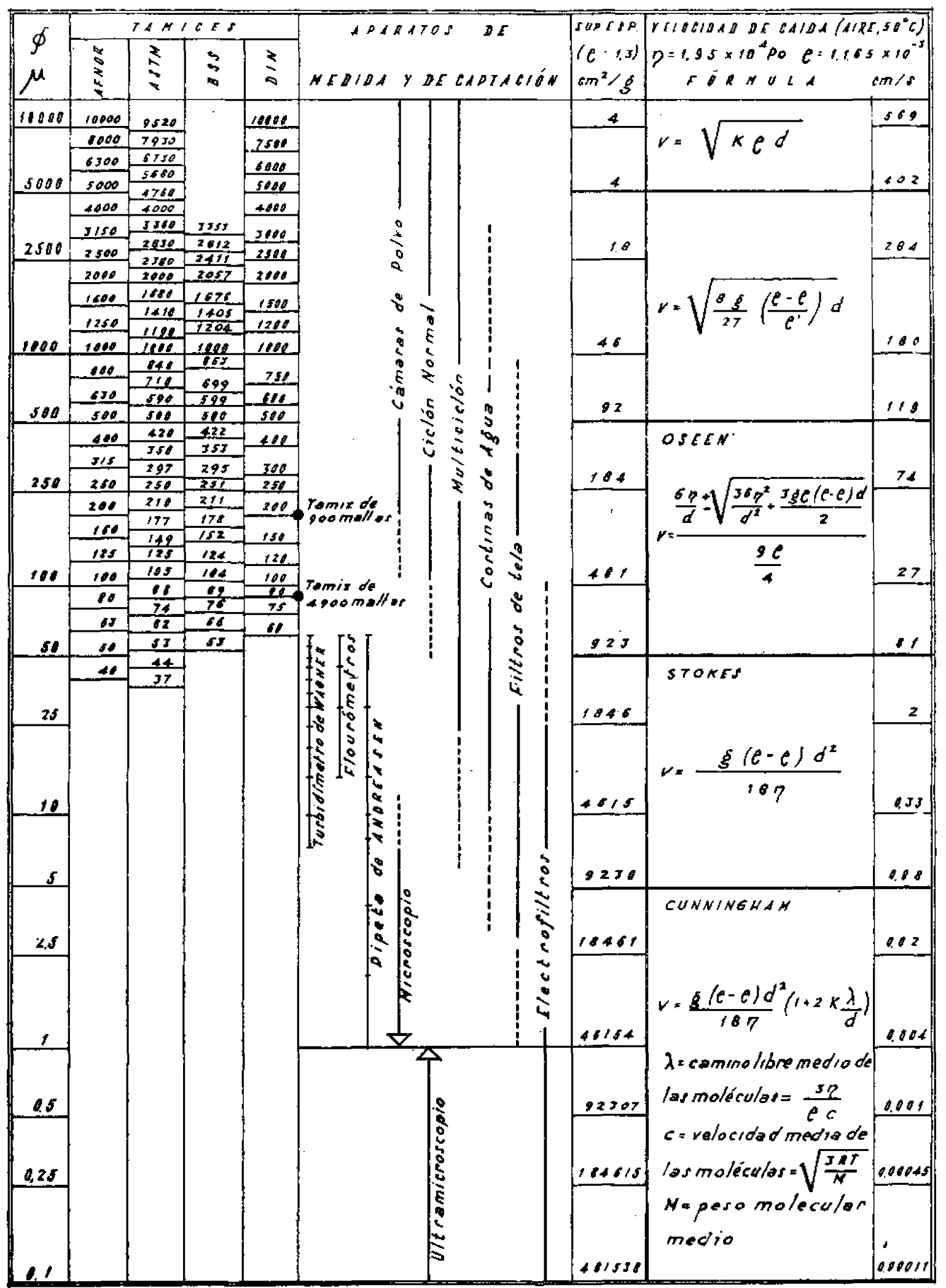

Fig. 25.-Medlda, eapteción y velocidad de caida del polvo de carbón+ 
El estudio más elemental del problema nos conduce a la conocida Ley de Stokes:

$$
\forall=g d^{p} \frac{\rho-\rho^{\prime}}{18 r_{1}}
$$

donde:

$$
\text { : }
$$

$v=$ velocidad de caida de una particula esférica de $d$ micras de diametro en un medio de viscosidad $\eta$.

$g=$ aceleración de la gravedad $\left(980 \mathrm{~cm} \mathrm{.}^{-5}\right)$

$q=$ densidad de la partícula.

$\rho^{\prime}=$ densidad del medio viscoso.

Supongamos que se trata de partículas de un carbón con una densidad de $1,3 \mathrm{~g}^{-\mathrm{cm}^{-3}}$ y con un tamaño de 90 micras $(0,009 \mathrm{~cm})$. La ecuación [23] se puede transformar en:

$$
v=4410 \times 10^{-6} \frac{1,3-\rho^{\prime}}{r_{i}}
$$

dónde vemos que la velocídad de caída es función de las variables densidad del aire y vlscosidad.

De las leyes de los gases perfectos, $\mathrm{y}$ suponiendo que el aire se comporte de acuerdo con ellas, deducimos que la densidad varía en razón directa de la presión e inversa de la temperatura absoluta:

$$
f^{\prime}=\rho_{0} \frac{\mathbf{T}_{\mathbf{u}} \mathbf{P}_{\mathbf{L}}}{\mathbf{T}_{\mathbf{t}} \mathbf{P}_{\mathbf{0}}}
$$

La viscosidad, en cambio, y de acuerdo con Sutterland, aumenta con la temperatura, según la expresión:

slendo, para el alre:

$$
r_{i}=\frac{k \mathbf{T}^{3 / 2}}{\mathrm{C}+\mathbf{T}}
$$

$$
\begin{aligned}
& k=150 \times 10^{-7} \\
& \mathrm{C}=124
\end{aligned}
$$

lo que nos da:

$$
r_{i}=\frac{150 \times 10^{-i T^{3 / 3}}}{\mathbf{T}+124}
$$

A presiones relativamente bajas, próxlmas a la atmosférica, la viscosidad absoluta de los gases es

\begin{tabular}{|c|c|c|c|c|}
\hline $\mathbf{t}^{\circ} \mathbf{C}$ & $\mathbf{T}^{\mathbf{o}} \mathbf{K}$ & $\begin{array}{l}\text { Densidad } \\
\left(\mathrm{g} \cdot \mathrm{cm}^{-4}\right)\end{array}$ & $\begin{array}{l}\text { Viscosidad } \\
(\mathbf{P O})\end{array}$ & $\begin{array}{c}\text { Velocidad } \\
\left(\mathrm{cm}^{-1}\right)\end{array}$ \\
\hline 0 & 273 & $1,378 \times 10^{-3}$ & $170 \times 10^{-6}$ & 33,7 \\
\hline 25 & 298 & $1,262 \times 10^{-3}$ & $183 \times 10^{-6}$ & 31,3 \\
\hline 50 & 323 & $1,165 \times 10^{-3}$ & $195 \times 10^{-6}$ & 29,4 \\
\hline 75 & 348 & $1,081 \times 10^{-3}$ & $206 \times 10^{-0}$ & 27,8 \\
\hline 100 & 373 & $1,009 \times 10^{-3}$ & $218 \times 10^{-6}$ & 26,2 \\
\hline 200 & 473 & $0,795 \times 10^{-3}$ & $259 \times 10^{-4}$ & 22,1 \\
\hline 300 & 573 & $0,657 \times 10^{-3}$ & $295 \times 10^{-9}$ & 19,4 \\
\hline
\end{tabular}
independiente de la presión.

Para fjar ideas, mediante un ejemplo, supongamos que inyectamos aire primario con una presión estática de $680 \mathrm{~mm}$ de columna de agua. La presión absoluta de este alre será:

$$
P_{\mathrm{t}}=760+\frac{680}{13,60}=810 \mathrm{~mm} / \mathrm{Hg}
$$

El peso específico del aire será:

$$
\rho^{\prime}=1,293-\frac{273 \times 810}{\mathrm{~T}_{\mathrm{t}} \times 760}=\frac{376,2}{\mathrm{~T}_{\mathrm{t}}} \mathrm{kg} \cdot \mathrm{m}^{-3}
$$

Variando la temperatura del alre y aplicando las ecuaciones [24], [25] y [27], se tendrá:

El cálculo demuestra que, según aumenta la temperatura, las cualidades del aire como medio soportante mejoran notablemente. Esta variación, sin embargo, no tiene influencla decisiva entre 25 y $100^{\circ} \mathrm{C}$ de temperatura, que constituyen los límites que encontramos en la práctica de la inyecclón del aire. 


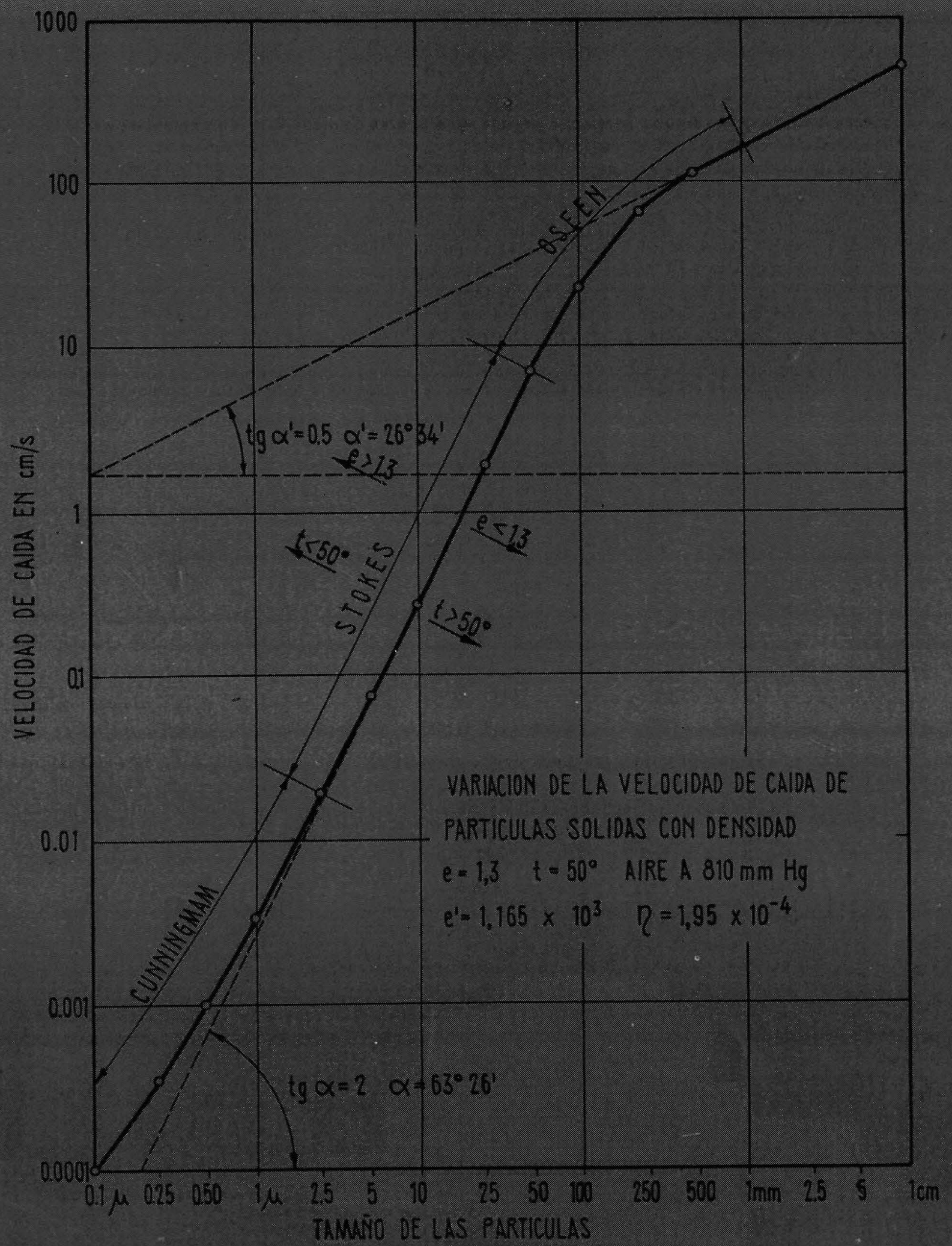


Es sabido que la ley de Stokes tiene una validez limitada. si las partículas de carbón son de un taman̆o superior a cien micras o inferior a una micra, las velocidades observadas se apartan algo de las que nos da la ley de Stokes. Hay que tener en cuenta las correcciones de Cunningham, Oseen y otras que aparecen en la figura 25. De acuerdo con estas correcciones se puede construir el gráfico de la flgura 26, donde se expresa el comportamiento de las particulas de diferente tamaño en el seno del aire a una presión absoluta de $810 \mathrm{~mm}$ de mercurio y una temperatura de $50^{\circ} \mathrm{C}$.

Como se dijo en 8,2, las velocidades de inyección del alre primario suelen ser superiores a $20 \mathrm{~m} / \mathrm{s}$, por lo que, sin duda alguna, tendremos una garantía absoluta de que las más pesadas partículas de carbón pulverizado serán transportadas al interior del horno.

St en las condiciones de presión y temperatura del ejemplo a que nos hemos referido empleamos una relación ponderal de tres partes de aire por una de carbón, siendo el peso especifico $1,165 \mathrm{~kg} / \mathrm{m}^{3}, 3 \mathrm{~kg}$ ocuparán $2,575 \mathrm{~m}^{3}$, y la concentractón de polvo de carbón será de $388 \mathrm{~g} / \mathrm{m}^{3}$. En el momento que comience la inyección de carbón el peso especiflco de la mezcla aire + carbón será:

$$
p^{\prime}=\frac{1,165+0,388}{1+\frac{0,388}{1,3}}=1,196 \mathrm{~kg} / \mathrm{m}^{3}
$$

Al encontrarse el ventilador con una mayor resistencla bajará inmediatamente la presión de inyección, pero será todavía suflciente para impulsar la totalidad del combustible al interior del horno.

\subsection{El dire primario como comburente}

Hay que tener en cuenta que el aire primario no se utiliza solamente como medio soportante, sino, además, como comburente. Como tal, debe contener suficiente çantidad de oxígeno para dar infeio a los fenómenos de combustión antes de conseguirse la mezcla con èl aire secundario.

Fn condiciones normales, el aire seco contiene 300 gramos de oxigeno por metro cúbico, Mantenlendo constante la presión estática y elevando la temperatura, disminuirá proporcionalmente la concentración de oxígeno y será preciso un mayor volumen de gas para aportar la misma cantidad de comburente.

Aire primario a $680 \mathrm{~mm}$ de columna de agua (Presión Estática)

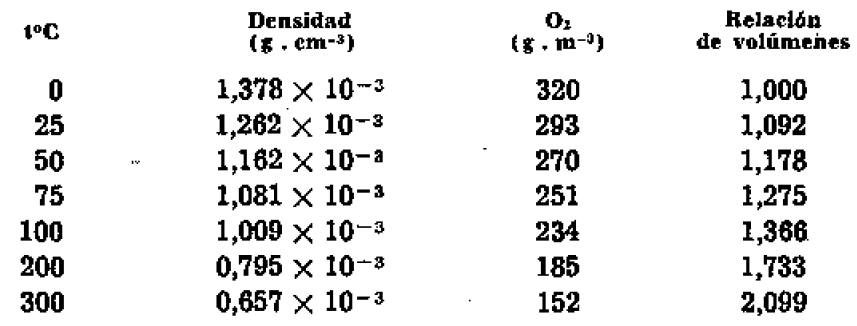

Suponiendo que se utilizara aire primario precalentado a $300^{\circ} \mathrm{C}$ para proporcionar al carbón la misma cantfdad de oxígeno, tendriamos que inyectar un volumen de aire dos veces mayor que si la temperatura fuese la del amblente.

Si, por el contrario, la capacidad de aumentar el caudal del ventilador tiene un límlte superior poco elevado, tendremos un medio de aumentar o disminuir el contenido de oxígeno, sin variar el caudal, pero si actuando sobre su temperatura.

Puede, asimismo, acudirse a medios que por lo inusitados podemos clasificar de heroicos. Nos referimos a la inyección con alre enriquecido con oxigeno, y aun con oxígeno puro. Recordamos que, en los coloquíos de 1957, López Peciña se refirió a las posibilíades de aumentar la producción de un horno vertical - o rotativo -con el empleo de oxígeno como comburente. Según La Velle, este procedimiento ya se ha empleado, con éxito, en la industria del acero en Alemania. El mismo método se podría apticar a la industria del cemento, con lo que aumentaría la capacidad de producción de los hornos, apenas . con la instalación de un generador de oxígeno, de coste relativamente bajo. En la 20. Reunión Técnica de Haubordin se trató de tan sugestivo problema. Se hizo la objeción de que el precio del oxígeno es, todavia, muy alto. Téenicamente, se opinó que la sobreoxigenación, con combustibles de alto contenido de carbono, proporcionaria temperaturas más elevadas y volveria la conducción del horno más regular y fácill.

Por nuestra parte no nos atreveriamos a apliear ni a recomendar un método que no deja de tener sus riesgos, principalmente cuando el combustible no es muy alto en su contenido de carbono y se corre el peligro de explosiones violentas.

Bornscheln, por ejemplo, señaló la conveniencia de emplear un gas protector cuando se trabaja con lignitos. El mencionado peligro de explosiones es muy pequeño si el contenido de oxígeno está por debajo del $13 \%$. 
Azbe también señaló que el aire no es el medio de inyección más adecuado y debe límitarse a un minimo. El empleo de gases puede ser más ventajoso si se pretende que las materias volátiles sufran una disociación apropiada llberando carbono sólido. La recirculación de los gases cargados de Co, extraídos de la cámara de humos, está cada día más extendida.

Ya expusimos que en el sistema de inyección directa el aire primarlo está cargado del vapor de agua procedente del secado del carbón. El caso extremo lo constituyen algunos tipos de quemadores de "fuel-oll" que emplean vapor de agua como medio de inyección.

Por último, un caso interesante de suboxdgenación lo constituye la mezcla de gas natural con el aire primario. Este caso se ha apilcado en los Estados Unidos, principalmente cuando se quema coque de petróleo u otro combustible pobre en volátiles.

\section{La combustion en el horno rotativo}

De acuerdo con las informaciones facilitadas por Townend acerca de las experienclas efectuadas en Ijmuiden, en la combustión del carbón pulverizado se observan tres fases consecutivas:

1." Preinflamación, con aumento de volumen de las partículas.

2.* Inflamación y combustlón de las materias volátiles.

3." Combustión del coque residual.

La temperatura mínima a que se inflama el carbón pulverizado varía de 200 a $300^{\circ} \mathrm{C}$, según la calidad dei carbón y según su finura. El carbón fino, pasado por un tamiz de 74 micras, se infiama entre 210 y $220^{\circ} \mathrm{C}$ cuando es antracitoso, y entre 170 y $175^{\circ} \mathrm{C}$ cuando es bituminoso. Los aceites combustibles tienen su punto de ignición de los 130 a los $150^{\circ} \mathrm{C}$. Los carbones groseros, comprendidos entre 177 y 210 micras, arden a los 550 ó $460^{\circ} \mathrm{C}$, según sean antracitas o hullas de gas.

Asombra constatar que las temperaturas de inflamación de los combustibles sóldos finamente pulverizados son inferiores a las de los combustibles gaseosos.

\section{Temperaturas minimas de inflamación de algunos gases en el aire}

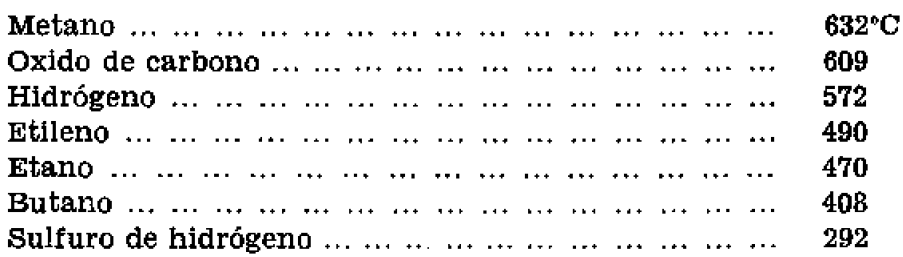

Algunos autores han llegado a suponer que el carbono sóltdo contenido en el carbón pulverizado se inflama antes que las materias volátiles. Estas queman acto seguido muy rápidamente. El coque continứa ardiendo después de estar ya quemados los gases, đe modo que, en definitiva, la combustión del carbono ocupa todo el tiempo que dura la llama.

Tiene su importancia la velocidad de propagación de la llama. En los carbones pulverizados aumenta con el contenido de materias volátiles y disminuye con el contenido de cenizas. También influye la proporción relativa aire/carbón. Los máximos se encuentran entre 2,5 partes a 4,5 partes de alre por una de carbón. Las velocidades de propagación oscllan entre 3 y $14 \mathrm{~m}$. $\mathrm{s}^{-1}$. Para un carbón con $20 \%$ de volátiles y $5 \%$ de cenizas se tiene:

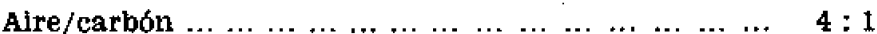

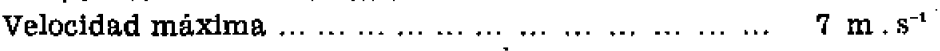

Hay que mantener un cierto equilibrio entre la velocidad de inyecclón y la de propagación de la lla- . ma a fln de que ésta se mantenga a una distancia flja del extremo del inyector, sin acercarse demasiado, y, también, sin apartarse mucho, pues, en este caso, la combustión podría sufrir intermitenclas, por sucesivos apagones $\mathrm{y}$ encendidos.

Nusselt estableció que el tiempo que dura la combustión de una particula de carbón es función de su tamaño:

y. según Rosin:

$$
\begin{gathered}
A=C d^{1 n} \text { segundos } \\
A=55 d^{1,8}
\end{gathered}
$$

Una partícula de $0,1 \mathrm{~mm}$ de diámetro tarda en quemar 0,87 segundos. 
gases:

La longitud de la llama queda defnida por el tiempo que dura la combustión y la velocidad de los siendo:

$$
1=v \text { A }
$$

$$
v=\frac{\mathrm{VT}_{\mathbf{t}}}{\mathbf{3} \mathrm{T}_{\mathrm{o}}} \mathrm{m} \cdot \mathrm{s}^{-1}
$$

$\mathrm{V}=$ Volumen de gases de la combustión en $\mathrm{m}^{3} \mathrm{~N} \cdot \mathrm{s}^{\cdot 2}$.

$\mathbf{S}=$ Sección de paso del horno en $\mathrm{m}^{2}$.

$\mathbf{T}_{\mathbf{t}}=$ Temperatura de la llama en grados Kelvin

Para un horno con $2,5 \mathrm{~m}$ de diámetro, con $4,91 \mathrm{~m}^{2}$ de sección, con una producción de $500 \mathrm{t} /$ día y un consumo específlco de $1.350 \mathrm{kcal} / \mathrm{kg}$, empleando un carbón con $\mathrm{H}_{1}=6.750 \mathrm{kcal} / \mathrm{kg}$, dando una cantidad de humos $f=7,6 \mathrm{~m}^{3} \mathrm{~N} / \mathrm{kg}$, se tiene:

\begin{tabular}{|c|c|c|c|c|}
\hline Temperatura de ia llama ("C) & 1,300 & 1.400 & 1.500 & 1.600 \\
\hline Velocidad de los gases $(\mathrm{m} / \mathrm{s}) \ldots \ldots \ldots \ldots \ldots$ & 10,22 & 10,87 . & 11,52 & 12,27 \\
\hline Longitud de la llama $(\mathrm{m}) \ldots \ldots$ & 8,89 & 0,46 & 10,02 & 10,60 \\
\hline
\end{tabular}

$$
\begin{gathered}
\mathrm{V}=\frac{10 \mathrm{P} q f}{86,400 \mathrm{H}_{1}}=\frac{500.000 \times 1.350 \times 7,6}{5.832 .000}=8,8 \mathrm{~m}^{3} . \mathrm{s}^{-1} \\
v=\frac{8,8 \mathrm{~T}_{\mathrm{t}}}{273 \times 4,91}=0,0065 \mathrm{Tt} \mathrm{m} / \mathrm{s} .
\end{gathered}
$$

En la práctica, las llamas corrientes de carbón pulverizado, ardiendo sus partículas en menos de un segundo, alcanzan una longitud aproximada de unos.10 metros.

Saj1, en el Japón, realizó interesantes estudios sobre este tipo de llamas, determinando fotográficamente sus dimensiones, en modelos reducidos. Obtuvo una longitud que se relacionaba con el diámetro de salida del quemador:

$$
\mathrm{L} / d_{\mathrm{o}}=65 \text { a } 75
$$

Los coeficientes de difusión molecular y de difusión turbulenta juegan un importante papel en la fijación de la longitud de la llama. Para llegar a un rápldo final de la combustión se debe emplear un quemador de tobera estrecha, que dé al chorro una mayor turbulencia. El aumento de la proporción aire/combustible acorta la llama mucho más que un simple aumento de la velocidad de inyección. El empleo de un ventilador de alta presión es, en cualquier caso, necesario y conveniente. En cambio, no hay que exagerar la importancia de la molienda fina.

\section{I. Temperatura de la llama}

Como sabemos, la temperatura teórica de la combustión neutra está en razón directa del poder calorifico inferior del combustible e inversa del producto del peso de humos resultantes por su calor especiflco medio:

$$
t_{*}=t_{\mathrm{o}}+\frac{\mathbf{H}_{\mathbf{i}}}{\mathrm{F} c_{\mathrm{p}}}
$$

De conformidad con el cuadro I, calculado para combustibles puros, quemando en el seno del aire, se thene:

COMB ESTBLES

Oxido de carbono

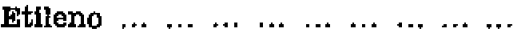

Hidrógeno $\quad \ldots \begin{array}{llllllllll} & \ldots & \ldots & \ldots & \ldots & \ldots & \ldots & \ldots\end{array}$

Propano $\ldots \ldots \ldots \ldots \ldots \ldots \ldots$

Etano $\ldots \ldots \ldots \ldots \ldots \ldots \ldots \ldots$

Metano $\ldots \ldots \ldots \ldots \ldots \ldots$

Sulfuro de hidrógeno ..............

Azufre

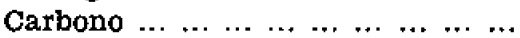

$\begin{array}{rc}\text { keal/ } / \mathbf{m}^{-\mathrm{k}} & \mathfrak{t}^{\circ} \mathrm{C} \\ 1.048 & 2.372 \\ 924 & 2.274 \\ 899 & 2.246 \\ 909 & 2.231 \\ 846 & 2.117 \\ 840 & 2.089 \\ 815 & 2.037 \\ 727 & 1.837 \\ 664 & 1.673\end{array}$

Las condiciones de la combustión neutra raramente se dan en la práctica de modo que las temperaturas teóricas nunca son alcanzadas. A lo más estas temperaturas indican, según los contenidos de unos $\mathrm{y}$ otros combustibles, el potenclal térmico que podemos esperar en cada caso. Así, vemos que, el óxido de carbono puro, sería un combustible Ideal porque da origen a una pequeña cantidad de humos. El carbono $y$ el hidrógeno, a pesar de slu poder calorif so muy diferente, se equiparan en lo referente al grado de temperatura. EI azufre, en último caso, contribuye bastante a disminulr la temperatura de la llama. 
La temperatura efectiva es, desde luego, inferior a la teórica. Para Anselm esta dismtnución representa unos $300^{\circ} \mathrm{C}$ a menos, o sea, una disminución de 15 a $20 \%$. Una de las causas, como sabemos perfectamente, es el exceso de aire. Para Baouman, con $10 \%$ de exceso de aire y un carbón de $7.000 \mathrm{kcal} / \mathrm{kg}$ se alcanzan $1.800^{\circ} \pm 25^{\circ} \mathrm{C}$. Un $5 \%$ de azufre volátil rebaja la temperatura a $1.777^{\circ} \mathrm{C}$. Momot calculó que, con $20 \%$ de exceso de aire y una temperatura teórica de $2.080^{\circ} \mathrm{C}$, se alcanzan, en la práctica, $1.700^{\circ} \mathrm{C}$ También para Folliot la temperatura aproximada es de $1.700^{\circ} \mathrm{C}$. Según Azbe, en un horno rotativo, produciendo cal, se alcanza una temperatura de la llama próxima a $1.600^{\circ} \mathrm{C}$. Persons, en un horno cementero, quemando fuel-oll, ha obtenido $1.593^{\circ} \mathrm{C}, \mathrm{y}$, según Lea y Desch, las temperaturas observadas por Martin \& Gilbert eran de $1.560^{\circ}$ y $1.510^{\circ} \mathrm{C}$, respectivamente.

Estos datos nos indlcan que las temperaturas de la llama varian de uno a otro horno, que existen grandes divergenclas entre las determinaciones de unos y otros autores, determinaciones que, en cualquier caso, parecen sujetas a grandes probabilidades de errores.

Debe existir, desde luego, un limite inferior, a partir del cual la llama ya no es apta para la obtención de clínker de cemento. En todo caso, la temperatura de la llama debe ser superior a la de formación del clínker, y para que éste se forme es necesario la preexistencla de una cierta cantidad de fase líquida. son:

Las temperaturas de fusión de algunos eutécticos posibles en las composiciones del cemento Portland

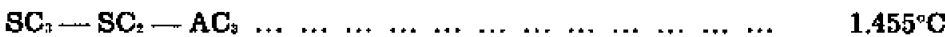

$$
\begin{aligned}
& \begin{array}{llllllllllll}
\mathbf{S C}_{3}-\mathbf{S C}_{3}-\mathbf{A C}_{3}-\mathbf{F e}_{2} \mathrm{O}_{3} & \ldots & \ldots & \ldots & \ldots & \ldots & \ldots & \ldots & \ldots & \ldots & 1.340^{\circ} \mathbf{C}
\end{array} \\
& \mathbf{S C}_{2}-\mathbf{S C}_{2}-\mathbf{A C}_{3}-\mathrm{FeO}_{3}-\mathbf{M g O} \ldots \ldots \ldots \ldots \ldots \ldots \ldots \quad 1.300^{\circ} \mathrm{C}
\end{aligned}
$$

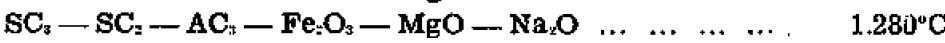

De acuerdo con estos datos, podemos pensar que, aumentando la proporción de fundentes, podremos rebajar la temperatura de la llama, to que, de hecho, ocurre en la práctica. Sin embargo, una llama a $1.500^{\circ} \mathrm{C}$ presenta ya una escasa diferencia de temperatura en relación al lecho de material, y no puede garantir una buena transmisión de calor.

Un lignito con $4.500 \mathrm{kcal} / \mathrm{kg}$ de poder calorifico inferlor, con diflcultad proporciona una temperatura superior a $1.500^{\circ} \mathrm{C}$; luego, en estas condiciones, dificilmente se puede conseguir una buena cocción del material. Para Guillon, un $40 \%$ de cenizas rebaja la temperatura de la llama en unos $200^{\circ} \mathrm{C}$. Si en la composición de las cenizas entra carbonato cálcico, aquéllas absorben, además del calor necesario para su calentamiento, una cantidad de calorias muy importante para su descarbonatación. En estas condlciones, no merece la pena intentar la cocción del cemento usando un combustible semejante.

\subsection{Exceso de cire}

La temperatura teórica de la combustión baja inmediatamente cuando se realiza en condiciones que no se ajustan a la neutralidad, según expresamos en el gráflco adjunto (flg. 27). Este es el caso general en los hornos rotativos, El combustible y el comburente no estän uniformemente distribuídos, por el contrario aparecen muy imperfectamente mezclados a lo largo del recinto tubular.

No estamos ante un proceso estático, sino ante un proceso dinámico, en constante evolución. Tenemos un chorro central de combustible, inyectado a gran velocidad apenas con un $20 \%$, 0 menos, del comburente necesario $\mathrm{y}$, por eso, en condlciones de una evidente falta de aire en las primeras fases de su recorrido.

Extste una entrada de aire, tangencial, que va tomando contacto con el combustible, a medida que éste se interna en el horno. En tales condiclones, el concepto de combustión neutra carece de sentido práctico. Asi, resulta que es necesario proporcionar un exceso de aire al combustible si no se quiere que éste arda tarde, mal o nunca.

La velocidad de reacción depende de la concentración de oxígeno en la fase gaseosa. Quemando polvo de lignito, y variando el exceso de alre, Hinz encontró un máximo, poco acusado, en la velocidad de combustión, para una proporción de alre entre 1,4 y 1,5 .

De otra parte, con el empleo de carbones de baja calidad es necesario aumentar la cantldad y la velocidad del aire primarto para asegurar el transporte de las cenlzas inertes y garantizar la turbulencia necesarfa. Indirectamente, y porque la mezcla con el chorro central se vuelve más difícil, se tiene que aumentar la cantidad de aire secundario.

Baouman cree que, quemando carbón pulverizado, es necesario un exceso de aire del orden de $10 \%$ si se quiere que arda la totalidad del carbón. La buena conducción de un horno consiste en obtener una combustión completa con un mínimo exceso de aire. En Matouschek vemos la recomendación de un $6 \%$ de exceso de aire, con $1,3 \%$ de oxigeno en los humos finales. Tomamos de Anselm los siguientes excesos de aire medios: $8.7 \%$ para un horno normal, $9,7 \%$ para un horno Lepol, $12 \%$ para un horno con precalentador y $15 \%$ para un horno con caldera de recuperación.

En el año 1944 Ruiz Monje admitia un $20 \%$ de exceso de aire en un estudio sobre el empleo de los lodos del lavado de carbones. Un tal exceso de alre podia ser tenido como exagerado cuando predominaban las ldeas de aproximarse, lo más posible, a una combustión neutra. Estas ideas eran, en general, tomadas de paises europeos, en los cuales, al tratar de carbones malos, acababan donde los peninsulares comenzamos. Actualmente, en ciertos paises, $\mathrm{y}$ entre ellos Bélgica, se han instalado hornos de 


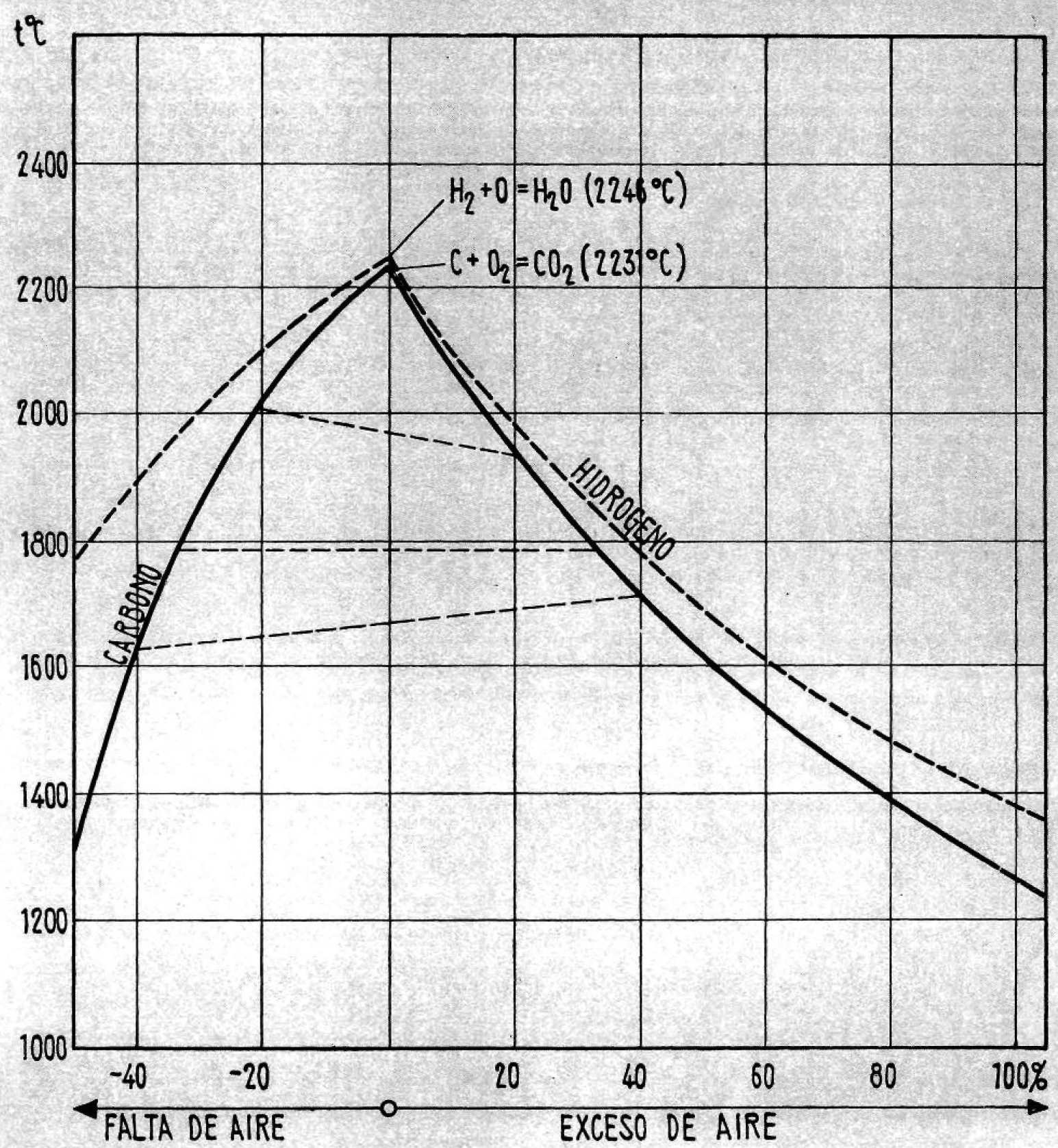

Fig. 27.-Variación de las temperaturas teóriess

de la llams en función de la cantidad de aire. 
grandes dimenstones, destinados a quemar malos carbones; $y$ al tratar de ellos hiro observar slegten que se obtuvieron rendimientos sensacionales, trabajando, en magnificas condiciones, con $6 \%$ de oxigeno, o sea, aproximadamente, un $46 \%$ de exceso de alre. El caso de este horno abrió los ojos a Anselm, poco antes de su muerte, asi como a muchos otros. Se puede suponer-continuamos siguiendo a Blegten-que un aumento del volumen gaseoso reduce las estratiflcaciones y mejora la homogeneldad de los gases calientes, actuando sobre ellos análogamente a los agitadores.

En cualquier caso, hay que vigilar constantemente el exceso de aire si se quiere conduclr un horno con clerto cuidado. La instalación de analizadores de oxígeno automátícos se está imponlendo. La interpretactón de los resultados del anélisis de los humos se conslgue con facilidad con el empleo de nomogramas, tal como el de la figura 28, preparado para la combustión de aceites combustibles.

\subsection{Densidad y flujo tormicos}

Podemos definir la densidad térmica de un horno rotativo como la cantidad de calor desarrollada por hora y por unidad de volumen. Para calctilarla, no hay que tener en cuenta la longitud total del horno. Un cálculo aproximado nos ha dado, para un horno de $2,5 \mathrm{~m}$ de diámetro, una liama con $10 \mathrm{~m}$ de longilud. Podemos aceptar, como media bastante generalizada, una longitud igual a cuatro veces el díametro. En estas condiciones se tiene:

$$
\mathrm{V}=\frac{\pi \mathrm{D}^{2}}{4} \times 4 \mathrm{D}=\pi \mathrm{D}^{3}
$$

Suponiendo una producción de Pt/día, con un consumo de calor de Ckcal/kg, la densidad térmlca o carga de calor sera:

$$
\mathrm{q}_{\mathrm{g}}=\frac{10^{\mathrm{s} P \mathrm{C}}}{24 \pi \mathrm{D}^{8}} \mathrm{kcal} \cdot \mathrm{h}^{-4} \cdot \mathrm{m}^{-\pi}
$$

Rosin calculó téricamente el valor de la densidad térmica para un combusttble de poder calorifico $H_{1}$ y un volumen específlco medio de los gases de la combustión $v_{m}$ :

$$
q_{*}=\frac{Q}{v}=\frac{9.600 \mathrm{H}_{\mathrm{i}}}{v_{\mathrm{m}} \mathrm{\theta}}
$$

donde $\theta$ es el tiempo de combustión, el cual, según vimos en [28], vale

luego:

$$
\begin{gathered}
\theta=55 d^{1,8} \text { segundos } \\
q_{\mathrm{v}}=\frac{3.600 \mathrm{H}_{\mathrm{I}}}{55 d^{1.8} v_{\mathrm{m}}} \mathrm{kcal} \cdot \mathrm{h}^{-1} \cdot \mathrm{m}^{-1}
\end{gathered}
$$

Stendo la densidad térmjca función Inversa del tamaño de las partículas combustibles, podemos aumentar $q$, extremando la finura del carbón injectado. B1, ademés, comblnamos las expreslones [31] y [33], se tendrá:

$$
q_{\mathrm{r}}=\frac{10^{\mathrm{s} \mathrm{PC}}}{24 \pi \mathrm{D}^{s}}=\frac{3.600 \mathrm{H}_{\mathrm{i}}}{55 d^{1.6 v_{\mathrm{m}}}}
$$

Lo que nos dice que, para hornos de poco dímetro, y con cargas de calor bastante elevadas, es nece-

\begin{tabular}{|c|c|c|}
\hline $\begin{array}{l}\text { Tamanto } \\
\text { de lag pertienlas } \\
\text { (mferas) }\end{array}$ & $\begin{array}{c}\text { Tiempo } \\
\text { de combustibut } \\
\text { (negandos) }\end{array}$ & $\begin{array}{c}\text { Densitdad } \\
\text { térmiog } \\
\text { (keat. } \mathrm{m}^{-1}, \mathrm{~b}^{-1} \text { ) }\end{array}$ \\
\hline $\begin{array}{r}120 \\
100 \\
80 \\
60 \\
40 \\
20 \\
10\end{array}$ & $\begin{array}{l}1,21 \\
0,87 \\
0,57 \\
0,35 \\
0,17 \\
0,05 \\
0,014\end{array}$ & $\begin{array}{r}295.000 \\
410.000 \\
626.000 \\
1.020 .000 \\
2.100 .000 \\
7.140 .000 \\
25.490 .000\end{array}$ \\
\hline
\end{tabular}
sario moler con la mayor fnura.

Según el Cuadro I, para la combustión neutra del carbono se tiene:

$$
\begin{aligned}
& \mathrm{H}_{1}=8.080 \mathrm{kcal} / \mathrm{kg} \quad T=2.291^{\circ} \mathrm{C} \\
& v_{\mathrm{a}}=8,885 \mathrm{~m}^{3 / \mathrm{k}_{\mathrm{F}}} \quad \mathrm{v}_{\mathrm{r}}=81,5 \mathrm{~m}^{3} / \mathrm{kg} \\
& q_{*}=\frac{3.600 \times 8.080}{81,5 \theta} \\
& q=\frac{356.908}{\theta} \mathrm{kcal} \cdot \mathrm{h}^{-1} \cdot \mathrm{m}^{-3}
\end{aligned}
$$

Aplicando valores: 


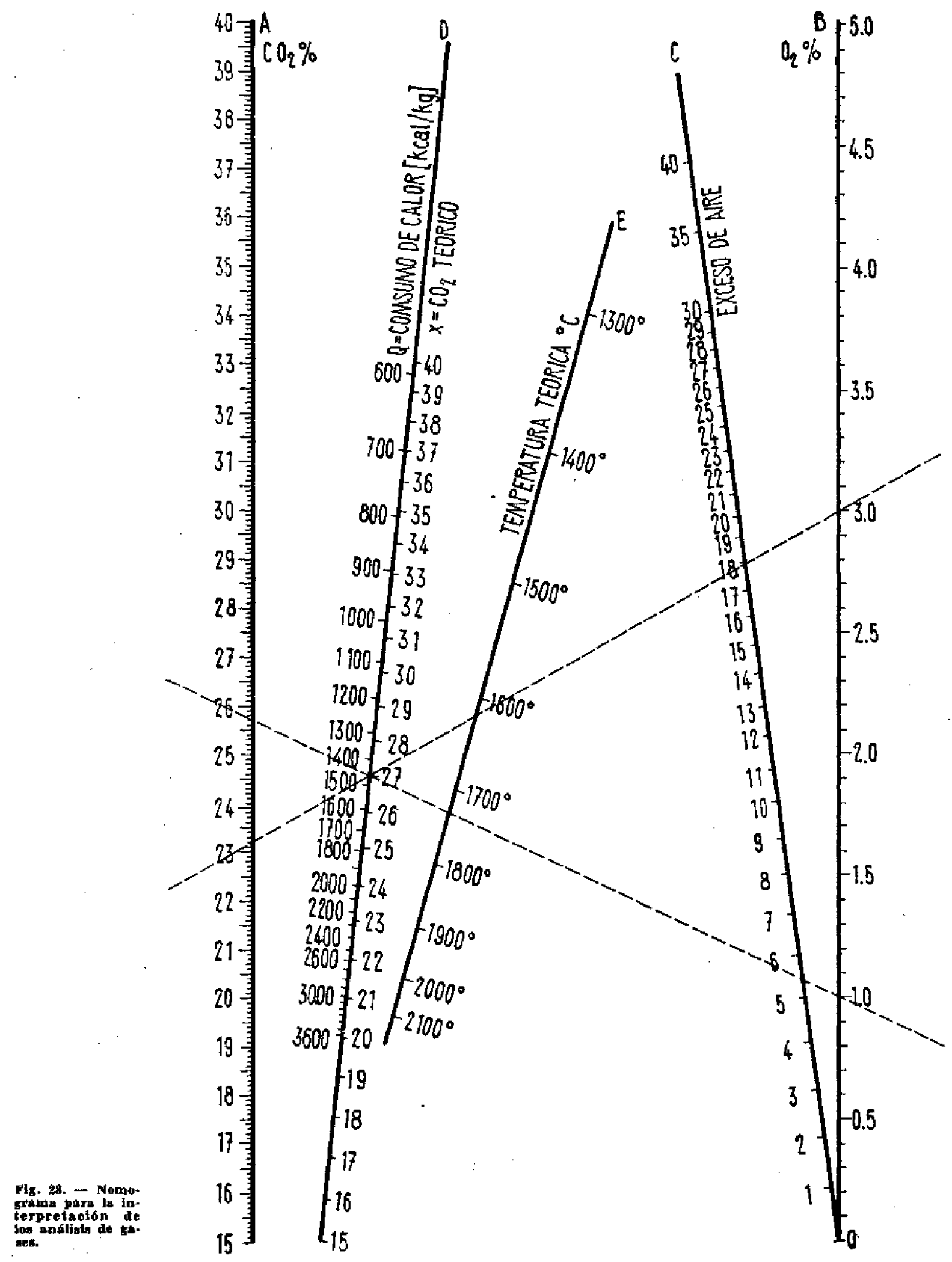


Suponiendo que las mayores partículas de carbon sean de 100 a 120 micras, la densiçad térmtca de los hornos rotativos estará comprendida entre las 300.000 y las $400.000 \mathrm{kcal} \mathrm{h}^{-1}, \mathrm{~m}^{-2}$, lo que concuerda con los valores que fueron dados por Anselm.

Según dicho autor, la densidad térmica se mantiene igual para todos los tamaños de hornos, jugando un importante papel el calentamiento del alre secundario. Asi, se tiene:

1) Consumo de calor: $2.000 \mathrm{kcal} / \mathrm{kg}$.

Temperatura del atre secundario: $720^{\circ} \mathrm{C}$.

Denstdad térmico: $240.000 \mathrm{kcal} . \mathrm{h}^{-1} \cdot \mathrm{m}^{-3}$.

2) Consumo de calor: $1.500 \mathrm{kcal} / \mathrm{kg}$.

Temperatura del alre secundario: $550^{\circ} \mathrm{C}$.

Densidad térmica: $310.000 \mathrm{kcal} \cdot \mathrm{h}^{-3} \cdot \mathrm{m}^{-3}$.

3) Consumo de calor: $1.000 \mathrm{kcal} / \mathrm{kg}$.

Temperatura del aire secundario: $450^{\circ} \mathrm{C}$.

Densidad térmica: $340.000 \mathrm{kcal} \cdot \mathrm{h}^{-1} \cdot \mathrm{m}^{-3}$.

No quiere esto decir que sea imposible alcanzar una mayor concentración térmica. Forzando un horno hemos sobrepasado las $500.000 \mathrm{kcal} . \mathrm{h}^{-\mathbf{t}} \cdot \mathrm{m}^{-t}$, utilizando fuel-oil como combustlble; pero, desde luego, la duración de los revestimientos refractarios en la zona de cocclón ha acusado la sobrecarga.

Con la densidad térmica se relaciona el flujo de calor, que se define por:

o bien:

$$
\Phi=\frac{\mathrm{Q}}{\mathrm{S}}=\frac{4 \cdot 10^{\mathrm{a}} \mathrm{PC}}{24 \pi \mathrm{D}^{2}}=\frac{10^{\mathrm{a} P C}}{6 \pi \mathrm{D}^{2}}
$$

$$
\Phi=4 \mathrm{D} g \text {, }
$$

Si admitimos una densidad térmica $q_{v}$ constante, según [31], la producción $P$ será una función directa del cubo del dí́metro $D$, luego el flujo térmico aumentará proporcionalmente al díámetro o a la raiz cúbica de la producción.

Labahn nos presenta, como ejemplos, los siguientes flujos:

1) Producción: $300 \mathrm{t} / \mathrm{dia}$. Consumo de calor: $1.450 \mathrm{kcal} / \mathrm{kg}$. Flujo de calor: $3.000 .000 \mathrm{kcal} \cdot \mathrm{h}^{-1} \cdot \mathrm{m}^{-\mathrm{x}}$.

2) Producción: $300 \mathrm{t} /$ día. Consumo de calor: $1.250 \mathrm{kcal} / \mathrm{kg}$. Flujo de calor: $2.400 .000 \mathrm{kcal}, \mathrm{h}^{-1}, \mathrm{~m}^{-4}$.

3) Producción: $300 \mathrm{t} / \mathrm{dfa}$. Consumo de calor: $900 \mathrm{kcal} / \mathrm{kg}$.

Flujo de calor: $2.200 .000 \mathrm{kcal} \cdot \mathrm{h}^{-1} \cdot \mathrm{m}^{-3}$.

Para $600 \mathrm{t}$ /día de producción y a igualdad de consumos de calor los flujos pasan a ser: $\mathbf{3 . 5 0 0 . 0 0 0}$ 2.900 .000 y $2.700 .000 \mathrm{kcal} \cdot \mathrm{h}^{-1} \cdot \mathrm{m}^{-2}$. Tamblén hemos alcanzado mayores flujos de calor, próximos a 4.500.000 $k c a l \cdot h^{-3} \cdot \mathrm{m}^{-2}$, desde luego quemando fuel oil, combustible, que según se dijo, puede proporcionar una alta densidad térmlca. Porque, según López Pechña, siendo constante la velocidad de clrculaclón de los gases en Ios hornos rotativos, el mejor combustjble será aquel que pueda transportar una mayor cantidad de calor en un menor volumen de gases. $Y$ nuevamente llegamos a la conclusión de que un combustible será o no utilizable en un horno determinado según pueda proporcionar el flujo de calor mínimo establecido en su caso.

\subsection{Transmision del calor}

Enfocando debidamente el problema, podremos decir que no basta producir en el interior de un horno la cantidad de calor necesaria para la producción del clínker; es necesarto, además, asegurar la transmisión del calor de la llama al material. Esta transmisión se efectúa por radiación y por convección.

El calor transmitido por convección es función de la diferencla de temperaturas:

$$
Q_{s}=\alpha\left(T,-T_{b}\right) \mathbf{k c a l} \cdot h^{-1}, m^{-2}
$$

mientras que el calor radiado es proporcional a la cuarta potencia de las temperaturas absolutas:

donde:

$$
Q_{r}=\sigma:\left(T_{s} *-T_{0}^{4}\right) \mathrm{kcal} \cdot \mathrm{h}^{-1} \cdot \mathrm{m}^{-3}
$$

$0=$ Constante de ateffan, que vale: $5,03 \times 10^{-8} \mathrm{kcal}, \mathrm{h}^{-1} \cdot \mathrm{m}^{-3} \cdot \mathrm{g}^{-1}$.

$\varepsilon=$ Factor de emisión.

$\alpha=$ Coeflciente de convecelón.

Estas dos expresiones nos indican que la cantidad de calor radiado será muy superior a la cantidad transmitida por convección cuando las temperaturas sean muy elevadas y asimismo sea grande la diferencia existente entre las temperaturas de la llama y del material. 


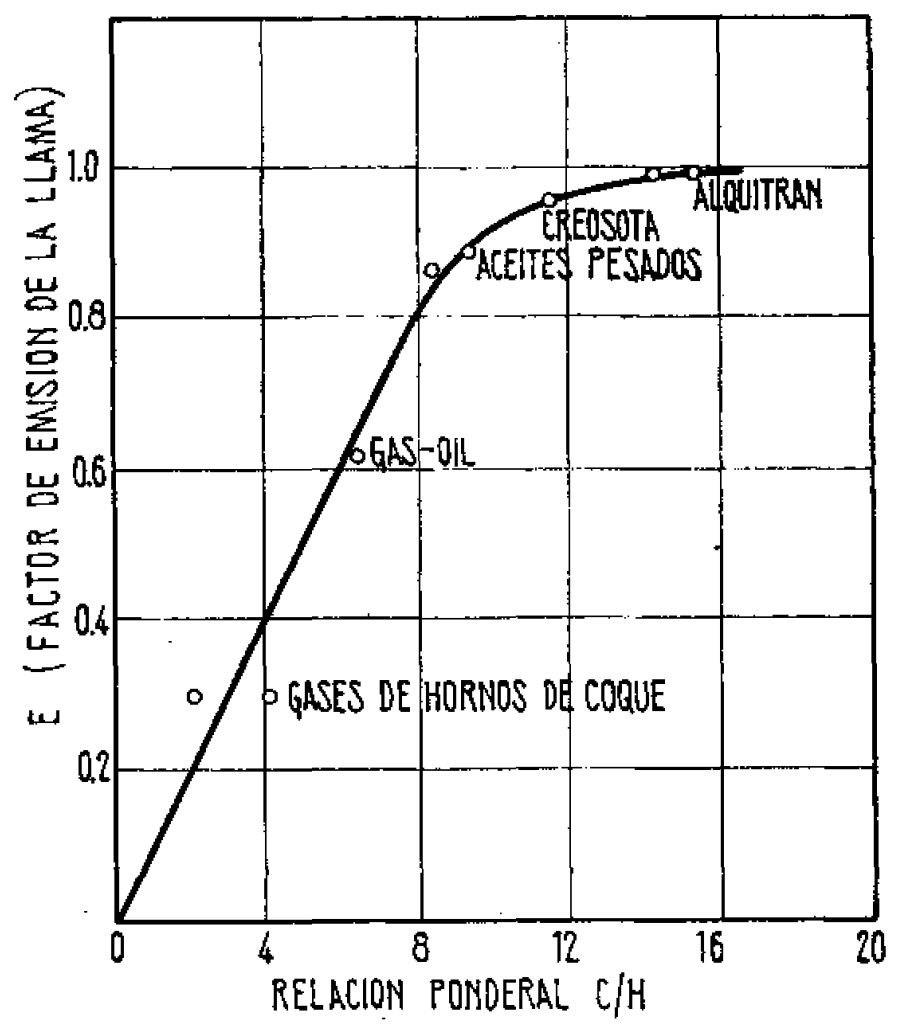

Fiz. 20.-Factor de emisión en función del contenido de earbono.

Tiene mucha importancia el valor del factor de emisión e que vale:

$$
=l-e^{-\mathbf{k} t}
$$

siendo: $k$ el coeflciente de absorción y $l$ el espesor del flujo gaseoso.

Como se sabe, Folliot calculó los coeficientes de absorción y de emisión-encontrando que dependían del tamaño de las partículas emisivas- $y$ también consiguió medir dichos coeficientes en Ias condiclones reinantes en los hornos rotativos:

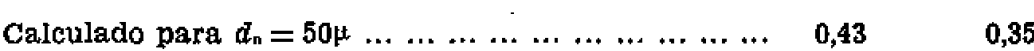

$$
\begin{aligned}
& \begin{array}{lllllllllllllllll}
\text { Medido } & \ldots & \ldots & \ldots & \ldots & \ldots & \ldots & \ldots & \ldots & \ldots & \ldots & \ldots & \ldots & \ldots & \ldots & \ldots & 1,72
\end{array}
\end{aligned}
$$

Admira el alto valor del factor de emisión práctico, muy superior al teórico. Folliot, y otros autores, creen que este aumento se debe a la formación de particulas de coque extremadamente finas, del orden de las 0,05 micras, así como a la presencia de las partículas sólidas incandescentes e incombustibles debidas a las cenizas.

No obstante, en la llama de los combustibles liquidos, donde no se cuenta con las cenizas, Thring ha medido elevados factores de emisión, aumentando con la proporción relativa de carbono (flg. 29), acercándose a la unidad cuando la relación ponderal $C / H$ es superior a 10 , o sea, para contenidos de carbono mayores que $90 \%$.

Como sea que, en general, se queman en los hornos de cemento combustibles con más de $90 \%$ de carbono, podremos obtener un buen factor de emisi in sf procuramos que la combustión se efectíe dando un alto grado de disociación de ios hidrocarburos, co a liberación de carbono elemental. $Y$ esto, según dijlmos, se logra reduciendo el poder comburente dal aire primario.

Pero el calor radiado tamblén depende de la cuarta potencia de la temperatura absoluta y ésta se eleva bastante cuando se aumenta el poder comburente del aire de inyección.

De estas dos condiciones opuestas resultarán dos modalidades de llamas:

I) Llamas largas, brillantes y templadas.

II) Llamas cortas, incoloras y calientes. 
En una llama cualquiera, el factor de emisión varía en cada punto del chorro incandescente, como varía también la concentración de partículas de carbono, alcanzando el máximo a $1 / 3$ de la longitud total El máximo de temperatura aparece más allá del máximo factor de emisión. Este disminuye en función inversa al máximo đe temperatura.

Planteado el dilema, parece que no sepamos para qué tipo de llama inclinar nuestras preferencias. Diremos que no hay que exagerar la tendencla para una llama luminosa y radiante a base de poco aire đe inyección. La experiencia demuestra que, al disminuir la cantidad de alre primarlo, también disminuyen la energia transmitịda al materiai y la producción del horno.

Baouman hizo notar que el coefieiente de utilización del calor, en la zona de cocción, es muy bajo, apenas un $5 \pm 0,5 \%$ de la enorme cantidad desarrollada, por lo que es necesario producir muchas calorías y a muy alta temperatura. Anselm indicó que podia intensificarse la combustión, aumentando la temperatura y acortando la llama, creando una mayor turbulencia mediante quemadores de construcclón apropiada. También para simon importa mucho la obtenclón de una llama corta, principalmente para la reducción del consumo de calor y de la pérdida de polvo. Momot concuerda en que la llama debe ser corta y caliente, siendo recomendable elevar la temperatura a un máximo compatible con la seguridad del revestimlento.

Para Folliot hay que contar con otros medios de transmisión del calor además de los ya clásicos, radiación y convecctón, señalando la llamada, por Vernon, convección viva. En el horno de cemento, cuando la llama se vuelve luminosa, la actividad de la combustión disminuye y la energía aportada por roce decrece. Con una llama cálida y transparente, a una velocidad de $1.5 \mathrm{~m} / \mathrm{s}$ y a una temperatura de $1.700^{\circ} \mathrm{C}$ se puede transmitir, por convección, unas $100 \mathrm{kcal} / \mathrm{h}^{-1} \mathrm{~m}^{-2}$ grado-1, coeflciente muy superior al que se obtiene por el cálculo clásico.

En este orden de ideas, y para aumentar la cantidad de calor transmitido por conveceión, se proponen modelos no convencionales de quemadores, como uno patentado por Nagel, que produce una llama aplastada y paralela al lecho del materlal. Con esta llama se consigue transmitir a la carga un $50 \%$ del calor emitido, obtenléndose un aumento de la proditeción de $15 \%$ con un $10 \%$ de disminuclón en el consumo de combustible.

\section{La combustión de carbones pobres}

\subsection{Influencia de Ias cenizas}

Dljimos que el factor de emisión medido en las llamas de carbón pulverizado se aproxima a 0,9. Un factor tan elevado se relaciona con la extstencia de partículas sólidas-carbón y cenizas-en el seno de la llama. La radiación debida al polvo es considerable, desde luego muy superior a la radiación gaseosa pero la radiaclón total no es la suma algebralca de una y otra, porque, como se ha dicho, existe una absorclón parcial de la una por la otra.

Se comprende, pues, que el aprovechamiento del poder radiante de las cenizas candentes sea un medio muy adecuado de obtener una llama callente-quemando el combustible con aire primarlo de alto poder comburente-y, a la vez luminosa, por efecto de las particulas sólidas.

La eflcacla de la presencia de las cenizas en las lamas se pone de maniflesto en los casos de combustíón mixta. Azbe relató el caso de un horno que habitualmente quemaba gas natural y vio aumentado su rendimiento cuando se mezcló carbón pulverizado con el aire primarlo. Algo parecido sucede cuando se trabaja quemando fuel-oil y polvo de carbón en conjunto. Con la adición de carbón se nota una inmediata mejora en la calidad del clínker obtenida, lo que se demuestra por el aumento del peso por litro, la uniformidad de la granulación la disminución del consumo especiflco de calor y aun por las mejores resistencias mecánicas del cemento obtenido.

Está claro que la influencia de las cenizas no se limita a sus efectos en la transmisión del calor. Se admite que, en una zona del horno determinada por su peso y por la velocidad de arrastre las cenizas caen sobre el crudo y se incorporan al material alterando la composición primitiva. En qué medida se incorporan las cenizas al clinker obtenido es asunto que ha sido muy debatido, tal vez desde la primera vez en que se comenzó a quemar carbón pulverizado en los hornos rotativos.

Lhopitallier y James, examinando al microscopio el clinker obtenldo con carbones altos en cenizas, encontraron importantes zonas de silicato bicálcico, en forma de arco de cfrculo, características de la formación de una capa envolvente, con menos cal, producida por el efecto de la caida de las cenlzas sobre los granos de clínker. Cuando los combustibles eran de muy baja calldad, con $50 \%$ de cenizas y se trabajaba por via seca, la mezcla del crudo con las cenizas era bastante intima, merced al estado pulverulento de ambos materiales. Trabajando por vía húmeda, por el contrario la heterogeneidad se manlfestaba mejor, con la aparteión de zonas bicálcicas y oxidos de hierro reducidos. Con la misma finalídad, Calleja, en su contribuclón al estudio de la estructura del clínker, consiguló determinar el efecto de las cenizas sobre algunos clínkeres. Las cenizas que se depositan sobre el clínker pueden contener algo de carbono sin quemar, el cual provoca la reducción del óxido férrico. La sílice, abundante en las cenizas, por su parte, se difunde hacia el interior de los gránulos, en busca de los puntos donde hay un exceso de cal.

Como sea que el clínker obtenido tíne una composteión que no se corresponde con el material crudo entrado en el horno, se atribuye por muchos autores, esta diferencia al resultado de la incorporación de las cenizas, Gascuñana consideró que las eenizas eran uno entre varlos factores desdosificadores, En 


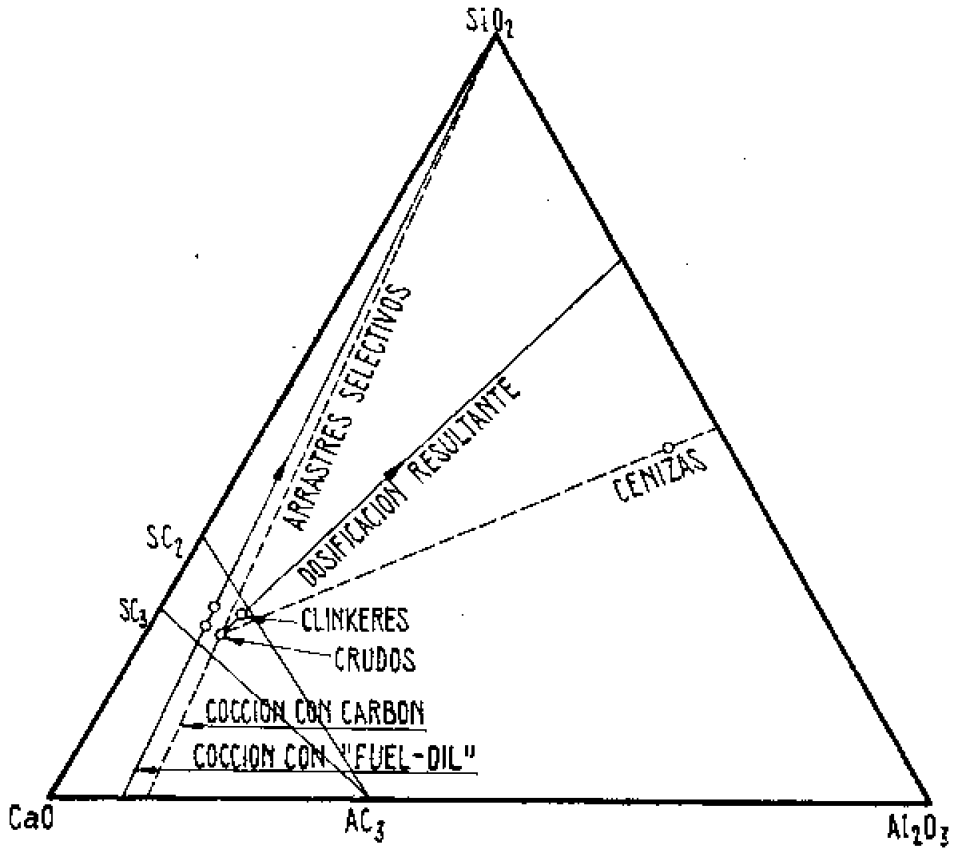

Fig. \$0.-Desdosificscion debida a las
cenizas y a la sezrezación del erudo.

un anterior trabajo nuestro demostramos que la desdoslficación también aparece cuando se queman combustibles sin cenizas. Debía existir algín otro, y bastante importante, factor desdosificador, y citamos como tal la que dehominamos segregacion del crudo (flg. 30).

Sin embargo, en los hornos modernos, equipados con cruces y cadenas, o con parrillas de calcinación. a con permutadores de suspensión en los gases, o con electrofiltros que devuelven la casi totalidad del polvo al cfrculto de alimentaclón, o que inyectan el polvo rectuperado junto con el combustible $y$ el alre primario, hay que contar con una casi total incorporación de las cenizas y también con una completa neutralización de los arrastres selectivos. En estos casos, la desdosificación producida por las cenizas adquiere todo su valor y plantea un problema relativamente fácil que tan solamente exige una mayor vigilancla por parte del laboratorio, de modo que se venga a compensar con un crudo sobresaturado de cal la aportación silicoaluminosa de las cenizas.

Es interesante señalar que Alegre, siguiendo a Hendrickx, recomienda mezclar al carbón la cal necesaria para saturar a las cenizas. Según sus cálculos, para un carbón con $20 \%$ de cenlzas, la adicloón es de 3 a $4 \%$ sobre el peso del carbón. $Y$ no hay que extrañar la adiclón de materias no combustibles al carbón, porque en las grandes unldades es costumbre cada vez más extendida la recirculación del polvo a traves del inyector de aire primario. Esta recirctulación se ha visto aplicada en Bélgica, Holanda, Suiza, Francia y el Canadá. En este último país la cantidad de polvo inyectado equivale a $14 \%$ del clinker prodưcido, según datos de una fábrlca de reciente instalación en las proximidades de Quebec.

\subsection{La calidad de los carbones}

$Y$, como era de esperar, el tema nos conduce nuevamente al problema de la caildad de los carbones. Recordamos un párrafo afortunado de Serratosa "Las fábricas de cemento están conceptuadas como fábricas que pueden emplear los peores combustibles para su desenvolvimiento. En algunas ocaslones he tenido que oir-por personas que se dicen enteradas-que el contenido de cenizas del carbón era interesante, pues con ellas se aumentaba la producción al incorporarse al clínker." Objetaba Berratosa que, si considerábamos a las cenizas como una materia prima, su precio era demasiado caro para los fabricantes de cemento.

El problema, en términos tan concretos como correctos, fue pianteado en 1944 por Ferrer-Vidal, bajo el sigufente enunciado: "Aprovechamiento de carbones de baja calidad en los hornos rotatorios de las fábricas de cemento sin perjuicio de la calidad del clínker producido." O sea, se trata de un aprovechamiento, el cual tan sólo será interesante si no causa perjuicios en la calidad del producto.

Con hispano arrojo se nos presentó López Pecifía "un poco en defensa de los tan vilipendiados carbones de baja calidad... por ser dichos carbones más baratos que los carbones buenos, arriesgándome a proclamar que la combustión de un carbón con $50 \%$ de cenizas, con unos $4.000 \mathrm{kcal} / \mathrm{kg}$ proporciona una temperatura tan elevada como un fuel-oil de $10.000 \mathrm{kcal} / \mathrm{kg}$." No nos place contrariar el sano optimismo, motor que impulsa las más arriesgadas empresas. Apenas tenemos que hacer notar que las cenizas no son un elemento absolutamente inerte. Su simple calentamiento, a $1.500^{\circ} \mathrm{C}$, admitlendo un calor especifico 
medio de $0,26 \mathrm{kcal} / \mathrm{kg}^{-1} /{ }^{\circ} \mathrm{C}^{-1}$, para un $50 \%$ de cenizas, absorbe $195 \mathrm{kcal} / \mathrm{kg}$, de modo que las supuestas 4.000 se convierten en $3.805 \mathrm{kcal} / \mathrm{kg}$, esto, sl las cenizas no contienen carbonatos, porque sl los contienen y tenemos en cuenta su calor de descarbonatación, la reducción es todavia menor y es dudoso que el calor restante sea capaz de produclr una temperatura tan elevada como un fuel-oil de $10.000 \mathrm{kcal} / \mathrm{kg}$.

Anselm, con su expertencia, se mostraba más cauteloso al recomendar que no se empleasen carbones con menos de $5.000 \mathrm{kcal} / \mathrm{kg}$ si se quería obtener un clínker blen cocido. Constató, además, que el consumo de calor por tonelada de clínker, aumentaba al bajar el poder calorífico inferior del combustible.

Además de los ya citados, existen otros fnconvenientes que diflcultan el empleo de carbones de baja calidad. Folliot hizo notar que antes del último conflicto mundial raramente se utilizaban carbones con más de $25 \%$ de cenizas. En Francla el promedio de cenizas era de $15 \%$. Al finalizar la última guerra se trabajaba normalmente con carbones conteniendo $30 \%$ de cenizas. Ahora bien, la mayor parte de las instalaciones estaban previstas para carbones con $7.000 \mathrm{kcal} / \mathrm{kg}$. Es fácil de comprender el agoblo con que se vieron estas instalaciones cuando tuvleron que preparar una cantidad equivalente de carbón pulverizado, con $5.000 \mathrm{kcal} / \mathrm{kg}$, o menos, y, en general, más dificil de moler que las buenas hullas.

Como quiera que 10 más costoso en nuestro ánimo slempre es reducir la producción, cuando nos vemos en el agoblo mencionado, lo que por lo menos intentamos, es moler la totalidad del carbón necesario, $\sin$ reparar mucho en la finura y en la humedad residual, con lo cual introducimos en el horno un combustible pobre y deficientemente preparado que puede ser un importante factor de muchas perturbaciones.

El problema de la utilización de los combustibles pobres puede resolverse con mayores probabilidades de éxito euando se posee una instalación de molienda y secado dimensionada con algún exceso.

\subsection{Moliendo conjunta del carbón y el crudo}

Sabemos que en 1943 Gascufana e Ynzenga propugnaron por la mollenda conjunta de carbones pobres con el crudo. El garbón mezclado con la pasta reemplazaba parclalmente al combustlble inyectado. Mucho más recientenfente, hemos visto cómo Folliot apoyaba el mismo sistema.

Pensamos que esta solueión puede ser interesante cuando se trabaja por vía húmeda en hornos largos, o con calderas de recuperación de calor. Por vía seca, no creemos que sea tan práctico. Nos exponemos que el combustible arda en zonas donde no nos interesa tener altas temperaturas. $Y$ no digamos lo que podria, suceder en los hornos con parrillas de calcinación o permutadores de ciclones..

Asi, pues, nos limitamos a dar fe de la existencia del procedimiento, proclamando, sinceramente, que desconocemos sus resultados.

\subsection{Combustión conjunfa de carbón y "fuel-oil"}

Otra cosa diremos respecto a la combustión conjunta de carbón pulverzado y aceites pesados. El problema, y su solución, fue debidamente expuesto por Serratosa en los coloquios de 1957. Sus ventajas son muchas. Como sea que la mezcla puede efectuarse en proporciones de una variabilidad casi llimitada, se puede afrmar que dejan de existir carbones pobres desde que se mezclen con la proporción apropiada de combustible liquido. La solución, además, no está sujeta ni a tipos de horno ni a sistemas de fabricación. Sirve para la vía seca, para la via húmeda, para hornos con parrillas o con permutadores de calor.

Pero el resultado más sensacional de la combustión mixta, no es tan sólo el haber resuelto el problema de los combustibles pobres, sino el haber mejorado las condiciones de la combustión en los hornos donde antes solamente se quemaban combustibles liquidos.

\subsection{Perturbaciones atribuidas a los carbones pobres}

No podemos concluir este trabajo sin referirnos, siquiera sea tangencialmente, a las perturbaclones de la marcha de los hornos rotativos que se atribuyen a los carbones pobres. Entre estas perturbaciones, la formación de anillos es la más importante.

Aquí nos tenemos que referir a un estudio publicado hace cinco años: "Formación $y$ destrucción de anillos en los hornos rotativos para cemento Portland", en el cual tratamos del problema en toda su amplitud. Entre las causas de formación de anillos dependientes de la combustión citábamos:

a) Composición química de los carbones (cenlzas).

b) Poder calorifico del combusttble.

c) Grado de tinura de los carbones.

d) Proporción relativa del aire utilizado.

e) Mezcla del combustible con el comburente.

De estas cinco causas tan solamente las dos primeras inclden sobre la calidad de los carbones. La tercera causa se atribuye a una molienda más o menos defectuosa, Las dos últimas dependen del aire que interviene en la combustión. En estas dos últimas se da mayor importancia a la forma de efectuar la combustión que a la calldad del combustible. O sea, con un buen combustible, mal quemado, también se pueden formar anillos, como sucede en los hornos donde se quema exclusivamente fuel-oil. 
La consecuencia recíproca es que no deben formarse inevitablemente anillos en los hornos rotativos cuando en ellos quemamos carbones de baja calidad sl consegulmos que estos quemen completa y perfectamente.

La formación de anillos de cenizas se puede explicar fácilmente: Al final de la zona de cocción, en un punto donde el chorro de inyección ya ha perdido parte de su velocidad inicial, $y$ donde la casi totalidad del carbono ya ha sido quemada, las centzas precipitan en flna lluvia sobre el material. Blendo, en general, bastante más fusibles que el crudo de cemento Portland, forman una clerta cantidad de líquido sobre el cual se cuelan y quedan retenidas porciones del crudo que va llegando. Puede que el antllo, en su hacer y deshacer, llegue a una situación estacionaria, a partír de la cual se mantenga sin aumentar ni llegar a perturbar grandemente ia marcha del horno. Es un caso bastante frecuente ver funcionar hornos rotativos con un pequeño antllo a la entrada de la zona de cocción. Pero también puede suceder que el anillo retenga cantidades de crudo cada vez mayores, hasta perturbar seriamente la contlnuidad del trabajo. Ilegado este momento, hay que destruirio, sea como sea, a lanzadas o a tiros, según recomiendan los más violentos. A fuego lento según pensamos nosotros. Pero la mejor forma de combatir los anillos, en todos Ios casos, es evitar que se formen. No se formarán anillos de cenlzas si éstas caen en un punto del horno donde no haya temperatura bastante para ocasionar su fusión. Esto se consigue aumentando, a la vez, la velocidad de inyección del aire primario, y la velocidad de circulación del flujo gaseoso que atraviesa el horno, o sea, abriendo el registro.

Tal vez el peor inconveniente que en nuestro entender tienen los carbones pobres, es el formar una nube oscura ante el mechero, que impide ver lo que pasa en el interior del horno más allá del punto donde comienza la llama. En este aspecto, la combustión de los derivados del petróleo es francamente superior, puesto que la tendencla a formación de anillos es notada-muchas veces-a partir de los primeros momentos, lo que nos permite maniobrar a tiempo. Por eso resulta recomendable la combustión mixta. En un momento dado, al tener la menor duda sobre la marcha del horno, nada nos lmpide suspender momentáneamente la inyección de carbón pulverlzado, quemando solamente fueI-oil hasta conseguir una buena visibilídad en el interior del horno. $Y$ si comprobamos que se está formando un anillo, puede ser que nos convenga utillzar temporalmente tan sólo combustlbles liquldos, por ser éstos más fácllmente maniobrables y con una llama más prolongada nos' permitan destruir, sin mayores complicaciones, el anillo en formación por fusión lenta.

$Y$ aquí vamos a poner punto final a este tema, que apenas hemos tratado en sus múltiples aspectos técnicos, evitando la parte económica, en la cual resíde su verdadero talón de Aquiles. Porque es por imperativos económicos-de interés particular o nacional-que nos vemos forzados a emplear clertos combustibles por los que tenemos muy pocas simpatías. $Y$, cuando esto sucede, no hay más remedio que seguir adelante con lo que nos dan para quemar y procurar salir victorlosos de la batalla sin gloria $n$ laureles que es nuestro diarlo quehacer, porque, a fin de cuentas, y como dice el refrán: "la habilidad del barbero es sacar patilla donde no hay pela".

\section{bibllografia}

ALEthe, R.: Formation et supression des anneaux de centres dans les fours rotatifs à ciment. (Formación y destrucción de anillos de cenizas en los hornos rotativos de cemento). "Revue des Matérisux", núm. 509, febrero 1958, pág. 42.

ANsEL, G.: La fabricación del cemento. Ediciones Asland. Barcelona, 1944, pag. 39.

- Eliminación del polvo. La técnica de la molienda. I. T. C. C. Monografia núm. 115. Madrid, jullo 1858.

- Hornos verticales de cemento Homos rotatorios I T C. C Monomu

- Calculs thermiques relatifs aux fours à ciment, à chaux, d̀ magnéste et à dolomie. (Ć́lculos térmicos relativos a los hornos de cemento, de cal, de magnesia y de dolomia). "Revue des Matériaux", núm. 447, pág. 325 (1952).

$\rightarrow$ L'influence du combustible sur la cuisson du ciment. (Influencia del combustible en la coccion del cemento.) "Revue des Matériaux", núm. 465, funio 1954, pág. 159.

ANset.M, G., y Frisce, W. H.: Der Drehofen. Probleme der Kohlen staubfeuerung. (El horno rotativo. Problemas del calentamlento con carbón pulverizado). "Zement-Kalk-Gips", octubre 1954, num. 5 (Número especial).

A. S. T. M.: Compilation of Standards on Coal and Coke. (Recopilación de normas sobre carbón $y$ coque). "American Society for Testing Materials", Phlladelphia, $\mathrm{Pa}$

Balzou, M., y Balis, M.: Comité de Normas alemán DIN. Ensayo de Combustibles. Bllbao, 1941

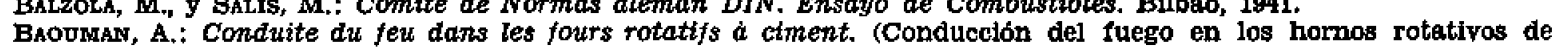
cemento). "Revue des Matériaux", num. 427, pag. 119.

- Produits refractaires, croutes, anneatux, boules. (Productos refractarios, costras, anillos $\mathrm{y}$ bolas). srevue des Matérlaux", núms. 457, 58, 59 (1953).

Blanc, E. C.: Le Ciment Portland. (El Cemento Portland). Cap. XI, págs. 236-260. Béranger, Paris y Liege, 1927.

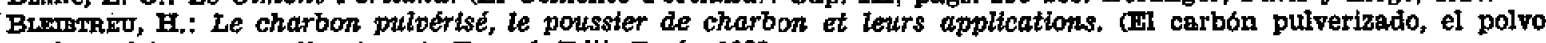
de carbón y sus aplicaciones). Dunod, Edit, Parts, 1932.

Bopmgr A., y Nisol.s., L.: Le Chauffage au Charbon Pulverise, (El calentamiento con carbón pulverizado). Dunod, Paris, 1933.

BoMks, K.: Fohlen und Zement. (Carbón y Cemento). "Zement-Kalk-Gips", 1958, núm. 6 (Número especial).

Cunuses, C. F.: Aspect actuel de lindustrie cimentiere Nord-Americaine. (Aspecto actual de la tndustria cementera norteamericana). "Revue des Matériaux", nim. 677, pág. 349.

Cormporta, R. M., y Lmi, E. R.- Firing kilns with fluid petroleth coke. (Combustion en los hornos con coque de petróleo flúido). "Rock Products", noviembre 1955.

Dussossor, P.: Carbones pobres, Resumen sobre los diferentes problemas rolacionados con los anilos. "Uitimos Avances", núm. 92, pág. 29. 
Ferfera Maluquha, J. M.: Experiencias sobre la fabricacion de cemento Portiand con fuel-oul nacionat como combustible de horno. "Cemento-Hormigón", núm. 235, octubre 1953, páss. 322-26.

Frrakr-Vmai, J.: Termotecnia en la Industria del cemento. "E. E. I. I.", Madrid, 1944.

- Aprovechamiento de carbones de baja calidad en los hornos rotatorios de las fabricas de cemento, stn perfuicio de la caltala del clinker prodictło. "Cemento-Hormigón", núm. 121, abril 1944, pág. 79.

Fonrodona, J.: Empleo del fuel-odl en la fabricación de cemento. I, T. C. C., Monografía núm. 156, 1955.

Follior, A.: Les études sur la flamme et le four rotatif a ciment. (Los estudios sobre las llamas y el horno rotativo de cemento). "Revue des Matériaux", núm. 459, diclembre 1953, ph́g. 329.

- La cuisson du ciment au fout rotatif. (La cocoín de cemento en el horno rotativo). "Revue des Materiaux", número 482-483, pags. 84-87.

- Transmisión del calor en el horno rotativo para cemento. "Ultimos Avances", nüm. 83, septiembre-octubre 1957.

- Estado de los estudios experimentales sobre la llama. Posible utilización de ios productos carboniferos de baja calidad en la preparactón de ta materia prima. "Ultimos Avances", núm. 91, enero-febrero 1959.

Follyz DE Joux, E, de la: Combustibles et combustion. (Combustibles y combustión). "Revue des Matériaux", número 306, marzo 1935, pág. 77.

Gascofana, C.: Lecctones sobre fabricación de cementos. Madrid, mayo 1942, pág. 122.

- Los carbones emplecdos en la cochura del cemento $y$ su influencia sobre los resultados obtenidos. "CementoHormigón", núm. 108, marzo 1943, păg. 56.

- El empleo de carbones bajos en volátiles para la cocción del clinker. "Cemento-Hormion", núm. 200, noviembre 1950 , pág. 330 .

Gunlow, H.: Utilización de combustibles pobres en la fabricación de cemento. "Ulttmos Avances", num. 90; noviembre-diciembre 1958 .

Farrington, P. D.: Ftel economy. (Economia de combustibles), "Pit and Quarry", julio 1949, pág. 42.

Imstituto Portugues de Combdrtiveis: Carvōes Portugtleses. Lisbọ, 1941.

LA Velle, M. J.: Oxygen entichment of primary air can improve kiln production. (E1 enriquecimlento del aire primario con oxigeno puede mejorar la producción de los hornos). "Tock Products", marzo 1959 , pag. 97.

LENHarr, W. B.: Economía de combustible: Alimentación de hornos con antractia. "Cemento-Hormigón", núm. 198, septiembre 1950, pág. 271 :

Iópz Pecrî, D.: La combustión del carbón en los hornos de cemento. "Cemento-Formigón", agosto a novlembre de 1952.

Lópgz Pecrīa, D.: Los combustibles y la combustión en los hornos de cemento. "Uitimos Avances". núm. 82, julioagosto 1957, pág. 10.

Matovscher, F.: Mauvaise combustion: Antreaux de collage. (Mala combustión: Formación de antllos). "Revue des Matériaux", núm. 427, pág. I16.

NORDBEAG, B.: Swotss Engineers Destgm Cement Plant with Dust Return into Firing End of Kin and Gravity Flow Packing. (Ingenleros suizos han proyectado una fábrica de cemento con retorno del polvo al quemador del horno y con ensacado por gravedad). "Rock Products", agosto 1955, pág. 87.

Paloukr Llover, P.: Un nuevo sistema para atmentat" la capqcidad de los hornos rotatorios. "Cemento-Hormigón", número 294, agosto 1958.

Foch в MELo, J. O. da: Alguns aspectos da tecnica do fabrico de cimento Portland, "Técnica", núm. 298, pag. 190.

Rurz Castmulasos, J. R.: Gráfico para interpretación de la combustión a partir del analisis de los gases en un horno de cemento. "Cemento-Hormigón", núm. 218, mayo 1952, pág. 162; Junio 1952, pág. 198.

Eutz MonjE, A.: Estudio termogufmico de la fabricactón de clinker con carbón schllamns, "Cemento-Hormigón", número 124, julto 1944, pág. 219.

SAJ, Kenjlro: Turbulent Diffusion wth gas and pulverized coal burners. (Difusión turbulenta en los quemadores con gas y carbon pulverizado). "Trock Products", agosto 1952, pág. 152.

Smanatosh Nadat, A. Combustion confunta de fuel-oil y carbón. "Ultimos Afances", núm. 82, pag. 24,

Smon, G, Reflexions sur quelques types de flammes utilises dans les fours rotatifs de cimenterie. (Reflexiones sobre algunos tipos de llamas empleados en los hornos rotativos de cemento). "Fevue des Materiaux", número 485 , febrero 1956 , pag. 42.

Sprars, H. M.: Technical Data on Fuel. (Datos técnicos de los combustibles). Londres, 1955.

TEIXerRA Loprs, A.: O cimento Portiand. Lisboa, 1942, pác. 131

Townmw, D. T. A.: La combustion des combustibles solides et le but des recherches sut le rayonnement des flammes relatives à la combustión du charbon pulvertsé. (L4a combustión de los combustibles sóliaos y la flnalidad de las investigaciones sobre la radiación de las lamas de carbón pulverizado). "Revue des Matériaux", núm. 498, página 27, enero 1957.

Virmit. A.: Notas sobre la conducción de hornos rotativos para centento Portland. "Cemento-Formfgón", febrero 1951 a mayo 1953 , núms. 203 a 230.

- La segregación de los crudos de cemento Portland. Memoria 28. Congreso Internacional de Quimica IndustriaI, I. pág. 719 .

- Des irregularités observés dans la cuisson des etinkers à ciment Portland. (Irregularidades observadas en la cocción de los clínkeres de cemento Portland). "Revue des Matériaux", núm. 490-91, Julio-agosto 1956, pig. 173.

- Formación $y$ destruccion de anillos en los hornos rotativos para cemento Portland. I. T. C. C., Monografía número 162, Madrid, 1956.

- Empleo de aceites combustibles en los hornos rotativos. "Cemento-Formigón", núms. 264 a 275 , marzo 1956 a febrero 1957.

- Les gaz d'échappement des fours rotatifs chauffés au mozout. (Los gases de escape de los hornos rotatipos calentados con aceites combustibies). "Revue des Matérlaux", núm. 510, marzo 1958, pág. 57.

- El rendimtento de los hornos rotativos $y$ la composictón de los gases de escape. "Cemento-Hormigón", numeros 298 y 299 , enero y febrero de 1959 .

YazGNG, F.: Sobre la ithcorporación del Schlamms de Puertollano al crudo del eemento Portland por via húmeda. "Cernento-Hormigon", núm. 112, jullo 1943, púg. 146.

Terminada la conferencia, los señores Sarabla, Fonrodona, Garcia Gll, Calleja, Gascuñana y Uría, comentan y solicitan aclaraciones, sobre todo en lo que respecta a poder calorifico, temperatura de llama, medida de finura de carbones y tipo de encendido de los hornos. 